UNIVERSIDADE DE SÃO PAULO

ESCOLA DE ENFERMAGEM

MAGDA APARECIDA DOS SANTOS SILVA

EFETIVIDADE DE DUAS MODALIDADES DE EQUIPE DE CUIDADO NO CONTROLE DE SINTOMAS EM PACIENTES COM CÂNCER AVANÇADO

São Paulo 


\title{
EFETIVIDADE DE DUAS MODALIDADES DE EQUIPE DE CUIDADO NO CONTROLE DE SINTOMAS EM PACIENTES COM CÂNCER AVANÇADO
}

\begin{abstract}
Tese apresentada ao Programa de Pós Graduação em Enfermagem na Saúde do Adulto, da Escola de Enfermagem da Universidade de São Paulo - EEUSP, para obtenção do título de Doutor em Ciências.
\end{abstract}

Área de Concentração: Saúde do Adulto

Orientadora: Prof. Dra Cibele Andruccioli de Mattos Pimenta

Versão original corrigida. A versão original não corrigida se encontra disponível na Biblioteca da EEUSP.

São Paulo 
AUTORIZO A REPRODUÇÃO E DIVULGAÇÃO TOTAL OU PARCIAL DESTE TRABALHO, POR QUALQUER MEIO CONVENCIONAL OU ELETRÔNICO, PARA FINS DE ESTUDO E PESQUISA, DESDE QUE CITADA A FONTE.

Assinatura:

Data:

\section{Catalogação na Publicação (CIP)}

Biblioteca "Wanda de Aguiar Horta"

Escola de Enfermagem da Universidade de São Paulo

Silva, Magda Aparecida dos Santos

Efetividade de duas modalidades de equipe de cuidado no controle de sintomas em pacientes com câncer avançado / Magda Aparecida dos Santos Silva. São Paulo, 2014.

$121 \mathrm{p}$.

Tese (Doutorado) - Escola de Enfermagem da Universidade de São Paulo.

Orientadora: Prof. ${ }^{a}$ Dr. ${ }^{a}$ Cibele Andruccioli de Mattos Pimenta

Área de concentração: Saúde do Adulto

1. Cuidados paliativos. 2. Neoplasias. 3. Sintomas e patologia geral. I. Título. 
Nome: Magda Aparecida dos Santos Silva

Título: Efetividade de duas modalidades de equipe de cuidado no controle de sintomas em pacientes com câncer avançado.

Tese apresentada ao Programa de Pós-Graduação Saúde do Adulto da Escola de Enfermagem da Universidade de São Paulo para obtenção do título de Doutora em Ciências.

Aprovada em:

Banca Examinadora

Prof. Dr. Instituição:

Julgamento: Assinatura:

Prof. Dr. Instituição:

Julgamento: Assinatura:

Prof. Dr. Instituição:

Julgamento: Assinatura:

Prof. Dr. Instituição:

Julgamento: Assinatura:

Prof. Dr. Instituição:

Julgamento: Assinatura: 


\section{DEDICATÓRIA}

Aos meus pais, João e Lúcia, pelo carinho, apoio, dedicação e por um dos principais ensinamentos: a perseverança que me auxilia até os dias de hoje a enfrentar os obstáculos da vida.

Ao meu marido, Marcos, pelo apoio, compreensão e paciência durante as várias dificuldades enfrentadas durante este desafio.

Ao meu filho, Dimitri, um presente de vida, que amo, minha luz, minha enorme motivação e desde pequeno com grande senso de compreensão. 


\section{AGRADECIMENTOS}

O maior desafio não está no doutorado per si, mas o que ele movimenta.

Portanto, gostaria de agradecer algumas pessoas que direta ou indiretamente me auxiliaram neste processo. Primeiramente, agradeço aos pacientes que concordaram em participar deste estudo, mesmo em um momento ímpar de suas vidas.

Agradeço,

À Prof. Dra. Cibele Andruccioli de Mattos Pimenta, orientadora e amiga, uma mulher forte, pelos ensinamentos e orientação neste trabalho.

Ao Dr. Ricardo Tavares de Carvalho, amigo, grande lutador, dedicado, obrigada pelo incentivo, pelo apoio, viabilização e grande auxílio nas dificuldades vivenciadas na execução da coleta de dados deste trabalho.

À equipe do Núcleo de Cuidados Paliativos do HCFMUSP, em especial à Camila $O$. Venâncio, Ednalda $M$ Franck, Maria Fernanda F. Angelo e Ana Beatriz Brandão Santos, pelo apoio, desde os momentos iniciais da coleta de dados.

À equipe de enfermagem do IC. HCFMUSP, pelo apoio.

Ao Prof. Dr. Moacyr Roberto Cuce Neto, pelas valiosas sugestões e apoio.

Ao Dr Carlos Eduardo Paiva, uma pessoa maravilhosa, pelos conselhos.

Á Marina Salvetti. uma pessoa maravilhosa, pelo apoio, compreensão e sugestões.

Á Geana Kurita, pelas preciosas sugestões na qualificação e apoio.

Á Camila M. Gracielle e Laís G. da Silva, pela coleta de dados e, aos coletadores Cintia Luna dos Santos, Juliana M. Iqueda Pietro, Leandro L. Lima, Vanessa O. Santos, Jéssica Ramos e Erinéia S. 
dos Santos, pessoas especiais, comprometidas com o resultado do trabalho, responsáveis e de grande apoio ao longo da coleta de dados; o que tornou esta fase menos difícil.

Ao Márcio A. Diniz, pela análise dos dados, pela atenção e prontidão nas dificuldades, sem o qual minha busca não teria fim.

Ao Bernardo dos Santos, pela prontidão e análise inicial dos dados

À Vânia C. S. Silva, irmã querida, que apoiou e auxiliou em um momento de desespero.

Aos amigos Juliano dos Santos, Agnaldo Moreira, Ana Paula Quilici, Luciana S Aquino, Fátima F. Gil, Elaine Peixoto, Juliana Lima Lopes, Maria Helena Vettore, Rosa Maria M Ribeiro, Ana Carolina Ferreira e Eloisa Schimidt, Léia Yamada, Josiane Piccolo, Branca Brener, Aguinaldo Moreira, Erik Rodrigo de Paula, Renata Regazzine, Flora M Barbosa, Janaina M Tavares, Mariana B. Oliveira e Denise Canesin pela amizade e pelo apoio ao longo deste trabalho.

À amiga Sonia M. Sertório, pela compreensão e apoio ao longo deste trabalho.

Á amiga Mara Luis S Dantas, pessoa maravilhosa, pelo incentivo, pelo o apoio nos momentos mais difíceis.

À equipe da secretaria do Programa de Pós-Graduação Enfermagem em Saúde do Adulto.

Á equipe da biblioteca, pelas orientações e atenção.

As colegas do Grupo de Pesquisa Dor, Controle de Sintomas e Cuidados Paliativos da EEUSP: Karla A Albuquerque, Jessica Yumi Matuoka, Isanne Lima, Erica Brandão pela atenção.

À Nair M. da Silva, amiga, meu grande apoio e, sem ele este desafio seria muito maior.

Á Marcia Martins, pelo suporte nos momentos iniciais.

Ao amigo Alcino Ezidro Ribeiro (in memória), pelo incentivo e crém em meu potencial, que infelizmente não pôde presenciaı a finalização deste trabalho.

À Mitsuko, pelo apoio e prontidão na redação final. 
“Existe somente uma idade para ser feliz....

Somente uma época na vida de cada pessoa em que é possível sonhar, fazer planos e ter alegria suficiente para realizá-los....

Essa idade tão fugaz na vida da gente chama-se

PRESENTE.

E tem duração do instante que passa." 
Silva, MAS. Efetividade de duas modalidades de equipe de cuidado no controle de sintomas em pacientes com câncer avançado. [tese]. São Paulo: Escola de Enfermagem, Universidade de São Paulo; 2014.

\section{RESUMO}

Introdução. Embora existam diferentes estratégias para a prestação de cuidados paliativos ao paciente com câncer, pouco se conhece sobre a efetividade desses modelos. Objetivos. Comparar os efeitos da equipe de cuidado paliativo integrada ao cuidado tradicional com o cuidado tradicional sozinho no controle de sintomas em paciente com câncer avançado hospitalizado. Método. Ensaio clínico pragmático composto por dois grupos não randomizados. 73 pacientes foram admitidos para a equipe de cuidado paliativo integrada ao cuidado tradicional (Grupo ECP) e comparados a 75 atendidos no modelo de cuidado tradicional (Grupo CT). Os sintomas foram avaliados pela Escala de Avaliação de Sintomas de Edmonton (ESAS), a satisfação por escala numérica verbal (0-10), a funcionalidade pela Escala de Desempenho Funcional Físico Karnofsky (KPS) e a adequação analgésica pelo Índice de Manejo da Dor (IMD). Os pacientes foram avaliados na admissão, após 24 e 48 horas. O desfecho primário foi a melhora clinica significativa de 2 pontos na intensidade da dor e da náusea em 48 horas, comparados com a admissão. Os dados demográficos, os sintomas e sua redução foram comparados entre os Grupos pelo Teste Exato de Fisher ou Mann Whitney. O Teste de Wilcoxon analisou alterações dos sintomas intragrupos. A regressão múltipla de Poisson controlou fatores de confusão para a melhora do sintoma. O nível de significância adotado foi de $5 \%$. Resultados. A prevalência de sintomas foi alta em ambos os grupos: no Grupo ECP a variação foi de $43.8 \%$ (depressão) a $87.7 \%$ (sensação de bem estar), e no Grupo CT, de 24\% (dispneia) a 85.5\% (dor). A magnitude dos sintomas, pelo escore da mediana, foi importante em ambos os Grupos: na admissão, no Grupo ECP, variou entre 5.5 (sensação de bem estar) a 8.0 (ansiedade, apetite, constipação e tristeza), e no Grupo CT, variou de 6.0 (sensação de bem estar e dispneia) a 9.0 (perda do apetite). A mediana de sobrecarga de sintomas, avaliada pelo ESAS, foi de 50.0 em ambos os grupos. $\mathrm{Na}$ análise de 24 horas (intragrupo), no Grupo ECP cinco sintomas (dor, náusea, perda do apetite, dispneia, prejuízo do sono) e sobrecarga de sintomas foram reduzidos $(p<0.05)$, enquanto no Grupo Grupo CT três sintomas (dor, náusea e prejuízo do sono) foram reduzidos $(\mathrm{p}<0.05)$. $\mathrm{Na}$ análise de 48 horas (intragrupo), dez sintomas e sobrecarga de sintomas no Grupo ECP foram reduzidos $(p<0.05)$, enquanto quatro sintomas melhoraram no Grupo CT $(p<0.05)$. A regressão múltipla mostrou que a dor $(R R=2.2$ [IC95\%1.27-3.81]) e bem estar ( $R R=4.6$ [IC95\% 1.34-15.88]) reduziram 2 pontos e foi favorável somente no Grupo ECP. Verificou-se melhor adequação da analgesia no Grupo ECP comparado ao CT $(p<0.05)$. A satisfação do doente foi elevada e similar em ambos os grupos. Conclusão. Os doentes de ambos os grupos mostraram grande sobrecarga de sintomas e somente o sintoma dor foi adequadamente controlado pelo Grupo ECP. Os resultados encontrados demandam análise de fatores da estratégia de tratamento que possam melhorar a efetividade das ações, como avaliação sistematizada dos sintomas em curtos períodos e estratégias que permitam ajuste rápido da terapêutica quando necessário.

PALAVRAS-CHAVES: Cuidados Paliativos, Equipe de Cuidado Paliativo, Câncer Avançado, Sintomas, Sintomas múltiplos, Escala de Avaliação de Sintomas de Edmonton, ESAS. 
Silva, MAS. Effectiveness of two modalities of team care in symptoms control in patients with advanced cancer. [thesis]. São Paulo (SP), Brasil: Escola de Enfermagem, Universidade de São Paulo; 2014.

\section{ABSTRACT}

Introduction. Although there are many different strategies for provision of palliative care to patients with cancer, little is known about the effectiveness of these modalities. Objective.To compare the effects of a palliative care team integrated with traditional care to traditional care alone on symptom control in inpatients with advanced cancer. Method. Pragmatic clinical trial composed of two nonrandomized groups. Seventy-three patients were admitted to the palliative care team integrated to traditional care (PCT Group) and compared to 75 patients treated in the traditional care model (TC Group). Symptoms were assessed by the Edmonton Symptom Assessment Scale (ESAS), satisfaction with treatment by the verbal numeric scale (0-10), performance status by the Karnofsky Performance Status Scale (KPS) and analgesic adequacy by the Pain Management Index (PMI). Patients were assessed upon admission, and after 24 and 48 hours. The primary outcomes were significant clinical improvements of 2 points in pain intensity and nausea in 48 hours, compared to admission. The demographic data, symptoms, and reduction in symptoms were compared between the groups by using Fisher's or Mann Whitney's Exact Tests. The Wilcoxon test examined the intragroup alteration of symptoms. The Poisson multiple regression controlled for confounding factors of improvement in symptoms. A p-value of $\leq 0.05$ indicated statistical significance for all analyses. Results. The prevalence of symptoms at admission was high in both groups. In the PCT Group, it ranged from $43.8 \%$ (depression) to $87.7 \%$ (loss of well-being) and, in the TC Group, it ranged from $24 \%$ (dyspnoea) to $85.5 \%$ (pain). The magnitude of median score of symptoms was substantial in both groups: at admission for the PCT group, it ranged from 5.5 (sense of well-being) to 8.0 (anxiety, appetite, constipation, sadness), while for the TC Group, it ranged from 6.0 (sense of well-being and dyspnoea) to 9.0 (loss of appetite). The median score of the symptom burden assessed by ESAS was 50.0 in both groups. In 24 hours (intragroup), the PCT Group had significant reductions in intensity of five symptoms (pain, nausea, loss of appetite, dyspnoea, and sleep disturbance) and symptom burden, while the TC Group had significant reductions in intensity of three symptoms (pain, nausea, and sleep disturbance). In 48 hours (intragroup), the PCT Group had significant reductions in intensity of ten symptoms and symptom burden and while the TC Group had significant improve in intensity of four symptoms. Multiple regression analysis showed that pain $(\mathrm{RR}=2.2[95 \% \mathrm{Cl}$ 1.27-3.81]) and loss of well-being $(\mathrm{RR}=4.6$ [95\% $\mathrm{Cl} 1.34-15.88])$ were reduced by two points and it was significantly more favourable only in the PCT Group. The PMI revealed better adequacy of analgesia in the PCT Group. Satisfaction was high and similar in both groups. Conclusion. Patients with advanced cancer in both groups showed a pronounced burden of symptoms and only pain was properly controlled in the PCT Group. The results indicate that factors that can improve treatment strategy should be implemented to improve the effectiveness of clinical assistance. Examples of factors that can improve treatment are frequent and systematic assessment of symptoms in short periods, and strategies that allow for timely adjustment of therapy when necessary.

KEY WORDS: Palliative Care, Hospital Based Palliative Care Team, Advanced Cancer, Symptom, Inpatient, Edmonton Symptom Assessment Scale, ESAS. 


\section{LISTA DE QUADROS}

Quadro1- Características do trabalho da equipe de cuidado 39 paliativo do IC.HCFMUSP. São Paulo, 2014

Quadro 2- Representação dos pesos atribuídos aos 47 analgésicos e intensidade de dor do índice de manejo de dor. São Paulo, 2014

Quadro 3- Categorização das variáveis independentes 51 relacionadas aos sintomas e satisfação do doente. São Paulo, 2014

Quadro 4- Categorização das variáveis relacionadas à 51 terapia para o controle dos sintomas. São Paulo, 2014

Quadro 5- Categorização das variáveis relacionadas às 52 características demográficas e clínicas. São Paulo, 2014 


\section{LISTA DE TABELAS}

Tabela 1- Resultados dos estudos primários sobre o impacto 20 do cuidado paliativo. São Paulo, 2014

Tabela 2- Distribuição das causas das exclusões dos grupos 41 ECP e CT. São Paulo, 2014

Tabela 3- Distribuição dos doentes dos grupos ECP e CT, 50 nas três avaliações. São Paulo, 2014

Tabela 4- Distribuição das causas de perda de seguimento 50 dos grupos ECP e CT. São Paulo, 2014

Tabela 5- Distribuição das características demográficas e 58 clínicas dos pacientes dos grupos ECP e CT. São Paulo, 2014

Tabela 6- Comparação da frequência dos sintomas, na 60 avaliação incial, entre os Grupos ECP e CT. São Paulo, 2014

Tabela 7- Comparação da intensidade dos sintomas, na 61 avaliação inicial, entre os Grupos ECP e CT. São Paulo, 2014

Tabela 8- Evolução da intensidade dos sintomas e da 62 sobrecarga de sintomas no Grupo ECP, em 24 horas e 48 horas, segundo o instrumento ESAS. São Paulo, 2014

Tabela 9- Evolução da intensidade dos sintomas e da 64 sobrecarga de sintomas no grupo CT, em 24 horas e 48 horas, segundo o instrumento ESAS. São Paulo, 2014

Tabela 10- Comparação da evolução da intensidade dos 66 sintomas e da sobrecarga de sintomas pelo ESAS, ao longo de 48 horas. São Paulo, 2014. 


\section{LISTA DE TABELAS}

Tabela 11- Comparação entre os Grupos ECP e CT quanto ao percentual de redução de 1 ponto na intensidade dos sintomas, ao longo de 48 horas. São Paulo, 2014

Tabela 12- Comparação entre os Grupos ECP e CT quanto 68 ao percentual de redução de 2 pontos na intensidade dos sintomas, ao longo de 48 horas. São Paulo, 2014

Tabela 13- Estimativa do risco relativo de melhora de 1 ponto nos sintomas do Grupo ECP em relação ao Grupo $\mathrm{CT}$, pelo modelo de regressão múltipla de Poisson. São Paulo, 2014

Tabela 14- Estimativa do risco relativo de melhora de 2 pontos nos sintomas do Grupo ECP em relação ao Grupo CT, pelo modelo de regressão múltipla de Poisson. São Paulo, 2014.

Tabela 15- Comparação da adequação analgésica nos grupos ECP e CT, segundo o IMD. São Paulo, 2014

Tabela 16- Comparação da satisfação dos doentes com o 72 alivio da dor nos grupos ECP e CT. São Paulo, 2014

Tabela 17- Distribuição da adesão às recomendações de 73 controle de sintomas do Grupo ECP pelo Grupo CT. São Paulo, 2014

Tabela 18- Distribuição do número de óbitos nos Grupos ECP 74 e CT. São Paulo, 2014 


\section{SUMÁRIO}

1. Introdução ........................................................ 16

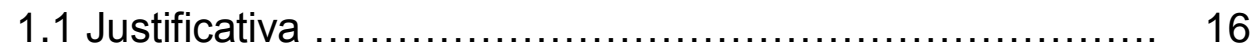

1.2 Revisão sistemática ......................................... 17

1.3 Breve histórico, Terminologia e Modalidades .................... 25

1.4 Sintomas, instrumentos e sobrecarga sintomas ................ 28

2. Objetivos …................................................................... 33

3. Hipóteses ………...................................................... 35

4. Casuística e Método …………………………................ 37

4.1 Tipo de estudo ……................................................. $\quad 37$

4.2 Local do estudo ........................................................... 37

4.3 Período de coleta de dados ............................................ 37

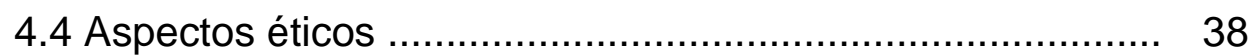

4.5 População e Amostra ................................................... 38

4.6 Instrumentos, classificação dos instrumentos ................... 42

4.7 Procedimentos de coleta ............................................ 47

4.8 Variáveis e categorias das variáveis ............................... 50

4.9 Análise estatística ........................................................... 53

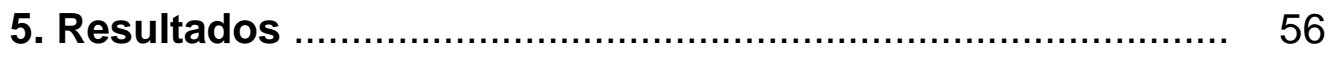

5.6 Sumário dos resultados …………………………........ 75

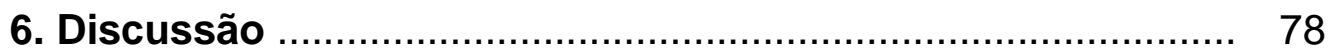

6.1 Características demográficas e clínicas ............................ 79

6.2 Prevalência e magnitude dos sintomas ............................. 79

6.3 Evolução dos sintomas .................................................. 84

6.4 Limitações, contribuições e sugestões ............................. 96

7. Conclusão ………........................................................... 99

Referências ................................................................... 101

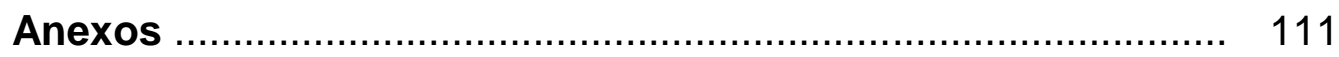


1.INTRODUÇÃO 


\section{INTRODUÇÃO}

\subsection{Justificativa}

Pacientes com câncer apresentam sintomas múltiplos e intensos, especialmente, nas fases avançadas da doença, que podem trazer prejuízos à funcionalidade e piora da qualidade de vida $^{1,2}$. Há relatos de ocorrência de onze a treze sintomas concomitantes nesses doentes ${ }^{1,3-8}$ e, dor, fadiga, náusea, sonolência, ansiedade, anorexia, perda de peso, insônia, depressão e constipação intestinal, entre outros, são os mais frequentes.

Pacientes com sintomas múltiplos, intensos e prolongados podem chegar a um quadro de desgaste que tem sido denominado symptom burden ${ }^{9}$. Essa condição é fonte de sofrimento físico, emocional, espiritual e deve ser considerada como importante agravo à saúde do paciente. Por outro lado, a redução dos sintomas parece trazer grande benefício ${ }^{2} \mathrm{e}$, considerando-se que vários sintomas parecem ser passíveis de adequado controle, não aliviá-los é inadmissível.

Equipes de cuidado paliativo têm se organizado visando o alívio do sofrimento de pacientes com doença que ameaçam a vida, em diferentes modalidades de atendimento como hospice, cuidado domiciliar e cuidado em unidades hospitalares.

O modelo hospice parece produzir bons resultados no controle de sintomas e bem-estar de doentes com câncer avançado e essa experiência vem sendo adaptada aos hospitais por meio de equipes de cuidado paliativo hospitalar, em inglês, denominadas "hospital based palliative care team" ou "hospital palliative care" ${ }^{\text {" }}$. Tais equipes podem atuar como interconsultoras ou como únicas responsáveis pelos doentes. Pode também não haver equipes 
específicas de cuidados paliativos e o cuidado dos doentes ficar sob a responsabilidade das equipes tradicionais de cuidados. Quaisquer dessas modalidades de atendimento têm necessidade de recursos humanos, físicos e materiais diversos e diferente impacto nos custos hospitalares. Apesar dessas modalidades de cuidado coexistirem, pouco se sabe sobre a efetividade delas.

Acredita-se que equipes de cuidado paliativo podem melhorar o controle de sintomas em pacientes com câncer e modificar a qualidade de vida positivamente ${ }^{11-12}$. No entanto, há poucas pesquisas que avaliaram a efetividade da equipe de cuidados paliativos no controle de sintomas, em curto prazo, e que compararam o desempenho dessa equipe com a de cuidado tradicional, que é o objetivo da presente pesquisa.

\subsection{Revisão sistemática da literatura: efetividade da equipe de cuidado paliativo no controle de sintomas}

Para verificar os efeitos do atendimento da equipe de cuidados paliativos (ECP) sobre o controle dos sintomas foi realizada revisão sistemática da literatura.

A pergunta de pesquisa para esta revisão foi: "A equipe consultora em cuidado paliativo integrada ao hospital melhora o controle de sintomas em pacientes hospitalizados com câncer avançado?"

Com base na estratégia PICO formou-se o seguinte raciocínio: P (amostra): pacientes hospitalizados com câncer avançado; I (intervenção): equipe consultora em cuidado paliativo integrada ao hospital; C (controle): equipe de cuidado tradicional e O (desfecho): alívio/controle de sintomas. 
A partir desse raciocínio, foram realizadas buscas pelos artigos nas seguintes bases de dados científicas: PUBMED, EMBASE, CINAHL, Web of Science, LILACS, Biblioteca Cochrane e SCIELO. As palavras chaves utilizadas foram "palliative care", "supportive care", "specialized palliative care", "symptom control", "neoplasm*", "advance cancer", "inpatient". Utilizando os operadores boleanos, a estratégia de busca formada foi: (("palliative care"[MeSH Terms]) OR ("palliative care"[All Fields]) OR ("palliative care"[All Fields]) OR ("supportive care"[All Fields]) OR ("specialized palliative care"[MeSH Terms]) AND ("symptom control"[All Fields]) AND ("neoplasms*"[MeSH Terms] OR "advanced cancer"[All Fields]) AND ("inpatients"[MeSH Terms] OR "inpatients"[All Fields])).

Os critérios de inclusão dos artigos foram: referir-se a pacientes com câncer avançado, maior que 18 anos, ambos os sexos, analisar ocorrência/evolução de sintomas (dor e outros sintomas), artigos na língua inglesa, portuguesa, espanhola e francesa.

Foram excluídos estudos sobre teste de medicamentos, de atualização sobre manejo de dor e outros sintomas, editorial, carta ao leitor, normas, recomendações e duplicatas.

Para ampliar a revisão, foi realizada busca manual a partir da lista de referências dos artigos resultantes da busca principal. A busca compreendeu o período de 2000 a 2013.

Da busca resultaram 48 artigos, dos quais foram excluídos 44 . Os motivos da exclusão foram: artigos relacionados a intervenções específicas (farmacológicas e não farmacológicas), caracterizações de serviços. O objetivo não era a avaliação de sintomas e sim a avaliação de custo e satisfação, entre outros.

Foram selecionados para análise 04 artigos da busca principal e 12 de busca manual, totalizando 16 estudos $^{13-28}$. Os estudos estão sintetizados na Tabela 1. 
Desses estudos, dois avaliaram somente o sintoma dor ${ }^{15,18}$, um deles foi longitudinal ${ }^{15}$ e o outro foi transversal ${ }^{18}$. Os demais estudos avaliaram mais de um sintoma, sendo que: 03 foram longitudinais prospectivos ${ }^{14,21,24}, 05$ estudos retrospectivos ${ }^{16,19,26-28}$, 03 estudos quasi experimentais ${ }^{17,23,25}, 02$ estudos transversais ${ }^{20,22}$, e 01 qualitativo $^{13}$.

Onze estudos utilizaram instrumentos de avaliação de sintomas múltiplos de (ESAS, PACA, STAS, EORTC-QLQ-30)*, os outros utilizaram uma lista livre de sintomas. O intervalo de avaliação dos sintomas foi de $3^{15}$ a $100^{14}$ dias.

Todos os estudos relataram melhora dos sintomas após seguimento com a equipe de cuidado paliativo. Porém, dos estudos citados, somente um apresentou efetividade comparada com o cuidado tradicional ${ }^{17}$.

Foram localizadas sete revisões sistemáticas que avaliaram resultados do cuidado paliativo.

Uma revisão sistemática identificou se a presença de equipes apoiadas por equipe especializada em cuidado paliativo melhorou os resultados de pacientes com câncer avançado, sua família ou cuidador, quando comparado com serviços de cuidado tradicional. Os desfechos considerados foram controle de sintomas, satisfação (paciente, família e cuidador), custo e qualidade de vida. Foram incluídos, na análise, 18 estudos até o ano de 1996. Os autores observaram que há evidência de maior satisfação e menor custo em pacientes acompanhados pela equipe de cuidado paliativo ${ }^{12}$.

\footnotetext{
* Edmonton Symptom Assessment Scale (ESAS); Palliative Care Assessment (PACA); Schedule for Team Assessment Scale (STAS); European Organization Research Treatment Cancer - Quality Life Questionnaire (EORTC-QLQ-30)
} 
Tabela 1- Resultados dos estudos primários sobre o impacto do cuidado paliativo. São Paulo, 2014

\begin{tabular}{|c|c|c|c|c|c|c|c|}
\hline Autor/país & $\begin{array}{l}\text { Periódico/ } \\
\text { Ano }\end{array}$ & Objetivo Principal & Desenho do estudo/Avaliação & $\begin{array}{c}\text { Amostra/ } \\
\text { Instrumento }\end{array}$ & Resultados Chaves & $\begin{array}{l}\text { Efetividade } \\
\text { Comparada? }\end{array}$ & Comentários \\
\hline $\begin{array}{l}\text { 1.Viney, et al. } \\
\text { Australia } 13\end{array}$ & $\begin{array}{l}\text { J Consulting } \\
\text { and Clinical } \\
\text { Psychologic, } \\
1994\end{array}$ & $\begin{array}{l}\text { Comparar QV em ca terminal } \\
\text { em duas unidades de } \\
\text { cuidados paliativos com um } \\
\text { hospital geral }\end{array}$ & Natureza quanti e qualitativa & $\begin{array}{l}\text {-183 pacientes } \\
\text { oncológicos } \\
\text { terminais: } 62 \text { em } \\
\text { CP, } 60 \text { em CP e } 61 \\
\text { em hospital geral } \\
\text { - QV: com likert } \\
\text {-ansiedade } \\
\text { depressão }\end{array}$ & $\begin{array}{l}\text {-cuidados paliativos } \\
\text { promoveram menos raiva e } \\
\text { mais sentimentos positivos } \\
\text {-hospital geral promoveu } \\
\text { mais ansiedade, isolação, }\end{array}$ & $\operatorname{sim}$ & $\begin{array}{l}\text {-metodologia } \\
\text { não clara } \\
\text {-cita } \\
\text { randomização } \\
\text { mas não está } \\
\text { explicitada }\end{array}$ \\
\hline $\begin{array}{l}\text { 2.Ellershaw } \\
\text { et al. } \\
\text { Inglaterra }^{14}\end{array}$ & $\begin{array}{l}\text { Palliat } \\
\text { Medicine, } \\
1995\end{array}$ & $\begin{array}{l}\text { Avaliar o resultado das } \\
\text { intervenções feitas no prazo } \\
\text { de duas semanas de } \\
\text { referência no que diz } \\
\text { respeito a: controle dos } \\
\text { sintomas, alteração nos } \\
\text { pacientes e seus familiares a } \\
\text { respeito de uma visão } \\
\text { diagnóstico e prognóstico }\end{array}$ & $\begin{array}{l}\text {-Longitudinal } \\
-2 \text { semanas e } 5 \text { avaliações: } \\
1,3,7,10 \text { e } 13\end{array}$ & $\begin{array}{l}\text {-125 pacientes } \\
\text { neoplasia maligna } \\
\text { encaminhados } \\
\text { para ECP } \\
\text {-PACA (palliative } \\
\text { care assessment) }\end{array}$ & $\begin{array}{l}\text {-melhora: dor, } \\
\text { náusea,insônia,anorexia e } \\
\text { constipação } \\
\text { - percepção do paciente é } \\
\text { alterada } \\
\text { - ECP efetiva }\end{array}$ & não & 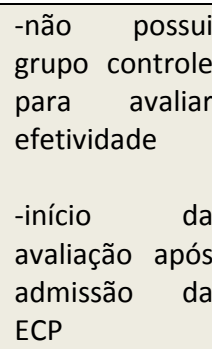 \\
\hline $\begin{array}{l}\text { 3. Higginson } \\
\text { et } \quad{ }^{\text {al. }} \\
\text { Inglaterra }\end{array}$ & $\begin{array}{l}\text { J Pain } \\
\text { Symptom } \\
\text { Manage, } \\
1997\end{array}$ & $\begin{array}{l}\text {-Identificar prevalência de } \\
\text { dor e severidade } \\
\text { - Comparar } 02 \text { modalidades } \\
\text { de atendimento em paciente } \\
\text { oncológico }\end{array}$ & $\begin{array}{l}\text { - Longitudinal } \\
\text { - } 6 \text { meses: avaliações semanais } \\
\text { - 485/695: CP }\end{array}$ & $\begin{array}{l}\text {-695 pacientes } \\
\text { oncológicos } \\
\text { encaminhados } \\
\text { para CP } \\
\text { - escala de dor: } 0 \text { a } \\
4\end{array}$ & $\begin{array}{l}-70 \% \text { encaminhados } \\
\text { apresentam dor } \\
\text { - redução de dor }(p<0,0001) \\
\text { em CP } \\
\text { - não houve dor excruciante }\end{array}$ & não & $\begin{array}{l}\text {-somente } \\
\text { sobre dor } \\
\text { - escala de dor } \\
\text { utilizada difícil } \\
\text { de se comparar }\end{array}$ \\
\hline $\begin{array}{l}\text { 4.Mercadante } \\
\text { et al. Itália } 16\end{array}$ & $\begin{array}{l}\text { Support } \\
\text { Care Cancer, } \\
2000\end{array}$ & $\begin{array}{l}\text { Avaliar o impacto da equipe } \\
\text { de cuidado paliativo } \\
\text { domiciliar }\end{array}$ & $\begin{array}{l}\text { - Retrospectivo: sintomas e } \\
\text { sobrevivência } \\
\text { - avaliações: admissão, } 10 \text { dias e } \\
\text { antes da morte }\end{array}$ & $\begin{array}{l}\text { - } 211 \text { pacientes } \\
\text { com câncer } \\
\text { avançado em ECP } \\
\text { - lista de sintomas }\end{array}$ & $\begin{array}{l}\text {-ECP melhora sintomas } \\
\text {-redução significativa: dor, } \\
\text { náusea/vomito, } \\
\text { desconforto gástrico e } \\
\text { diarreia } \\
\text { - sonolência, fraqueza, } \\
\text { confusão, dispneia e } \\
\text { constipação aumentou nos } \\
\text { últimos dias de vida }\end{array}$ & não & $\begin{array}{l}\text { Escala de } \\
\text { sintomas não } \\
\text { padronizada }\end{array}$ \\
\hline
\end{tabular}

ECP: equipe de cuidados paliativos; QV: qualidade de vida; PACA: palliative care assessment 
Tabela 1- continuação

\begin{tabular}{|c|c|c|c|c|c|c|c|}
\hline Autor/país & $\begin{array}{l}\text { Periódico/ } \\
\text { Ano }\end{array}$ & Objetivo Principal & Desenho do estudo/Avaliação & $\begin{array}{c}\text { Amostra/ } \\
\text { Instrumento }\end{array}$ & Resultados Chaves & $\begin{array}{l}\text { Efetividade } \\
\text { Comparada? }\end{array}$ & Comentários \\
\hline $\begin{array}{l}\text { 5.Jack B et al. } \\
\text { Inglaterra }\end{array}$ & $\begin{array}{l}\text { Palliat Med, } \\
2003\end{array}$ & \begin{tabular}{llr} 
Avaliar o & impacto & no \\
controle de & sintomas em \\
pacientes & \multicolumn{2}{c}{ oncológicos } \\
admitidos & para ECP \\
hospitalar & &
\end{tabular} & 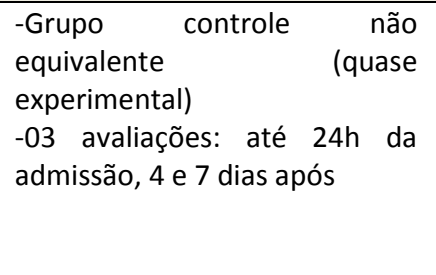 & $\begin{array}{l}-50 \text { intervenção } \\
\text { (encaminhados } \\
\text { para a ECP) } \\
-50 \text { controle (não } \\
\text { encaminhados para } \\
\text { ECP) } \\
\text {-PACA }\end{array}$ & $\begin{array}{l}\text {-grupo intervenção } \\
\text { melhora em todos os } \\
\text { sintomas } \\
\text {-principalmente: dor e } \\
\text { anorexia }\end{array}$ & $\operatorname{sim}$ & $\begin{array}{l}\text {-compara } \\
\text { cuidado } \\
\text { convencional } \\
\text { versus } \\
\text { cuidado } \\
\text { paliativo }\end{array}$ \\
\hline $\begin{array}{l}\begin{array}{l}\text { 6.Boström } \\
\text { et }\end{array} \text { al. } \\
\text { Suécia }^{18}\end{array}$ & $\begin{array}{l}\text { Eur J Cancer } \\
\text { Care, } 2004\end{array}$ & $\begin{array}{l}\text { - Determinar dor antes e } \\
\text { após CP } \\
\text { - Correlacionar dor e } \\
\text { aspectos do cuidado }\end{array}$ & - Transversal & $\begin{array}{l}-75 \text { pacientes } \\
\text { oncologicos }\end{array}$ & $\begin{array}{l}\text {-melhora da dor } \\
\text {-correlação com } \\
\text { sentimento de segurança e } \\
\text { continuidade do cuidado } \\
\end{array}$ & não & $\begin{array}{l}\text {-apenas dor } \\
\text { como sintoma }\end{array}$ \\
\hline $\begin{array}{l}\text { 7..Strasser et } \\
\text { al. } \\
\text { Irlanda/EUA }^{19}\end{array}$ & $\begin{array}{l}\text { J Pain } \\
\text { Symptom } \\
\text { Manage, } \\
2004\end{array}$ & $\begin{array}{l}\text { Caracterizar o atendimento } \\
\text { de dois serviços no controle } \\
\text { de sintomas em pacientes } \\
\text { oncológicos }\end{array}$ & $\begin{array}{l}\text {-Retrospectivo } \\
\text { - admissão e } 5 \text { semanas }\end{array}$ & $\begin{array}{l}-138 \text { pacientes para } \\
\text { ECP (MD Clinic) e } 77 \\
\text { manejo tradicional } \\
\text { (PSM Clinic) } \\
\text { - ESAS } \\
\end{array}$ & $\begin{array}{l}\text { - MD Clinic apresentou } \\
\text { melhora dos sintomas e } \\
\text { melhor satisfação }\end{array}$ & $\operatorname{sim}$ & $\begin{array}{lr}\text {-desenho do } \\
\text { estudo não } \\
\text { permite } \\
\text { estabelecer } \\
\text { causalidade } \\
\end{array}$ \\
\hline $\begin{array}{l}\text { 8. Morita et al. } \\
2005^{20}\end{array}$ & $\begin{array}{l}\text { J Pain } \\
\text { Symptom } \\
\text { Manage, } \\
2005\end{array}$ & $\begin{array}{l}\text {-Comparar características do } \\
\text { pac. em unidade de CP } \\
\text { (UCP)e tratamento médico e } \\
\text { melhora de sintomas após } \\
\text { consulta com ECP }\end{array}$ & $\begin{array}{lll}\text {-Transversal } \quad \text { (estudo } & \text { de } \\
\text { auditoria) } & & \\
\text {-Avaliação: admissão e } & 1 \\
\text { semana após } & & \end{array}$ & $\begin{array}{l}\text { - } 101 \text { consulta de } \\
\text { ECP } \\
\text { - } 100 \text { em UCP } \\
\text { - STAS }\end{array}$ & $\begin{array}{lr}\text {-melhora do sintomas: dor, } \\
\text { náusea, } & \text { constipação, } \\
\text { dispneia, } & \text { insônia, } \\
\text { ansiedade } & \\
\text {-mas não: fadiga, boca } \\
\text { seca, sonolência e delirium }\end{array}$ & $\operatorname{sim}$ & $\begin{array}{l}\text { Apresentou } \\
\text { dados } \\
\text { descritivos } \\
\text { sobre consulta } \\
\text { da UCP e ECP }\end{array}$ \\
\hline $\begin{array}{l}\text { 9.Modonesi C } \\
\text { et al. Itália } 21\end{array}$ & $\begin{array}{l}\text { J Pain } \\
\text { Symptom } \\
\text { Manage, } \\
2005\end{array}$ & $\begin{array}{l}\text { Avaliar o impacto do cuidado } \\
\text { paliativo nos sintomas de } \\
\text { pacientes oncológicos pela } \\
\text { ESAS }\end{array}$ & $\begin{array}{l}\text { - Longitudinal } \\
\text { - } 02 \text { avaliaçoes: admissão e } 7 \\
\text { dias após }\end{array}$ & $\begin{array}{l}\text {-162 pacientes } \\
\text { - ESAS }\end{array}$ & $\begin{array}{l}\text {-mostrou que os pacientes } \\
\text { que se beneficiaram da } \\
\text { ECP foram aqueles com } \\
\text { sintomas mais complexos }\end{array}$ & não & Sem controle \\
\hline
\end{tabular}

ECP: equipe de cuidados paliativos; QV: qualidade de vida; PACA: palliative care assessment; STAS: Schedule forTeam Assessment Scale 
Tabela 1- continuação

\begin{tabular}{|c|c|c|c|c|c|c|c|}
\hline Autor/país & $\begin{array}{l}\text { Periódico/ } \\
\text { Ano }\end{array}$ & Objetivo Principal & Desenho do estudo/Avaliação & $\begin{array}{c}\text { Amostra/ } \\
\text { Instrumento }\end{array}$ & Resultados Chaves & $\begin{array}{l}\text { Efetividade } \\
\text { Comparada? }\end{array}$ & Comentários \\
\hline $\begin{array}{l}\text { 10.Peters L et } \\
\text { al. Australia }^{22}\end{array}$ & JAN, 2006 & $\begin{array}{l}\text { - Comparar sintomas e saúde } \\
\text { psicológica, controle } \\
\text { percebido dos efeitos do } \\
\text { câncer, qualidade de vida em } \\
\text { câncer terminal sob cuidados } \\
\text { da ECP hospitalar e domiciliar } \\
\text {-Identificar fatores preditores } \\
\text { de QV }\end{array}$ & - Transversal & $\begin{array}{lr}-32 \text { em } & \text { ECP } \\
\text { hospitalar } & \\
-26 \text { em } & \text { ECP } \\
\text { domiciliar } & \\
\text {-Memorial } & \\
\text { Symptom } & \\
\text { Assessment } & \text { Scale } \\
\text { (MSAS), EORTC } \\
\begin{array}{ll}\text { QLC-C30, escala de } \\
\text { ansiedade } \\
\text { hospitalar, escala } \\
\text { tipo Likert }\end{array}\end{array}$ & $\begin{array}{l}\text {-ECP domiciliar com menor } \\
\text { severidade e sofrimento, } \\
\text { menor depressão, melhor } \\
\text { QV e melhor controle dos } \\
\text { efeitos de sua doença }\end{array}$ & $\operatorname{sim}$ & $\begin{array}{l}\text {-Tipo de } \\
\text { desenho não } \\
\text { permite } \\
\text { comparação } \\
\text { com atribuição } \\
\text { de causalidade } \\
\text {-ECP } \\
\text { hospitalar } \\
\text { versus ECP } \\
\text { domiciliar }\end{array}$ \\
\hline $\begin{array}{l}\text { 11.Jack B et al. } \\
\text { Inglaterra }^{23}\end{array}$ & $\begin{array}{l}\text { Eur J Cancer } \\
\text { Care, } 2006\end{array}$ & $\begin{array}{l}\text { Avaliar o impacto de uma } \\
\text { ECP hospitalar sobre a dor } \\
\text { em pacientes oncológicos }\end{array}$ & $\begin{array}{l}\text { - Grupo controle não } \\
\text { equivalente (quase } \\
\text { experimental) } \\
\text { - Avaliações:até } 24 \mathrm{~h} \text { da } \\
\text { admissão, } 4 \text { e } 7 \text { dias após }\end{array}$ & $\begin{array}{l}\text { - } 50 \text { intervenção } \\
\text { sob cuidados da } \\
\text { ECP hospitalar } \\
\text {-50 controle sob } \\
\text { cuidados } \\
\text { hospitalares } \\
\text { convencionais } \\
\text { - PACA }\end{array}$ & $\begin{array}{l}\text { - todos os pacientes } \\
\text { apresentaram melhora da } \\
\text { dor inicialmente, mas } \\
\text { aqueles atendidos pela ECP } \\
\text { a melhora da dor foi maior }\end{array}$ & $\operatorname{sim}$ & $\begin{array}{l}\text {-comparou } \\
\text { cuidado } \\
\text { convencional } \\
\text { versus cuidado } \\
\text { paliativo }\end{array}$ \\
\hline $\begin{array}{l}\text { 12.Dumitrescu } \\
\text { et al. } \\
\text { Romenia }^{24}\end{array}$ & $\begin{array}{l}\text { J Pain } \\
\text { Symptom } \\
\text { Manage, } \\
2007\end{array}$ & $\begin{array}{l}\text { Analisar as mudanças de } \\
\text { sintomas e dor e relacionar } \\
\text { com as características sócio } \\
\text { demográficas e médicas }\end{array}$ & $\begin{array}{l}\text { - Longitudinal } \\
\text { - } 2 \text { anos: avaliação diária a } \\
\text { mensal }\end{array}$ & $\begin{array}{l}\text {-102 pacientes } \\
\text {-busca livre de } \\
\text { sintomas, } \\
\text { intensidade de } 0 \mathrm{a} \\
10\end{array}$ & $\begin{array}{l}\text { - redução da dor e outros } \\
\text { sintomas }\end{array}$ & não & $\begin{array}{l}\text { Não explicitou } \\
\text { quais eram os } \\
\text { outros } \\
\text { sintomas, } \\
\text { apenas os } \\
\text { quantificou }\end{array}$ \\
\hline
\end{tabular}

ECP: equipe de cuidados paliativos; QV: qualidade de vida; PACA: palliative care assessment 
Tabela 1- continuação

\begin{tabular}{|c|c|c|c|c|c|c|c|}
\hline Autor/país & $\begin{array}{l}\text { Periódico/ } \\
\text { Ano }\end{array}$ & Objetivo Principal & Desenho do estudo/Avaliação & $\begin{array}{c}\text { Amostra/ } \\
\text { Instrumento }\end{array}$ & Resultados Chaves & $\begin{array}{l}\text { Efetividade } \\
\text { Comparada? }\end{array}$ & Comentários \\
\hline $\begin{array}{l}\text { 13. Gomez- } \\
\text { Baptiste et al. } \\
\text { Espanha }^{25}\end{array}$ & $\begin{array}{l}\text { J Pain } \\
\text { Symptom } \\
\text { Manage, } \\
2010\end{array}$ & $\begin{array}{l}\text { Avaliar a efetividade do } \\
\text { serviço de cuidado paliativo } \\
\text { em melhorar sintomas na } \\
\text { Espanha }\end{array}$ & $\begin{array}{l}\text { - Multicêntrico, quase } \\
\text { experiemental, do tipo antes e } \\
\text { depois } \\
\text { - Avaliações: admissão, } 7 \text { e } 14 \\
\text { dias após }\end{array}$ & $\begin{array}{l}\text {-265 pacientes } \\
\text { oncológicos de } 105 \\
\text { serviços } \\
\text { - } 08 \text { sintomas, } \\
\text { pontuadas em } 0 \text { a } \\
\text { 10: dor, dor } \\
\text { incidental, } \\
\text { náusea/vomito, } \\
\text { anorexia, } \\
\text { constipação, } \\
\text { insônia, dispneia. }\end{array}$ & $\begin{array}{l}\text { - } 7 \text { dias: todos os sintomas } \\
\text { - } 14 \text { dias: dor, constipação, } \\
\text { ansiedade e depressão } \\
\text { - redução da frequência de } \\
\text { dor incidental }\end{array}$ & não & $\begin{array}{l}\text {-Não utilizou } \\
\text { escala de } \\
\text { sintomas } \\
\text { padronizada } \\
\text {-não ficou } \\
\text { claro os tipos } \\
\text { de serviço } \\
\text { envolvidos }\end{array}$ \\
\hline $\begin{array}{l}\text { 14.Paiva et al. } \\
\text { Brasil }^{26}\end{array}$ & $\begin{array}{l}\text { Eur J Cancer } \\
\text { Care, } 2012\end{array}$ & $\begin{array}{l}\text { Avaliar a efetividade do } \\
\text { cuidado paliativo } \\
\text { ambulatorial em reduzir } \\
\text { sofrimento de sintomas }\end{array}$ & $\begin{array}{l}\text { - Retrospectivo } \\
\text { - Avaliações: duas (inicial e } \\
\text { retorno da consulta). O } \\
\text { intervalo entre as avaliações } \\
\text { variou entre } 5 \text { a } 100 \text { dias }\end{array}$ & $\begin{array}{l}-232 \text { pacientes } \\
\text {-ESAS }\end{array}$ & $\begin{array}{l}\text {-redução de todos os } \\
\text { sintomas } \\
\text { - correlação positiva com } \\
\text { bem estar, fadiga/ } \\
\text { ansiedade } \\
\text { fadiga/dispnéia }\end{array}$ & não & $\begin{array}{l}\text {-Apenas } \\
\text { pacientes } \\
\text { ambulatoriais } \\
\text { e critério de } \\
\text { inclusão não } \\
\text { claro }\end{array}$ \\
\hline $\begin{array}{l}\text { 15. Santiago } \\
\text { et }{ }^{\text {al. }} \\
\text { Espanha }^{27}\end{array}$ & $\begin{array}{l}\text { Support } \\
\text { Care } \\
\text { Cancer, } \\
2012 \\
\end{array}$ & $\begin{array}{lll}\text {-Verificar a eficiência } & \text { da } \\
\text { equipe consultora } & \text { em } \\
\text { pacientes com câncer }\end{array}$ & $\begin{array}{l}\text { - Retrospectivo } \\
\text { - } 03 \text { avaliaçoes: inicial, } 3 \text { e } 7 \\
\text { dias após a admissao }\end{array}$ & $\begin{array}{l}\text { - } 611 \text { pacientes com } \\
\text { cancer } \quad(49 \% \\
\text { hospitalizadoss) } \\
\text { - ESAS }\end{array}$ & $\begin{array}{l}\text {-melhora da dor, } \\
\text { náusea,depressão, } \\
\text { ansiedade e sonolência }\end{array}$ & não & $\begin{array}{l}\text {-ambulatorial, } \\
\text { hospitalizados } \\
\text { e } \\
\text { retrospectivo }\end{array}$ \\
\hline $\begin{array}{l}\text { 16. Kang et al. } \\
\text { EUA }^{28}\end{array}$ & $\begin{array}{l}\text { J Pain } \\
\text { Symptom } \\
\text { Manage, } \\
2013\end{array}$ & $\begin{array}{l}\text {-Verificar mudança de } \\
\text { sintomas na primeira semana } \\
\text { de admissão para o ECP }\end{array}$ & $\begin{array}{l}\text { - Retrospectivo } \\
-02 \text { avaliações: admissão e } 7 \\
\text { dias após }\end{array}$ & $\begin{array}{l}\text { - } 1612 \text { pacientes } \\
\text { ambulatoriais com } \\
\text { cancer } \\
\text { - ESAS }\end{array}$ & $\begin{array}{l}\text { - melhora da maioria dos } \\
\text { sintomas pelo ESAS }\end{array}$ & não & $\begin{array}{l}\text {-apenas } \\
\text { descritivo e } \\
\text { retrospectvo }\end{array}$ \\
\hline
\end{tabular}

ECP: equipe de cuidados paliativos; QV: qualidade de vida; PACA: palliative care assessment 
Qualidade de vida foi o foco de outra revisão sistemática. Oitenta e seis artigos foram incluídos em uma revisão sistemática com o objetivo de verificar o impacto do cuidado paliativo especialista na qualidade de vida dos doentes, quando comparado ao cuidado convencional. Concluiu-se que devido a limitações metodológicas e variedade nos instrumentos de avaliação não foi possível desenhar uma resposta consistente ${ }^{29}$.

Outra revisão sistemática investigou se a equipe de cuidado paliativo integrada ao hospital melhorou o processo ou o resultado no cuidado a pacientes e familiares no fim da vida. Foram incluídos estudos quantitativos e qualitativos. Foram localizados 13 estudos com natureza de intervenção variada. Os estudos foram considerados limitados quanto à qualidade metodológica. As comparações entre os grupos apresentaram viés e não foram ajustados os fatores de confusão. Observaram que os estudos indicaram pequeno efeito positivo da equipe hospitalar e que a equipe de cuidado paliativo integrada ao hospital oferece alguns benefícios, porém afirma que esses achados deveriam ser interpretados com cautela devido às fraquezas metodológicas ${ }^{11}$.

Revisão sistemática de ensaios clínicos envolveu vinte e dois ensaios clínicos publicados até o ano de 2008. O objetivo foi verificar a evidência da efetividade do cuidado paliativo especializado. Foram incluídos estudos que analisaram satisfação, qualidade de vida e custo. Os autores concluíram haver evidência fraca de benefício do cuidado paliativo ${ }^{30}$.

A efetividade da equipe de cuidado paliativo e hospice sobre a dor e outros sintomas, sobre a satisfação e intervenções terapêuticas foi avaliada em 44 estudos por meio de uma revisão sistemática com metanálise e metassíntese. Dentre os desfechos, foi possível afirmar que houve pequeno benefício para dor e outros sintomas ${ }^{31}$. A efetividade de diferentes modelos de cuidado 
paliativo foi verificada em revisão sistemática que avaliou custoefetividade em doentes terminais. $O$ período de busca foi entre $o$ ano de 2003 a 2008. Seis revisões sistemáticas e quatro estudos originais foram incluídos. Observaram-se limitações metodológicas e, devido à heterogeneidade dos programas, não foi possível responder qual modelo de cuidado paliativo especializado é mais efetivo ou qual deles têm melhor custo-efetividade ${ }^{32}$.

Oito ensaios clínicos e 32 estudos observacionais e quase experimentais foram analisados para verificar se cuidados paliativos melhoraram o controle de dor, sintomas, qualidade de vida ou reduziram problemas emocionais do cuidador familiar. Os resultados demonstraram que há evidencia que cuidado paliativo especializado em pacientes internados em domicílio e em hospital melhoraram a dor, o controle de sintomas, a ansiedade e reduziram o número de admissões hospitalares ${ }^{33}$.

Do exposto, percebem-se as controvérsias sobre a efetividade de cuidados paliativos ofertados em diferentes modalidades de cuidado. Ainda, os estudos apresentaram limitações e variações como inadequação metodológica, variação dos instrumentos de medidas de sintomas utilizados, inadequação da população analisada, contaminação de grupo controle, viés de seleção e a falta de estudos comparativos, tornando difícil a análise de evidência sobre a efetividade do cuidado paliativo para controle de sintomas, qualidade de vida, satisfação ou custos. Assim, ainda é escassa a evidência sobre a efetividade do cuidado paliativo comparado a outras modalidades de cuidado, principalmente ao cuidado tradicional, o que justifica a realização da presente pesquisa.

1.3. Cuidados Paliativos: definição, breve histórico, terminologia e modalidades de modelos de cuidado 
Cuidado paliativo foi definido pela Organização Mundial da Saúde (OMS) em 1990. Em 2002, houve uma atualização e, a OMS atualmente conceitua cuidado paliativo como uma abordagem multidisciplinar com o objetivo de melhorar a qualidade de vida dos pacientes e familiares que convivem com uma doença que ameaça a vida, em qualquer fase da doença, executando ações de prevenção e alívio do sofrimento por meio de identificação precoce, avaliação e tratamento de dor e demais sintomas físicos, sociais, psicológicos e espirituais. Em definição posterior, cuidado paliativo envolvia o período de tratamento ativo da doença e não somente a fase terminal ${ }^{34}$.

A equipe especializada em cuidado paliativo possui como dever o controle não somente da dor, mas de todos os sintomas físicos, sociais, emocionais e espirituais do doente e família, tarefa bastante ambiciosa, cujas bases iniciaram-se com o movimento hospice na década de 60 com Cecily Saunders ${ }^{35}$.

Na década de 70, o movimento hospice, passou a denominarse cuidado paliativo e tem evoluído de uma filosofia de cuidado para uma prática de cuidado, feita por uma equipe profissional especializada ${ }^{35-38}$. Tal "sofisticação" tem um custo educacional e de assistência, cuja superioridade precisa ser demonstrada.

No Brasil, desde os anos 80, ocorreram iniciativas de Cuidados Paliativos, porém, somente, a partir dos anos 90, surgem os primeiros serviços organizados ${ }^{38}$.

Associações profissionais também surgiram nas décadas de 90, como a Associação Brasileira de Cuidados Paliativos (1997) e, em 2005, funda-se a Academia Nacional de Cuidados Paliativos ${ }^{38}$.

Ao longo das últimas décadas, ampla variedade de termos foi utilizada para descrever cuidado paliativo.

Os termos mais comumente encontrados na língua inglesa foram "care of the dying, terminal care, end-of-life care, continuing 
care, total care, holistic care, comprehensive care, comfort care, pain and symptom management and quality-of-life care" ${ }^{39-41}$. Os termos adicionados mais recentemente foram "supportive care e best supportive care" e ganharam popularidade ${ }^{42-44}$.

Os termos e definições na área de cuidado paliativo estão longe de serem homogêneos. Estudos prévios consideram o termo "palliative care" confuso para médicos e pacientes ${ }^{45-47}$.

Cuidado paliativo tem se desenvolvido em mais de 100 países ao redor do mundo e se adaptado aos diversos sistemas de saúde. Uma publicação recente procura buscar esclarecimento sobre os termos e conceitos utilizados e duas categorias apareceram: serviço de cuidado generalista ou especialista. Generalistas compreendem a assistência não relacionada a profissionais especialistas em cuidado paliativo, enquanto que especialistas são profissionais especificamente treinados em cuidado paliativo ${ }^{48}$.

Os pacientes podem ser assistidos em unidades de cuidados paliativos integradas ao hospital, em ambientes específicos de cuidado paliativo (unidade especializada) ou por uma equipe tradicional do hospital tendo a equipe de cuidado paliativo como interconsultora. Podem também serem assistidos no domicílio. Portanto, as equipes de cuidado paliativo podem oferecer assistência seja no hospital (internação ou ambulatório), unidade de internação não hospitalar (hospices), em clínicas de cuidado diário ("palliative day care") ou programas de assistência domiciliar.

No meio hospitalar, chama a atenção do modelo de equipe de interconsulta em cuidado paliativo.

A assistência dos serviços de cuidado paliativo difere na forma de trabalho entre os países e de acordo com fatores políticos, econômicos, sociais e culturais de cada serviço.

Autores de uma revisão sistemática tiveram como objetivo buscar evidencia sobre 0 impacto de diferentes modelos especialistas em cuidado paliativo na qualidade de vida. Oitenta e 
seis artigos foram identificados e observaram que alguns modelos comparados ao cuidado tradicional são mais efetivos no controle da dor e mostrou efeito limitado nas outras comparações ${ }^{29}$.

As clínicas diárias ou "specialist palliative day care" foi tema de outra revisão que incluiu artigos primários quantitativos e qualitativos. Os autores observaram alta satisfação dos clientes, porém não houve evidência consistente para o controle de sintomas e qualidade de vida ${ }^{49}$.

Os custos gerados pela assistência paliativa foi tema de uma revisão sistemática. Um dos objetivos foi comparar o impacto das diversas modalidades de cuidado paliativo especializado no custoefetividade. Verificou-se que a equipe especializada em cuidado paliativo mostrou melhor custo-efetividade comparado ao cuidado tradicional $^{32}$.

As diversas modalidades de assistência em cuidado paliativo, a falta de evidência e as controvérsias sobre os melhores modelos, motivaram a organização desta pesquisa.

\subsection{Sintomas, instrumentos de avaliação e sobrecarga de sintomas}

Em pacientes com câncer, sintomas múltiplos são muito frequentes.

Ampla revisão sistemática sobre a prevalência de sintomas em pacientes com câncer incurável foi realizada em 44 estudos (25.074 pacientes). A prevalência foi de $74 \%$ para fadiga (IC 63-83), $71 \%$ para dor (IC $67-74$ ), 69\% para falta de energia (IC57-79), 60\% para fraqueza (IC51-68), 53\% para anorexia (IC48-59), 46\% para perda de peso (IC34-59), 39\% para depressão (IC33-45), 37\% para 
constipação intestinal (IC33-40), 36\% para insônia (IC30-43), 35\% para dispneia (30-39), 31\% para náusea (IC27-35), 30\% para ansiedade (IC17-46) e 20\% para sonolência (IC12-32). Nas duas últimas semanas de vida, os sintomas mais relatados foram perda de peso, fadiga, fraqueza, anorexia, dor e náusea ${ }^{50}$.

Em estudo que investigou a frequência e intensidade dos sintomas em 3030 pacientes (143 centros de cuidado paliativo), em 21 países europeus, observou-se que sintomas clinicamente relevantes eram frequentes, e que, entre $30 \%$ a $50 \%$ dos pacientes com sintomas de moderados a intensos não recebiam qualquer tratamento ${ }^{51}$.

Em estudo retrospectivo envolvendo 1612 pacientes ambulatoriais em radioterapia paliativa, verificou-se alta prevalência de sintomas de moderados a intensos. Fadiga ocorreu em $85 \%$ do doentes, dor, em $71 \%$ dos avaliados, $70 \%$ deles referiu perda de bem estar, $62 \%$, referiram sonolência e prejuízo no sono, $52 \%$ relatou anorexia, depressão e ansiedade ocorreram em cerca de $40 \%$ dos pacientes, $38 \%$ verbalizou dispneia e $27 \%$, náusea ${ }^{28}$.

Sintomas não controlados podem ser o principal motivo para a procura do departamento de emergência. Um estudo foi desenvolvido com o objetivo de avaliar as razões da admissão no setor de emergência, as intervenções realizadas durante a hospitalização, a intensidade dos sintomas na admissão e na alta dos pacientes com câncer avançado. Observaram que: $50 \%$ dos pacientes já tinham sido hospitalizados no mês anterior, a mediana de hospitalização foi de 7 dias e a de sobrevivência foi de 50 dias. A principal razão para admissão no departamento de emergência foi a dor. Os pacientes relataram que a intervenção visita domiciliar pela equipe de cuidado paliativo preveniu hospitalização ${ }^{52}$.

O comportamento dos sintomas deve ser observado na assistência a essa população. Com adequado controle, alguns 
doentes podem permanecer estáveis nos últimos 6 meses de vida. Porém, no último mês de vida, alguns sintomas acentuam-se (cerca de $1 / 3$ dos 10.750 pacientes tinham sintomas de moderados a intensos no último mês de vida) e a funcionalidade diminui com a proximidade da morte ${ }^{53}$.

A intensidade dos sintomas, principalmente, dor mostrou relação inversa com a funcionalidade em estudos com pacientes com câncer avançado ${ }^{54}$. Menor funcionalidade, maior sonolência, dor, fadiga, depressão e perda do apetite foram fatores independentemente associados à perda de bem-estar ${ }^{55}$. Outro ponto importante é que alta pontuação na escala de sintomas pode gerar impactos negativos importantes ${ }^{56}$.

Os termos sobrecarga de sintomas e sofrimento são utilizados de maneira intercambiável entre os estudos pela falta de definições claras. Sobrecarga de sintomas para muitos é a expressão do número de sintomas observados ou a soma da intensidade dos sintomas ${ }^{21,57,58}$. Para outros, é a medida de interferência ${ }^{60}$ ou a intensidade dos sintomas ${ }^{59,60}$.

A monitorização sistemática dos sintomas utilizando uma escala de avaliação de sintomas múltiplos é recomendada para avaliar a resposta ao tratamento ou intervenção ${ }^{61-62}$, pois facilitaria o manejo dos sintomas ${ }^{61}$.

Há diversas escalas de avaliação de sintomas múltiplos, porém, não há consenso sobre seu uso em cuidado paliativo ${ }^{65}$.

As principais escalas com avaliação da sobrecarga de sintomas são ${ }^{65}$ : MD Anderson (MDASI), European Organization for the Research and Treatment of Cancer QLQ30 (EORTC-QLQ30) e Memorial Symptom Assessment Scale (MSAS).

Nos últimos anos, a escala mais frequentemente utilizada foi a Escala de Avaliação de Sintomas de Edmonton (ESAS) ${ }^{66}$. 
O presente estudo comparou a efetividade de duas modalidades de prestação de cuidado paliativo sobre o controle de sintomas e sobrecarga de sintomas em doentes com câncer avançado. 
2.OBJETIVOS 


\section{OBJETIVOS}

\subsection{Objetivo geral}

Comparar a efetividade de duas modalidades de equipe profissional no controle de sintomas de pacientes com câncer avançado.

\subsection{Objetivos específicos}

- Analisar a frequência e a magnitude dos sintomas dos doentes orientados pela Equipe de Cuidado Paliativo (ECP) e Equipe de Cuidado Tradicional (CT) na admissão, após $24 \mathrm{~h}$ e $48 \mathrm{~h}$ da admissão.

- Comparar o controle de sintomas e a satisfação de doentes com câncer avançado, atendidos pela equipe de cuidado paliativo (ECP) ao controle de sintomas e satisfação dos doentes obtidos pela equipe de cuidado tradicional (CT).

- Comparar o escore da Sobrecarga de Sintomas da Escala de Avaliação de Sintomas de Edmonton (ESAS) dos doentes orientados pelas duas equipes (ECP e CT) na admissão, após $24 \mathrm{~h}$ e $48 \mathrm{~h}$ da admissão.

- Comparar o tratamento analgésico para o controle da dor do câncer entre doentes dos Grupos ECP e CT, de acordo com o Índice de Manejo da Dor (IMD). 
3.HIPÓTESES 


\section{HIPÓTESES}

As principais hipóteses deste estudo foram:

- Doentes atendidos pela equipe de cuidado paliativo (ECP) obterão melhor controle de sintomas que os doentes atendidos pela equipe de cuidado tradicional (CT).

- Doentes atendidos pela equipe de cuidado paliativo (ECP) relatarão maior satisfação com o atendimento que os doentes atendidos pela equipe de cuidado tradicional (CT).

- Na avaliação inicial, o escore da sobrecarga de sintomas da Escala de Avaliação de Sintomas de Edmonton (ESAS) será semelhante nos dois Grupos (ECP=CT); na avaliação de $24 \mathrm{~h}$ e 48h, após a admissão, o Grupo ECP apresentará menor Sobrecarga de Sintomas.

- Doentes atendidos pelo Grupo ECP terão Índice de Manejo da Dor (IMD) mais adequados. 


\section{CASUÍSTICA E MÉTODO}

\subsection{Tipo de estudo}

Estudo observacional e longitudinal para comparar a efetividade de duas modalidades de equipe profissional no controle de sintomas de pacientes com câncer avançado.

\subsection{Local do estudo}

A coleta dos dados foi realizada no Instituto Central do Hospital das Clínicas da Faculdade de Medicina da Universidade de São Paulo (IC.HCFMUSP), um hospital público geral, acadêmico de grande porte, de assistência de alta complexidade, de ensino, pesquisa, e composto por diversas unidades de atendimento. $O$ atendimento é realizado por equipes multidisciplinares compostas por profissionais de diferentes especialidades.

A escolha da instituição esteve relacionada com a possibilidade de assistir o paciente por meio da equipe de cuidado tradicional ou em parceria com a equipe de cuidado paliativo e com o desejo de verificar o controle de sintomas em pacientes oncológicos de um hospital geral.

\subsubsection{Período de coleta de dados}


O período de coleta de dados no IC.HCFMUSP ocorreu de 28 de novembro de 2012 a 16 de dezembro de 2013.

\subsection{Aspectos éticos}

O estudo foi submetido e aprovado pela Comissão de Ética em Pesquisa da Escola de Enfermagem da Universidade de São Paulo (CAEE: 08839412.8.3001.0068; Parecer no. 597.590-0) e tal aprovação foi aceita pela instituição onde os dados foram coletados (Anexo 1). Todos os pacientes elegíveis foram convidados e orientados sobre o estudo e aqueles que concordaram em participar assinaram o Termo de Consentimento Livre e Esclarecido (TCLE) em duas vias (Anexo 2).

\subsection{População e Amostra}

A amostra de conveniência foi composta por pacientes com câncer avançado atendidos no Instituto Central do HCFMUSP. Os pacientes poderiam ser atendidos pela equipe de cuidados paliativos (Grupo ECP), na modalidade de interconsulta, ou pela equipe de cuidado tradicional (Grupo CT), sem a interconsulta da equipe de cuidados paliativos. Não houve interferência da pesquisadora quanto à modalidade de tratamento. Os doentes foram analisados compondo-se dois grupos.

- Grupo ECP: composto por pacientes atendidos pela equipe de cuidados paliativos (ECP), na modalidade de equipe interconsultora.

- Grupo CT: composto por pacientes atendidos pela equipe de cuidado tradicional (CT), sem a interconsulta da equipe de cuidados paliativos. 
A equipe de cuidados paliativos do IC. HCFMUSP foi composta por médicos, enfermeiros, assistentes sociais e psicólogos. Os profissionais possuem formação específica em cuidados paliativos.

O Quadro 1 mostra as características de trabalho da equipe de cuidado paliativo.

Quadro 1- Características do trabalho da equipe de cuidado paliativo do IC.HCFMUSP. São Paulo, 2014

\begin{tabular}{|l|c|}
\hline \multicolumn{1}{|c|}{ Estrutura de trabalho } & IC.HCFMUSP \\
\hline $\begin{array}{l}\text { Equipe multiprofissional (médicos, enfermeiro, } \\
\text { psicólogo e assistente social). }\end{array}$ & sim \\
\hline $\begin{array}{l}\text { Atendimento da ECP na modalidade interconsulta } \\
\text { a pacientes hospitalizados (em parceria com a } \\
\text { equipe médica tradicional) }\end{array}$ & não \\
\hline $\begin{array}{l}\text { Existência de leitos exclusivos para atendimento } \\
\text { pela ECP nos hospitais de coleta de dados (a } \\
\text { ECP como única responsável pelo paciente) }\end{array}$ & não \\
\hline $\begin{array}{l}\text { Existência de unidade exclusiva de cuidados } \\
\text { paliativos para atendimento pela ECP nos } \\
\text { hospitais de coleta de dados.. }\end{array}$ & sim \\
\hline $\begin{array}{l}\text { A ECP coordena unidade de cuidados paliativos } \\
\text { (hospices) fora dos hospitais de coleta de dados }\end{array}$ & sim \\
\hline \begin{tabular}{l} 
A ECP realiza atendimento ambulatorial \\
\hline $\begin{array}{l}\text { A ECP é acionada pela equipe tradicional para } \\
\text { interconsulta aos doentes. }\end{array}$
\end{tabular} \\
\hline
\end{tabular}

\subsubsection{Cálculo do tamanho da amostra}

O tamanho amostral foi calculado a partir de uma amostra piloto de 9 indivíduos do Grupo ECP e 10 indivíduos do Grupo CT. Dessa forma, obteve-se a média e erro padrão (EP) da diferença do escore da avaliação em 48 horas em relação a avaliação inicial (redução de 20 pontos da sobrecarga de sintomas). Assim, o Grupo 
ECP apresentou -14(EP5.4) e o Grupo CT 0.2(EP6.9). Pelo teste Mann Whitney nível de significância 5\% e poder de 95\%, calculou-se o tamanho amostral de 41 indivíduos por grupo, totalizando 82 indivíduos.

\subsubsection{Critérios de inclusão e de exclusão}

Os critérios de inclusão foram: diagnóstico de câncer avançado*, idade igual ou superior a 18 anos, ambos os sexos, ter até 24 horas da admissão hospitalar para o cuidado tradicional ou para a admissão para a equipe de cuidados paliativos, capacidade de compreensão e verbalização preservada, dor com intensidade maior ou igual a 4 ou, no mínimo, dois dos outros sintomas não dor (náusea, fadiga, perda do apetite, sonolência, ansiedade, perda da sensação de bem-estar, dispneia, sensação de depressão, insônia, constipação intestinal e sensação de tristeza) com intensidade maior ou igual a 4.

Os critérios de exclusão do estudo foram: alteração aguda da consciência (rebaixamento do nível de consciência, sonolência excessiva, confusão mental ou delírio hiperativo).

Foram avaliados 624 pacientes para a inclusão no estudo e destes, 148 foram incluídos nos grupos ECP $(n=73)$ e CT $(n=75)$. Foram excluídos 476 doentes, sendo 227 doentes do grupo ECP e 249 do grupo CT (Figura 1).

* Localmente avançado ou a distância 


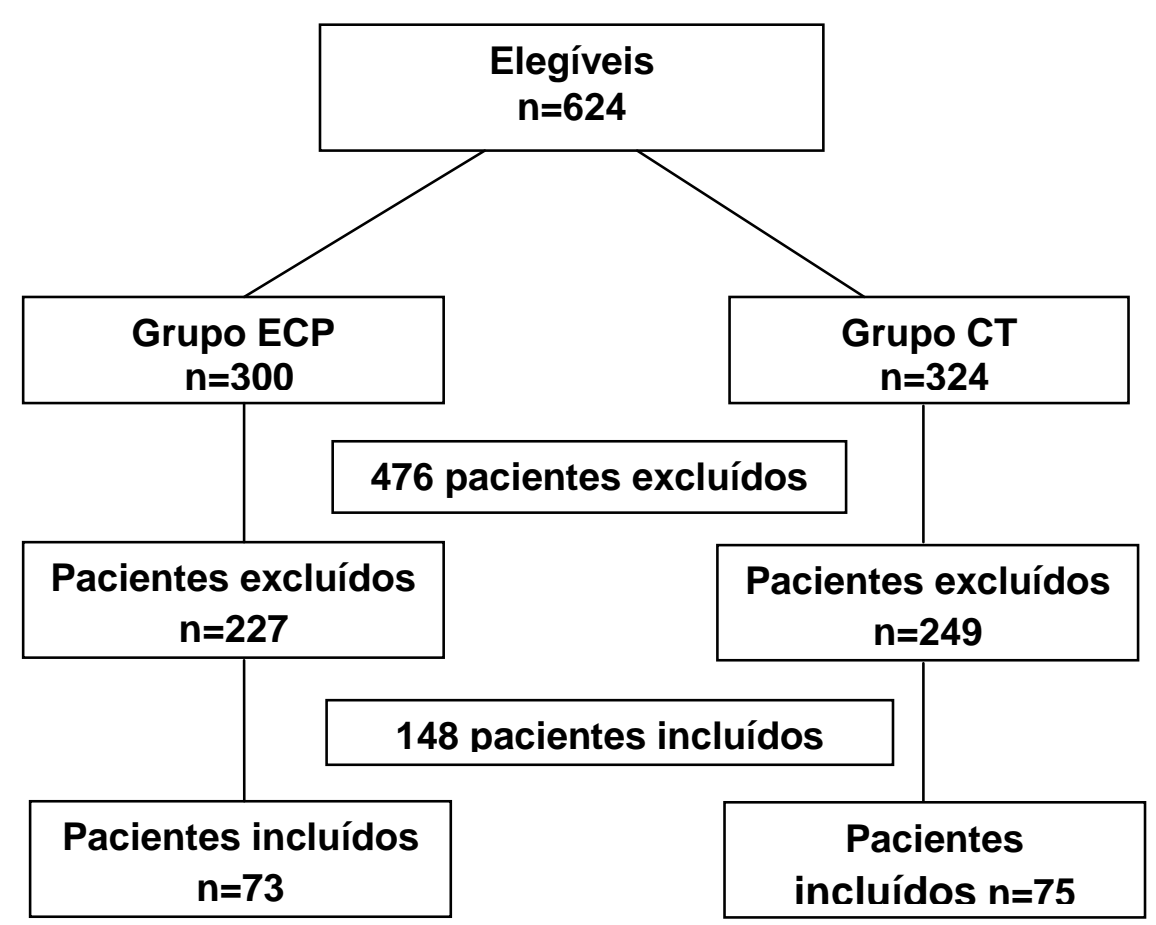

Figura 1- Fluxograma de pacientes incluídos e excluídos no estudo. São Paulo, 2014

Tabela 2- Distribuição das causas das exclusões dos grupos ECP e CT. São Paulo, 2014

\begin{tabular}{lcc}
\hline \multicolumn{1}{c}{ Causas da Exclusão } & $\begin{array}{c}\text { ECP } \\
\text { n }\end{array}$ & $\begin{array}{c}\text { CT } \\
\text { n }\end{array}$ \\
\hline Sem sintomas & 22 & 53 \\
$\begin{array}{l}\text { Comunicação prejudicada (não deseja conversar, prejuízo } \\
\text { na fala, acuidade auditiva diminuída, intubação } \\
\text { orotraqueal, traqueostomia, não compreende a escala, não }\end{array}$ & 125 & 134 \\
fala português) & & \\
$\begin{array}{l}\text { Mal estado geral (rebaixamento do nível de consciência, } \\
\text { sonolência excessiva, sedação paliativa, confusão mental) }\end{array}$ & 51 & 42 \\
$\begin{array}{l}\text { Sintomas intensos impedindo a comunicação: fadiga, } \\
\text { dispneia, dor, náusea, chorando muito/depressivo }\end{array}$ & 23 & 13 \\
Recusa & 06 & 07 \\
Total & $\mathbf{2 2 7}$ & $\mathbf{2 4 9}$ \\
\hline
\end{tabular}




\subsection{Instrumentos e classificação dos instrumentos}

Foram utilizadas fichas estruturadas elaboradas pelo pesquisador (Anexos 3 e 6), a Escala de Avaliação de Sintomas de Edmonton-ESAS e satisfação do doente (Anexo 4) e a Escala de Desempenho Físico de Karnofsky-KPS (Anexo 5).

A seguir, estão descritos os instrumentos citados.

\subsubsection{Características demográficas e clínicas, Satisfação do doente, Terapêutica empregada para o controle dos sintomas}

O Instrumento 1 (Anexo 3), nomeado Características sociodemográficas e clínicas, constou de dados relativos às variáveis sociodemográficas e coletados pelo relato do paciente (sexo, idade, escolaridade, situação conjugal, renda familiar mensal, prática religiosa), variáveis relacionados às características da doença do paciente (sítio primário do tumor, estadiamento clínico, número de metástase, funcionalidade física de Karnofsky, unidade de internação e número de óbitos). Os dados foram coletados pelo prontuário.

O Instrumento 2 (Anexo 4), denominado Satisfação do doente, investigou a satisfação com o alívio dos sintomas. Os dados foram coletados pelo relato do paciente.

O Instrumento 3 (Anexo 6), nomeado Terapêutica empregada para o controle dos sintomas, investigou os dados da terapêutica empregada para o controle da dor para posterior investigação da adequação do tratamento analgésico farmacológico. Registraram-se todos os fármacos prescritos para o controle da dor. 


\subsubsection{Escala de Avaliação de Sintomas Edmonton (Edmonton Symptom Assessment Scale-ESAS)}

O objetivo dessa escala é realizar triagem rápida sobre diversos sintomas dos doentes oncológicos e tem sido amplamente aplicada no mundo na assistência a pacientes em cuidados paliativos. É de auto relato e identifica a presença e a intensidade de sintomas ${ }^{67}$.

O ESAS foi desenvolvido por Bruera e colaboradores, em $1991^{67}$. Inicialmente, o seu uso foi proposto para pacientes oncológicos em fase terminal, atualmente é utilizada em populações diversas.

A escala pode ser composta por nove itens (dor, fadiga, náusea, depressão, ansiedade, sonolência, apetite, bem-estar, dispneia) e um décimo item denominado outro (a opção que permite ao paciente relatar outro sintoma não listado) ou composta por 10 itens de avaliação sistemática, ESAS acrescido do sono (Anexo 4$)^{28}$. A intensidade pode ser pontuada por meio de uma escala de 11 pontos ( 0 a 10), na qual zero representa ausência do sintoma e 10, pior sintoma possível. A severidade dos sintomas pode ser categorizada em: sem sintoma (0), leve (1 a 3), moderado (4 a 6) e intensa $\left(7\right.$ a 10) ${ }^{68,69}$. Neste estudo, foi utilizado o ESAS com o sono ${ }^{28}$ e os pacientes foram inquiridos para relatar a intensidade de seu sintoma. O ESAS ainda permite o cálculo da sobrecarga de sintomas, que é obtido pela somatória da intensidade de todos os sintomas relatados pelo paciente. A sobrecarga de sintomas do ESAS com o sono varia entre 0 a 100 pontos Essa somatória é realizada na tentativa de expressar a magnitude do sofrimento ocasionado pelo número de sintomas concomitantes e sua intensidade. 
O ESAS foi traduzido em 34 línguas* ao redor do mundo e, mais recentemente, no $\mathrm{Brasil}^{70}$. Por meio da análise psicométrica dos dados obtidos em estudos prévios, é considerada uma escala confiável e válida para avaliar os sintomas físicos de pacientes no contexto da rotina clínica dos cuidados paliativos ${ }^{71-72}$. A confiabilidade na escala total pelo alfa de Cronbach variou de 0,75 a 0,88 e o re-teste variou de 0,45 a $0,89^{73-75}$. Ao se testar a confiabilidade do instrumento para os sujeitos deste estudo, verificou-se alfa de Cronbach inicial de 0,50 e no re-teste após 48 horas, de 0,70.

\subsubsection{Constipação intestinal e sensação de tristeza}

Foram incluídos, na investigação, mais outros dois sintomas: a constipação intestinal e a sensação de tristeza (Anexo 4), visto serem sintomas comuns no câncer avançado e causadores de desconforto $^{1-6}$. Assim, como no ESAS, os pacientes pontuaram esses sintomas por meio de escala verbal numérica de 0 a 10 (0, sem sintoma a 10, pior sintoma possível). A confiabilidade do instrumento para os sujeitos deste estudo foi testada em conjunto com a ESAS com o sono e verificou-se alfa de Cronbach inicial de 0,59 no re-teste após 48 horas, de 0,75.

\subsubsection{Satisfação do doente}

O grau de satisfação do doente foi investigado quanto ao alívio dos sintomas (Anexo 4). Foi verificada por meio de escala numérica de 0 a 10, na qual zero representou total insatisfação com

\footnotetext{
* Disponível em: https://www.cancercare.on.ca/cms/one.aspx?objectId=58189\&contextId=1377. Acessado em janeiro de 2012.
} 
o alívio dos sintomas e 10, completa satisfação. Esse dado foi coletado pelo relato do paciente.

\subsubsection{Escala de Desempenho Físico Karnofsky (Karnofsky Permormance Status Scale-KPS)}

Por meio do KPS, avaliou-se a capacidade funcional dos indivíduos para desempenhar atividades da vida diária, atividades laborais e a necessidade de cuidados especiais. (Anexo 5).

A pontuação da Escala varia de 100 a 10, sendo que 100 a 80 indica capacidade normal para desempenhar as atividades sem a necessidade de cuidados especiais; 70, capaz de cuidar de si mesmo (incapaz de levar suas atividades normais ou exercer trabalho ativo); 60, necessita de assistência ocasional (ainda é capaz de prover a maioria de suas atividades); 50, requer assistência considerável e cuidados médicos frequentes; 40, incapaz (requer cuidados especiais e assistência); 30, muito incapaz (indicada hospitalização, apesar de a morte não ser iminente); 20, muito debilitado (hospitalização necessária; exigindo tratamento de apoio ativo); 10, moribundo (processos letais progredindo rapidamente) e 0 , morte ${ }^{76,77}$. Esse dado foi coletado pelo pesquisador.

\subsubsection{Tratamento analgésico farmacológico}

Para verificar a adequação da analgesia foi utilizado o Índice de Manejo da Dor (PMI)

Índice de Manejo da Dor (Pain Management Index) - IMD 
O IMD é uma forma objetiva de avaliar a adequação analgésica com base na Escada Analgésica da OMS. Foi proposto por Cleeland et al., em $1994,{ }^{81}$ e utilizado no Brasil ${ }^{78-80}$. O IMD compara a potência do analgésico à intensidade da dor.

Para essa comparação, atribui-se peso de 0 a 3 para a intensidade da dor e peso de 0 a 3 para a potência do analgésico utilizado. Após a subtração do peso da potência do analgésico prescrito do peso da pior intensidade de dor nas últimas 24 horas, obtém-se o IMD (IMD=potência do analgésico - severidade da dor), conforme Quadro 2.

A pontuação varia de -3 a +3 , e valores negativos representam inadequação ou insuficiência analgésica; zero equivale à adequação e acima de zero, analgesia adequada ou analgesia superior à intensidade de dor relatada.

Para o cálculo desse dado foi coletado do prontuário os analgésicos prescritos. 
Quadro 2- Representação dos pesos atribuídos aos analgésicos e intensidade de dor do índice de manejo de dor. São Paulo, 2014

\begin{tabular}{|l|c|c|c|}
\hline \multicolumn{1}{|c|}{ Potência Analgésica } & Peso & Intensidade da dor & Peso \\
\hline Ausência de analgésicos & $\mathbf{0}$ & Sem dor & $\mathbf{0}$ \\
\hline $\begin{array}{l}\text { Analgésico simples, AINH e } \\
\text { adjuvantes }\end{array}$ & $\mathbf{1}$ & Leve & $\mathbf{1}$ \\
\hline Opioide fraco & $\mathbf{2}$ & Moderada & $\mathbf{2}$ \\
\hline Opioide potente & $\mathbf{3}$ & Intensa & $\mathbf{3}$ \\
\hline
\end{tabular}

\subsection{Procedimentos de coleta}

A coleta de dados foi realizada pela pesquisadora e três enfermeiros auxiliares de pesquisa, treinados especialmente para isso. A pesquisadora contou com dois auxiliares de coleta e mais um para ajudar nos finais de semana. A seleção dos sujeitos de pesquisa foi realizada de segunda à sexta-feira, no período da manhã. O seguimento dos pacientes ocorreu de segunda-feira à segunda-feira, com início às 8:00h e término às 18:00h, ou até a última entrevista.

A descrição desse processo da triagem dos doentes está representada a seguir.

O Serviço de Arquivo Médico (SAME) do IC.HCFMUP forneceu ao pesquisador lista impressa dos pacientes hospitalizados para a seleção dos pacientes do Grupo CT. Para o grupo ECP, a secretária do Núcleo dos Cuidados Paliativos forneceu a lista de pacientes com solicitação de interconsulta médica para a equipe de cuidados paliativos.

Os pacientes elegíveis foram convidados a participar do estudo, informados sobre a proposta, sobre os procedimentos de 
coleta de dados e do TCLE e aqueles que concordaram assinaram o TCLE em duas vias (Anexo 2). Nesse momento, o paciente foi entrevistado para a realização da primeira avaliação.

Foram feitas três avaliações. A primeira foi nomeada inicial (admissão), a segunda ocorreu após 24 horas e a terceira, após 48 horas. O período de 48 horas foi considerado suficiente para que sintomas físicos de moderados a intensos fossem aliviados, visto que pacientes em cuidados paliativos precisam ter seus desconfortos aliviados rapidamente. Além disso, se o intervalo fosse maior, haveria dificuldades com as altas precoces e o rápido declínio clínico do paciente, o que inviabilizaria a entrevista $e$ as comparações.

Na primeira entrevista, os doentes foram avaliados quanto às características demográficas e clínicas (Anexo 3), presença e magnitude dos sintomas (Anexo 4), satisfação com o alívio dos sintomas (Anexo 4), capacidade funcional pelo KPS (Anexo 5) e quanto à terapêutica farmacológica empregada (Anexo 6). $\mathrm{Na}$ segunda e terceira entrevistas (após 24 horas e 48 horas respectivamente), os doentes foram avaliados quanto à presença $\mathrm{e}$ magnitude dos sintomas (Anexo 4), satisfação com o alívio dos sintomas (Anexo 4), capacidade funcional pelo KPS (Anexo 5) e quanto à terapêutica farmacológica empregada (Anexo 6).

Foram colhidos do prontuário, os dados demográficos e clínicos (Características demográficas e clínicas - Anexo 3) e os dados relacionados à terapêutica para o controle da dor (Terapêutica empregada para o controle dos sintomas - Anexo 6).

Os doentes foram inquiridos para obtenção dos dados sobre os sintomas e a satisfação com o alívio obtido (Anexo 4), os dados da escolaridade, sexo, idade, religião e renda familiar mensal (parte das variáveis do Anexo 3). 
O pesquisador e os enfermeiros auxiliares de pesquisa aplicaram a Escala de Desempenho Físico Karnofsky (Anexo 5) em todos os doentes.

A ordem de aplicação dos instrumentos seguiu a sequência que pode ser observada na Figura 1. A primeira entrevista do doente teve duração de 15 a 30 minutos. A segunda e a terceira entrevistas tiveram duração de 05 a 15 minutos. A variação no tempo de entrevista deveu-se a interrupções e condições clínicas do doente (Figura 2).

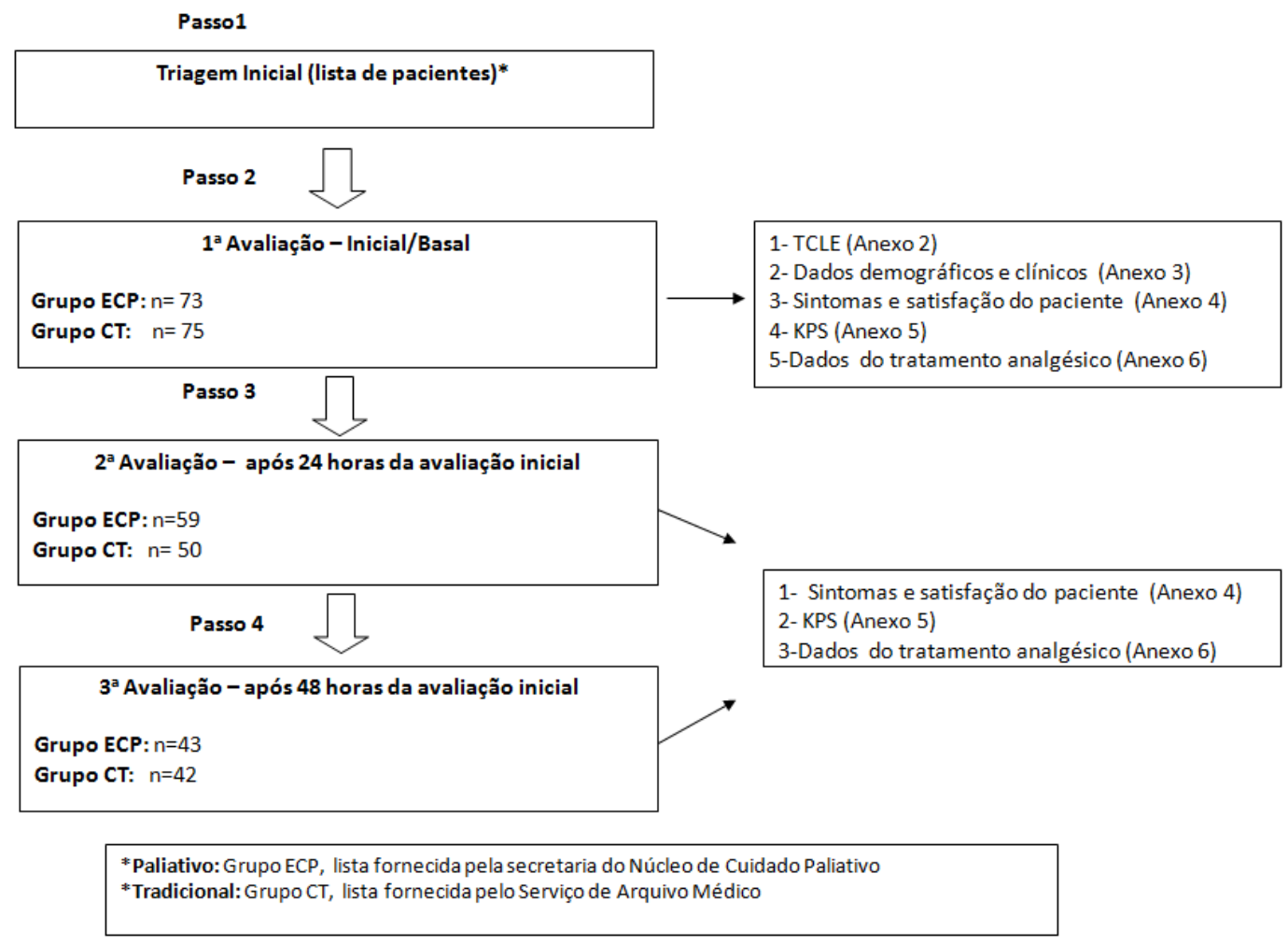

Figura 2- Fluxograma da coleta de dados. São Paulo, 2014

\subsubsection{Participação dos doentes nas três avaliações}

Nem todos os doentes participaram das três avaliações (Tabela 3). O total de perda de seguimento foi de 63 doentes, sendo 
30 do grupo ECP e 33 do Grupo CT. A Tabela 4 mostra as causas para a interrupção do seguimento dos doentes no estudo.

Tabela 3- Distribuição dos doentes dos grupos ECP e CT, nas três avaliações. São Paulo, 2014

\begin{tabular}{lccc}
\hline \multirow{1}{*}{ Grupos } & Inicial & 24 horas & 48 horas \\
\cline { 2 - 4 } & $\mathbf{n}$ & $\mathbf{n}$ & $\mathbf{n}$ \\
\hline ECT & 73 & 59 & 43 \\
CT & 75 & 50 & 42 \\
Total & $\mathbf{1 4 8}$ & $\mathbf{1 0 9}$ & $\mathbf{8 5}$ \\
\hline
\end{tabular}

Tabela 4- Distribuição das causas de perda de seguimento dos grupos ECP e CT. São Paulo, 2014

\begin{tabular}{lcc}
\hline \multicolumn{1}{c}{$\begin{array}{c}\text { Causas da } \\
\text { perda de seguimento }\end{array}$} & $\begin{array}{c}\text { ECP } \\
\text { n }\end{array}$ & $\begin{array}{c}\text { CT } \\
\text { n }\end{array}$ \\
\hline Transferência para UCP* & 12 & -- \\
Transferência para outra instituição & 03 & 16 \\
Alta hospitalar & 03 & 05 \\
Piora quadro clínico/Rebaixamento & 09 & 08 \\
nível consciência/Sonolência & & \\
excessiva & & \\
Óbito & 03 & 04 \\
Total & $\mathbf{3 0}$ & $\mathbf{3 3}$ \\
\hline *Unidade de Cuidado Paliativo & &
\end{tabular}

\subsection{Variáveis, Categorias das variáveis}

\subsubsection{Variável independente}

A variável dependente foi a equipe que atendeu o doente: Equipe de Cuidados Paliativos (Grupo ECP) ou Equipe Cuidado Tradicional (Grupo CT).

\subsubsection{Variáveis dependentes}


As variáveis independentes foram os sintomas, a satisfação do doente e o tratamento analgésico farmacológico. Os Quadros 3 e 4 apresentam as categorias das variáveis.

Quadro 3- Categorização das variáveis independentes relacionadas aos sintomas e satisfação do doente. São Paulo, 2014

\begin{tabular}{|l|l|c|}
\hline \multicolumn{1}{|c|}{$\begin{array}{c}\text { Variável } \\
\text { independente }\end{array}$} & \multicolumn{1}{|c|}{ Categoria da variável } & $\begin{array}{c}\text { Tipo de } \\
\text { variável }\end{array}$ \\
\hline $\begin{array}{l}\text { ESAS, constipação } \\
\text { intestinal e sensação } \\
\text { de tristeza }\end{array}$ & $\begin{array}{l}\text { Escore de 0 a } 10(0, \text { sem sintoma e } \\
10, \text { pior sintoma possível })\end{array}$ & Contínua \\
\hline $\begin{array}{l}\text { Sobrecarga de } \\
\text { sintomas }\end{array}$ & $\begin{array}{l}\text { Escore de 0 a } 100(0, \text { sem sobrecarga } \\
\text { e 10, pior sobrecarga })\end{array}$ & Contínua \\
\hline Satisfação do doente & $\begin{array}{l}\text { Escore de 0 a 10 (0, insatisfação e } \\
10, \text { completa satisfação) }\end{array}$ & Contínua \\
\hline
\end{tabular}

O Quadro 4 descreve as categorias das variáveis relacionadas à terapêutica empregada para o controle da dor.

Quadro 4- Categorização das variáveis relacionadas à terapia para o controle dos sintomas. São Paulo, 2014

\begin{tabular}{|c|l|c|}
\hline $\begin{array}{c}\text { Variável } \\
\text { independente }\end{array}$ & \multicolumn{1}{|c|}{ Categoria da variável } & $\begin{array}{c}\text { Tipo de } \\
\text { variável }\end{array}$ \\
\hline $\begin{array}{l}\text { Adequação da } \\
\text { analgesia (IMD) }\end{array}$ & $\begin{array}{l}<0=\text { insuficiente (-1 e -2: muito insuficiente); } \\
\begin{array}{l}\geq 0=\text { suficiente ( } 0 \text { : suficiente, 1 e 2: muito } \\
\text { analgesiados) }\end{array}\end{array}$ & Nominal \\
\hline
\end{tabular}

\subsubsection{Características demográficas e clínicas}

As categorias das características dos pacientes do estudo estão demonstradas no Quadro 5. 
Quadro 5- Categorização das variáveis relacionadas às características demográficas e clínicas. São Paulo, 2014

\begin{tabular}{|c|c|c|}
\hline $\begin{array}{l}\text { Características do } \\
\text { paciente }\end{array}$ & Categoria da variável & $\begin{array}{l}\text { Tipo de } \\
\text { variável }\end{array}$ \\
\hline Idade & Em anos & Contínua \\
\hline Sexo & Masculino e Feminino & Nominal \\
\hline Escolaridade & Em anos & Contínua \\
\hline Situação conjugal & Com companheiro e Sem companheiro & Nominal \\
\hline Renda Familiar* & Salários mínimos & Contínua \\
\hline Diagnóstico & Sítio primário do tumor & Nominal \\
\hline Metástase & Número de metástases & Contínua \\
\hline Unidade solicitante & $\begin{array}{l}\text { 1- Enfermaria } \\
\text { 2- Emergência }\end{array}$ & Nominal \\
\hline Funcionalidade** & $\begin{array}{l}\text { Pontuação: } 100 \text { a } 0 \\
\text { KPS: } 100 \text {,capaz de desempenhar as } \\
\text { atividades normais e } 0 \text {, morte }\end{array}$ & Contínua \\
\hline Óbito & $\begin{array}{l}\text { Número de óbito até } 3 \text { meses da } \\
\text { admissão no estudo }\end{array}$ & Nominal \\
\hline
\end{tabular}

*R\$ 678,00; ** Escala de Desempenho Físico de Karnofsky (KPS)

\subsection{Desfechos do estudo}

O desfecho primário foi a redução de dois pontos da avaliação inicial, nos sintomas físicos dor e náusea. O desfecho secundário será a redução de 20 pontos da avaliação inicial na sobrecarga de sintomas. O grupo do estudo que obteve essa diferença foi considerado mais efetivo no controle dos sintomas dos doentes. 


\subsection{Análise estatística*}

As variáveis quantitativas foram expressas em média (erro padrão) e mediana. Enquanto, as variáveis qualitativas foram expressas em percentual (número de indivíduos).

A prevalência de sintomas (presente ou ausente) assim como a intensidade (leve, moderada ou intensa), na avaliação inicial, foi comparada entre os grupos ECP e CT pelo teste de Fisher.

Para a avaliação da evolução dos sintomas, ao longo do tempo, (ESAS com o sono, constipação intestinal, sensação de tristeza e sobrecarga de sintomas com o sono), definiu-se a diferença entre as pontuações nos momentos 24 horas e 48 horas para cada sintoma:

- Variação $24 \mathrm{~h}$ do Sintoma = Escore $24 \mathrm{~h}$ do Sintoma - Escore Inicial do Sintoma

- Variação 48h do Sintoma = Escore 48h do Sintoma - Escore Inicial do Sintoma

Observe que somente os indivíduos com sintomas presentes na admissão foram considerados para o cálculo de cada variação de sintomas, isto é, indivíduos com dados faltantes ou sem sintoma em determinado sintoma, na admissão, foram excluídos.

Dessa forma, uma análise intragrupo para verificar se houve alteração ao longo de 24 horas e 48 horas em relação ao momento inicial para cada grupo, separadamente, foi realizada pelo teste $t$ ou

\footnotetext{
* Zou, Guangyong. "A modified poisson regression approach to prospective studies with binary data." American journal of epidemiology 159.7 (2004): 702-706.

R Core Team (2014). R: A language and environment for statistical computing. R Foundation for Statistical Computing, Vienna, Austria. URL http://www.R-project.org/.
} 
do teste de Wilcoxon se a suposição de normalidade não fosse verificada pelo teste de Anderson-Darling.

Em um segundo momento, a evolução dos grupos, ao longo de 24 e 48 horas, foi comparada, isto é, uma análise entregrupos. Nesse caso, o teste $\mathrm{t}$ ou Mann-Whitney $U$ foi utilizado após a verificação da suposição de normalidade.

No intuito de avaliar a evolução entregrupos com um significado clínico, foi definido que a redução de 2 pontos representaria uma melhora clínica. Nesse sentido, a variável Redução 2 pontos (sim ou não) foi considerada para cada sintoma do instrumento ESAS. Similarmente, também foi definida a variável Redução 1 ponto. Cabe ressaltar que para Sobrecarga, a redução considerada foi de 20 e 10 pontos.

Para comparar o percentual de indivíduos com redução de 2 pontos ou 1 ponto, em cada sintoma, mais uma vez, foi utilizado o teste de Fisher. Contudo, tal teste não permite controlar variáveis de confusão que consistem em indicadores de gravidade do paciente, a saber: KPS, idade e número de metástases.

Para tanto, a regressão de Poisson múltipla com estimador robusto para variância foi escolhida, considerando tais variáveis de confusão sem categorizá-las. A partir disso, a razão de probabilidade de redução de 2 pontos do Grupo ECP em relação ao Grupo CT foi estimada pontualmente e apresentada junto de seu respectivo intervalo de confiança 95\% (IC 95\%).

Todas as evidências foram consideradas estatisticamente significativas ao nível de significância $5 \%$. O programa $R$, versão 3.10 (R Core Team, 2014) foi utilizado para todos os cálculos. 
5.RESULTADOS 


\section{RESULTADOS}

Os dados foram organizados para descrever os principais resultados dos dois grupos (Grupo ECP e CT) e compará-los. Os resultados serão apresentados na seguinte ordem:

5.1 Características demográficas e clínicas

5.2 Características dos sintomas

5.3 Tratamento analgésico

5.4 Satisfação do doente

5.5 Adesão dos profissionais do Grupo CT às recomendações do Grupo ECP

5.6 Número de óbitos

5.7 Sumário dos resultados 


\subsection{Características demográficas e clínicas}

Nesta seção estão apresentadas as características

demográficas e clínicas da população e as comparações entre os grupos ECP e CT.

A Tabela 5 mostra as comparações das características demográficas e clínicas. 
Tabela 5- Distribuição das características demográficas e clínicas dos pacientes dos grupos ECP e CT. São Paulo, 2014

\begin{tabular}{|c|c|c|c|}
\hline Variáveis & $\begin{array}{c}\text { ECP=73 } \\
n(\%)\end{array}$ & $\begin{array}{c}C T=75 \\
n(\%)\end{array}$ & $\begin{array}{l}\text { Valor } \\
\mathbf{p}^{\mathrm{a}, \mathrm{b}}\end{array}$ \\
\hline \multicolumn{4}{|c|}{ DADOS DEMOGRÁFICOS } \\
\hline \multicolumn{4}{|l|}{ Sexo } \\
\hline Masculino & $39(53,4)$ & $31(41,3)$ & $0,18^{\mathrm{a}}$ \\
\hline \multirow{2}{*}{\multicolumn{4}{|c|}{ Situação conjugal }} \\
\hline & & & \\
\hline Com companheiro & $47(64,4)$ & $48(64)$ & $1,00^{\mathrm{a}}$ \\
\hline $\begin{array}{l}\text { Sem companheiro } \\
\text { Idade }\end{array}$ & $26(35,6)$ & $27(36)$ & \\
\hline Média(EP) & $61,3(1.3)$ & $58,6(1.5)$ & $0,36^{b}$ \\
\hline Mediana(mín-max) & $61(37-87)$ & $59(19-84)$ & \\
\hline \multicolumn{4}{|l|}{ Escolaridade } \\
\hline Média(EP) & $5,7(0.5)$ & $7,4(0.5)$ & $0,02^{b}$ \\
\hline Mediana(mín-max) & $4,0(1-16)$ & $6,0(1-16)$ & \\
\hline \multicolumn{4}{|l|}{ Renda mensal ${ }^{\star \star}$} \\
\hline Média(EP) & $3,1(0.2)$ & $3,6(0.4)$ & $0,79^{b}$ \\
\hline Mediana(mín-max) & $3,0(0-10)$ & $3,0(0-20)$ & \\
\hline \multicolumn{4}{|l|}{ Prática religiosa } \\
\hline Não & $27(34,3)$ & $35(45,9)$ & $0,17^{\mathrm{a}}$ \\
\hline Sim & $46(65,7)$ & $40(54,1)$ & \\
\hline \multicolumn{4}{|l|}{ DADOS CLÍNICOS } \\
\hline Emergência & $49(67,1)$ & $35(46,7)$ & $<0,001^{a}$ \\
\hline Enfermaria & $24(32,9)$ & $40(53,3)$ & \\
\hline \multicolumn{4}{|l|}{ Sítio do tumor** } \\
\hline Gastrodigestório & $52(71,3)$ & $43(57,3)$ & $0,09^{a}$ \\
\hline Hematológico & $04(5,5)$ & $14(18,7)$ & \\
\hline Pulmão & $05(6,8)$ & $06(8,0)$ & \\
\hline Geniturinário & -- & -- & \\
\hline Outros *** & $12(16,4)$ & $12(16,0)$ & \\
\hline \multicolumn{4}{|l|}{ Metástase } \\
\hline Média(EP) & $2,6(0,1)$ & $1,9(0,1)$ & $<0,001^{b}$ \\
\hline Mediana(Mín-Máx) & $2,0(1-5)$ & $2,0(1-5)$ & \\
\hline \multicolumn{4}{|l|}{ Karnofsky (KPS) ${ }^{\S}$} \\
\hline Média(EP) & $44,1(1,5)$ & $52,8(1,9)$ & $0,002^{b}$ \\
\hline Mediana(Mín-Máx) & $40(20-70)$ & $50(20-90)$ & \\
\hline
\end{tabular}

Média, Erro Padrão, Mediana

${ }^{\mathrm{a}}$ Teste Exato de Fisher; ${ }^{\mathrm{b}}$ Teste Mann Whitney, $\mathrm{p}<0,05$ (Estatisticamente significativo) $\mathrm{ECP}=$ Equipe de cuidados paliativos; ${ }^{*} \mathrm{CT}=$ equipe de cuidado tradicional;

**Salários Mínimos (SM) nacional no ano de 2013 (R $\$ 678,00 / 1$ SM) e

**Outros: sítio primário desconhecido, linfático, melanoma, ósseo;

${ }^{\S}$ KPS: índice de funcionalidade física de Karnofsky 
Observa-se, pela Tabela 5, que o Grupo ECP apresentou menor escolaridade $(p=0.02)$, menor funcionalidade pelo KPS $(p=0.002)$, maior número de metástases $(p<0.001)$ e a maioria dos pacientes estavam na unidade de emergência $(p<0.001)$. Os grupos foram semelhantes nas demais comparações.

\subsection{Características dos sintomas}

A análise dos sintomas foi organizada da seguinte maneira:

- Comparação da distribuição da frequência (Tabela 6) e magnitude dos sintomas (Tabela 7) na avaliação inicial, no Grupo ECP e Grupo CT.

- Evolução dos sintomas ao longo de 48 horas nos Grupo ECP (Tabela 8) e Grupo CT (Tabela 9).

- Comparação da evolução dos sintomas entre os grupos ECP e CT ao longo de 48 horas (Tabela 10).

- Comparação dos sintomas entre os Grupo ECP e Grupo CT ao longo de 48 horas, considerando-se redução no escore de 1 e 2 pontos, a partir da avaliação inicial (Tabelas 11 e 12).

- Risco relativo de melhora de 1 ponto do escore do sintoma pela regressão múltipla de Poisson (Tabela 13)

- Risco relativo de melhora de 2 pontos do escore do sintoma pela regressão múltipla de Poisson (Tabela 14)

Foram feitas comparações da frequência e magnitude dos sintomas dos doentes do Grupo ECP e CT, no início do estudo, visando identificar diferenças. 
Tabela 6- Comparação da frequência dos sintomas, na avaliação inicial, entre os Grupos ECP e CT. São Paulo, 2014

\begin{tabular}{lccc}
\hline \multicolumn{1}{c}{ Sintomas } & $\begin{array}{c}\text { ECP=73 } \\
\mathbf{n ~ \% ~}\end{array}$ & $\begin{array}{c}\text { CT=75 } \\
\mathbf{n ~ \% ~}\end{array}$ & Valor p* \\
\hline ESAS & & & \\
Dor & $57(78.1)$ & $64(85.3)$ & 0.57 \\
Fadiga & $64(87.7)$ & $52(69.3)$ & 0.26 \\
Nausea & $41(56.1)$ & $33(44.0)$ & 0.51 \\
Ansiedade & $54(73.9)$ & $56(74.7)$ & 0.98 \\
Sonolência & $61(83.5)$ & $55(73.3)$ & 0.63 \\
Apetite & $57(78.1)$ & $52(69.3)$ & 0.86 \\
Sensação bem-estar & $64(87.7)$ & $57(76.0)$ & 0.39 \\
Dispneia & $43(58.9)$ & $18(24.0)$ & $\mathbf{0 . 0 0 4}$ \\
Depressão & $32(43.8)$ & $37(49.3)$ & 0.32 \\
Sono & $55(75.3)$ & $62(82.7)$ & 0.79 \\
Outros & & & \\
Constipação intestinal & $40(54.8)$ & $35(46.7)$ & 0.81 \\
Tristeza & $41(56.2)$ & $48(64.0)$ & 0.65 \\
\hline * Teste Exato de Fisher, p<0,05 (Estatisticamente significativo) &
\end{tabular}

A Tabela 6 demonstra que a prevalência de sintomas foi elevada em ambos os grupos, mas dispneia foi mais frequente no Grupo ECP ( $p=0.004)$. 
Tabela 7- Comparação da intensidade dos sintomas, na avaliação inicial, entre os Grupos ECP e CT. São Paulo, 2014

\begin{tabular}{|c|c|c|c|c|c|c|c|}
\hline \multirow[b]{2}{*}{ Sintomas } & \multicolumn{2}{|c|}{ Leve } & \multicolumn{2}{|c|}{ Moderada } & \multicolumn{2}{|c|}{ Intensa } & \multirow[b]{2}{*}{$\begin{array}{c}\text { Valor } \\
\text { p }^{*}\end{array}$} \\
\hline & $\begin{array}{c}\text { ECP } \\
\text { n\% } \\
\end{array}$ & $\begin{array}{r}\text { CT } \\
\text { n\% } \\
\end{array}$ & $\begin{array}{c}\text { ECP } \\
\text { n\% } \\
\end{array}$ & $\begin{array}{r}\text { CT } \\
\text { n\% } \\
\end{array}$ & $\begin{array}{c}\text { ECP } \\
\text { n\% } \\
\end{array}$ & $\begin{array}{r}\text { CT } \\
\text { n\% } \\
\end{array}$ & \\
\hline \multicolumn{8}{|l|}{ ESAS } \\
\hline Dor & $03(5.3)$ & $05(7.8)$ & $22(38.6)$ & $17(26.6)$ & $32(56.1)$ & $42(65.6)$ & 0.57 \\
\hline Fadiga & $03(4.7)$ & $04(5.8)$ & $21(32.8)$ & $16(28.9)$ & $40(62.5)$ & $34(65.3)$ & 0.26 \\
\hline Náusea & $7(17.1)$ & $5(15.1)$ & $14(34.1)$ & $09(27.3)$ & $20(48.8)$ & $20(57.6)$ & 0.51 \\
\hline Ansiedade & $03(5.5)$ & $04(7.1)$ & $15(27.8)$ & $13(21.4)$ & $36(66.7)$ & $41(71.5)$ & 0.98 \\
\hline Sonolência & $02(3.4)$ & $03(3.6)$ & $25(40.9)$ & $25(43.7)$ & $34(55.7)$ & $30(52.7)$ & 0.63 \\
\hline Apetite & $03(3.5)$ & $04(5.8)$ & $15(26.3)$ & $10(17.3)$ & $41(70.2)$ & $40(76.9)$ & 0.86 \\
\hline $\mathrm{SBE}^{\mathrm{a}}$ & $07(9.4)$ & $05(8.7)$ & $32(50.0)$ & $26(43.9)$ & $26(40.6)$ & $28(47.4)$ & 0.39 \\
\hline Dispneia & $8(18.6)$ & $01(5.6)$ & $16(37.2)$ & $10(55.5)$ & $19(44.2)$ & 07(38.9) & $0.004 *$ \\
\hline Depressão & $7(21.9)$ & $4(10.8)$ & $12(34.4)$ & $09(24.3)$ & 14(43.7) & $24(64.8)$ & 0.32 \\
\hline Sono & $03(5.4)$ & $04(4.8)$ & $20(36.4)$ & $18(29.0)$ & $32(58.2)$ & $42(66.2)$ & 0.79 \\
\hline \multicolumn{8}{|l|}{ Outros } \\
\hline C.I ${ }^{b}$ & $06(15)$ & $5(11.5)$ & $10(25.0)$ & $9(25.7)$ & $24(60.0)$ & $23(62.8)$ & 0.81 \\
\hline Tristeza & $6(14.6)$ & $01(2.1)$ & $07(17.1)$ & $13(27.1)$ & $28(68.3)$ & $34(70.8)$ & 0.65 \\
\hline
\end{tabular}

A Tabela 7 mostra que a maioria dos sintomas foi de intensidade moderada à intensa, e a distribuição entre as categorias leve, moderada e intensa foram diferentes. A magnitude da dispneia distribuiu-se diferentemente entre os Grupos ( $p=0.004)$. O Grupo ECP mostrou maior relato de dispneia intensa, enquanto o Grupo CT apresentou maior distribuição para dispneia moderada. 
Tabela 8- Evolução da intensidade dos sintomas e da sobrecarga de sintomas no Grupo ECP, em 24 horas e 48 horas, segundo a ESAS. São Paulo, 2014

\begin{tabular}{|c|c|c|c|c|c|}
\hline \multirow[t]{2}{*}{ Sintomas } & \multicolumn{3}{|c|}{ Média(EP);Mediana } & \multicolumn{2}{|c|}{ Valor p* } \\
\hline & $\begin{array}{c}\text { Inicial } \\
n=73\end{array}$ & $\begin{array}{c}24 h \\
n=59\end{array}$ & $\begin{array}{c}48 h \\
n=43\end{array}$ & 0-24h & $0-48 h$ \\
\hline \multicolumn{6}{|l|}{ ESAS } \\
\hline Dor & 7.1(0.3);7.0 & $4.1(0.5) ; 5.0$ & $3.3(0.5) ; 3.0$ & $0.001 *$ & $<0.001 *$ \\
\hline Fadiga & $7.2(0.3) ; 7.5$ & $5.9(0.4) ; 6.0$ & $5.8(0.5) ; 7.0$ & 0.13 & $0.04 *$ \\
\hline Náusea & $6.4(0.4) ; 6.0$ & $2,6(0.4) ; 0.0$ & $2.6(0.5) ; 1.0$ & $0.007 *$ & $<0.001 *$ \\
\hline Ansiedade & $7.5(0.3) ; 8.0$ & $4.9(0.5) ; 5.0$ & $5.1(0.6) ; 6.0$ & 0.13 & $0.02 *$ \\
\hline Sonolência & $7.0(0.3) ; 7.0$ & $5.5(0.4) ; 6.0$ & $5.6(0.5) ; 6.0$ & 0.18 & 0.52 \\
\hline Apetite & $7.7(0.3) ; 8.0$ & $4,8(0.5) ; 5.0$ & $4.8(0.6) ; 5.0$ & $0.001 *$ & 0.07 \\
\hline $\mathrm{SBE}^{\mathrm{a}}$ & $6.2(0.3) ; 5.5$ & $5.5(0.4) ; 5.0$ & $5.7(0.5) ; 5.0$ & 0.73 & 0.47 \\
\hline Dispneia & $6.1(0.4) ; 6.0$ & $2.7(0.5) ; 0.0$ & $2.7(0.5) ; 0.0$ & $0.031 *$ & $0.003 *$ \\
\hline Depressão & $6.2(0.5) ; 6.0$ & $2.3(0.4) ; 0.0$ & $2.4(0.5) ; 0.0$ & 0.11 & $0.02 *$ \\
\hline Sono & $7.0(0.3) ; 7.0$ & $4.3(0.4) ; 5.0$ & $4.5(0.6) ; 5.0$ & $0.017 *$ & $0.04 *$ \\
\hline TSDS $^{\mathrm{b}}$ & $50(1.7) ; 50$ & $42.9(2.3) ; 42$ & $42.5(2.6) ; 40$ & $0.003 *$ & $0.01 *$ \\
\hline \multicolumn{6}{|l|}{ Outros } \\
\hline C.I ${ }^{\mathrm{c}}$ & $7.1(0.4) ; 8.0$ & $3.9(0.5) ; 3.0$ & $3.1(0.6) ; 1.5$ & 0.19 & $0.002 *$ \\
\hline Tristeza & $7.3(0.4) ; 8.0$ & $3.8(0.5) ; 3.0$ & $3.8(0.6) ; 3.0$ & 0.59 & $0.04 *$ \\
\hline
\end{tabular}

Média, Erro Padrão, Mediana

${ }^{*} T e s t e$ de Wilcoxon, em 24h e 48h, p<0,05 (estatisticamente significativo)

${ }^{a}$ Sensação de Bem Estar; ${ }^{\text {b }}$ Sobrecarga de sintomas; ${ }^{c}$ Constipação intestinal

Na Tabela 8, observa-se que houve redução estatisticamente significativa na intensidade de cinco sintomas em 24h (dor, náusea, prejuízo do apetite, dispneia, prejuízo do sono) e em nove sintomas em 48h (dor, fadiga, náusea, ansiedade, prejuízo do apetite, dispnéia, depressão, prejuízo do sono, constipação intestinal e tristeza). Houve também diferença no escore de sobrecarga de sintomas comparando-se $24 \mathrm{~h}(\mathrm{p}=0.003)$ e $48 \mathrm{~h}(\mathrm{p}=0.01)$ com o momento inicial.

Analisando-se as médias das diferenças da intensidade dos sintomas nas primeiras 24 horas, observou-se redução de 2.0 pontos $(23 \%)$ para a dor, 1.9 pontos $(18 \%)$ para a náusea, 1.5 pontos (19\%) para a perda do apetite, 1.4 pontos $(21 \%)$ para a 
dispneia e 1.5 pontos (8\%) para o sono, sugerindo a magnitude de melhora clínica.

$\mathrm{Na}$ análise de 48h, a média da diferença da intensidade do sintoma mostrou redução de 2.8 pontos (34\%) para a dor, 1.3 pontos (13\%) para fadiga, 3.3 pontos (35\%) para a náusea, 1.6 pontos (24\%) para a ansiedade, 1.2 pontos (7\%) para a prejuízo do apetite, 1.8 pontos (34\%) para dispnéia, 1.5 pontos (31\%) para a depressão, prejuízo do sono (14\%), 2.6 pontos (34\%) para constipação intestinal e 1.1 pontos (14\%) para a tristeza.

A sobrecarga de sintomas pelo ESAS sofreu redução de 5.3 pontos (10\%) na avaliação de $24 \mathrm{~h}$ e em 48 horas a redução foi de 6.4 pontos $(10 \%)$.

As médias e percentuais das diferenças da intensidade dos sintomas estão detalhadas nos Anexos 7 e 8. 
Tabela 9- Evolução da intensidade dos sintomas e da sobrecarga de sintomas no grupo CT, em 24 horas e 48 horas, segundo a ESAS. São Paulo, 2014

\begin{tabular}{|c|c|c|c|c|c|}
\hline \multirow[t]{2}{*}{ Sintomas } & \multicolumn{3}{|c|}{ Média(EP);Mediana } & \multicolumn{2}{|c|}{ Valor $\mathbf{p}^{*}$} \\
\hline & $\begin{array}{c}\text { Inicial } \\
n=75\end{array}$ & $\begin{array}{c}24 h \\
n=50\end{array}$ & $\begin{array}{c}48 h \\
n=42\end{array}$ & 0-24h & $0-48 h$ \\
\hline \multicolumn{6}{|l|}{ ESAS } \\
\hline Dor & $7.2(0.3) ; 8.0$ & $4.9(0.5) ; 6.0$ & $5.1(0.6) ; 5.0$ & $0.006 *$ & 0.15 \\
\hline Fadiga & $7.3(0.3) ; 8.0$ & $5.3(0.6) ; 6.5$ & $5.3(0.6) ; 6.0$ & 0.19 & 0.31 \\
\hline Náusea & $6.9(0.5) ; 8.0$ & $2.6(0.5) ; 0.0$ & $3.1(0.6) ; 0.0$ & $0.002 *$ & $0.02 *$ \\
\hline Ansiedade & $7.6(0.3) ; 8.0$ & $5.8(0.6) ; 6.0$ & $6.1(0.6) ; 6.0$ & 0.07 & $0.02 *$ \\
\hline Sonolência & $6.9(0.3) ; 7.0$ & $5.9(0.5) ; 7.0$ & $6.5(0.5) ; 7.0$ & 0.08 & 0.49 \\
\hline Apetite & $8.1(0.3) ; 9.0$ & $7.2(0.5) ; 9.5$ & $7.1(0.6) ; 10$ & 0.44 & 0.36 \\
\hline $\mathrm{SBE}^{\mathrm{a}}$ & $6.7(0.3) ; 6.0$ & $6.1(0.5) ; 7.0$ & $6.4(0.5) ; 6.0$ & 0.71 & 0.55 \\
\hline Dispneia & $6.4(0.5) ; 6.0$ & $1.4(0.4) ; 0.0$ & $1.4(0.4) ; 0.0$ & 0.11 & $0.03 *$ \\
\hline Depressão & $7.2(0.4) ; 8.0$ & $3.1(0.6) ; 0.0$ & $3.7(0.7) ; 0.0$ & 0.24 & 0.40 \\
\hline Sono & $7.5(0.3) ; 8.0$ & $5.7(0.6) ; 7.0$ & $4.9(0.6) ; 5.0$ & $0.016 *$ & $0.004 *$ \\
\hline TSDS $^{\mathrm{b}}$ & $47(2.1) ; 50$ & $48(2,7) ; 45.5$ & $49.5(3.4) ; 46$ & 0.153 & 0.86 \\
\hline \multicolumn{6}{|l|}{ Outros } \\
\hline C.I ${ }^{\mathrm{c}}$ & $7.4(0.5) ; 8.0$ & $4.0(0.6) ; 3.0$ & $4.0(0.6) ; 2.0$ & 0.45 & 0,18 \\
\hline Tristeza & $7.8(0.3) ; 8.0$ & $4.5(0.6) ; 5.0$ & $5.4(0.6) ; 6.0$ & 0.09 & 0.34 \\
\hline
\end{tabular}

Média, Erro Padrão, Mediana

${ }^{*} T e s t e$ de Wilcoxon, em 24h e 48h, p<0,05 (estatisticamente significativo)

a Sensação de Bem Estar; ${ }^{\text {b }}$ Sobrecarga de sintomas; ${ }^{c}$ Constipação intestinal

Na Tabela 9, observa-se que houve redução estatisticamente significativa na intensidade de três sintomas em $24 \mathrm{~h}$ (dor, náusea e sono) e, em $48 \mathrm{~h}$, ocorreu redução em quatro sintomas (náusea, ansiedade, dispneia e sono). Não houve diferença no escore de sobrecarga de sintomas comparando-se os três momentos (inicial, 24h e 48h).

Analisando-se as médias das diferenças da intensidade dos sintomas, nas primeiras 24 horas, observou-se redução de 1.9 pontos (22\%) para a dor, de 3.2 pontos (44\%) para náusea e de 1.6 pontos (16\%) para prejuízo do sono. 
$\mathrm{Na}$ análise de 48h, a média da diferença da intensidade mostrou redução de 2.3 pontos (29\%) para a náusea, 1.2 pontos (14\%) para ansiedade, 2.6 pontos (38\%) para a dispneia e de $2.1(17 \%)$ para o prejuízo do sono.

As médias e percentuais das diferenças da intensidade dos sintomas estão detalhadas nos Anexos 7 e 8.

Visando identificar a existência de superioridade de uma das modalidades de tratamento ao longo de 48 horas, procedeu-se à comparação da intensidade dos sintomas entre os grupos (Tabela 10). 
Tabela 10- Comparação da evolução da intensidade dos sintomas e da sobrecarga de sintomas pelo ESAS, ao longo de 48 horas. São Paulo, 2014

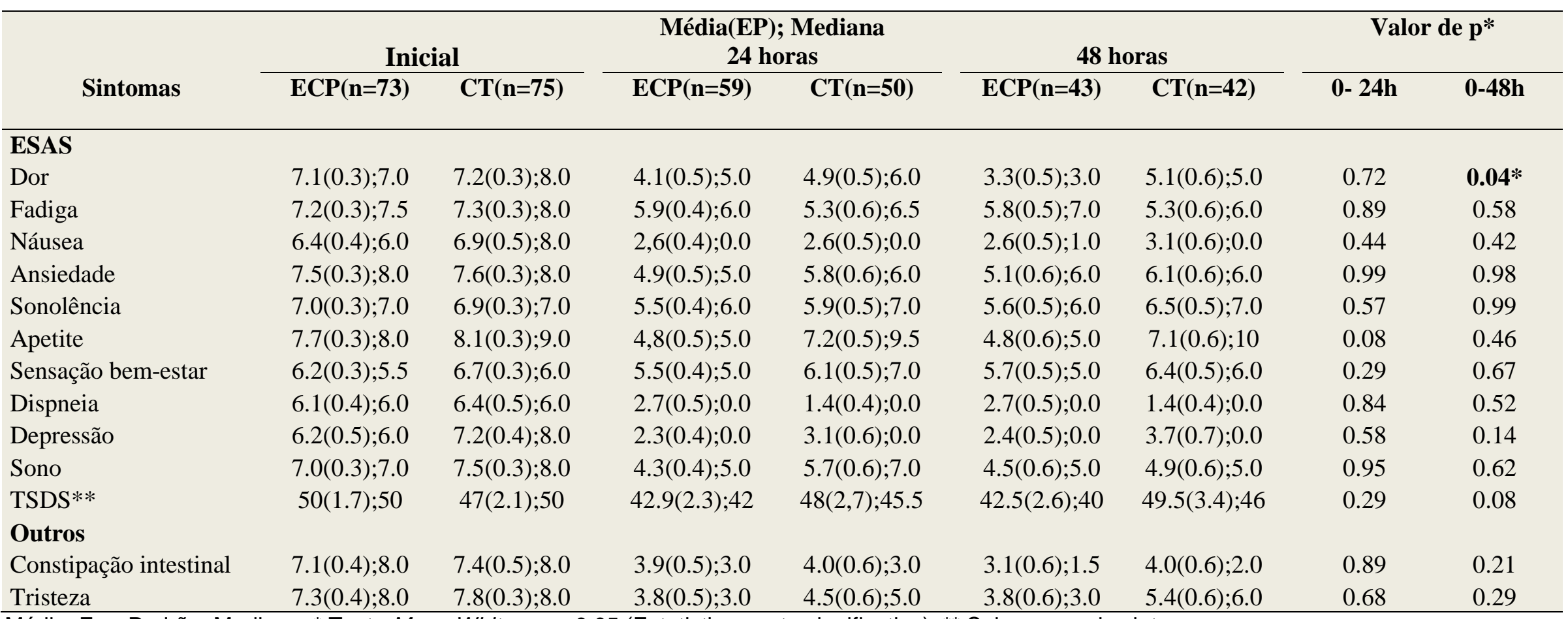

Média, Erro Padrão, Mediana. * Teste Mann Whitney, $\mathrm{p}<0,05$ (Estatisticamente significativo); ${ }^{* *}$ Sobrecarga de sintomas

$\mathrm{Na}$ Tabela 10, observa-se que na comparação entre os grupos, o Grupo ECP mostrou redução da dor em 48 horas $(p=0.04)$. Não houve diferenças estatisticamente significativas nas demais comparações. 
Visando aprofundar a análise, testou-se a existência de diferença clinicamente relevante para a dor (redução de 1 e 2 pontos), partindo-se da avaliação inicial. A análise pelo Teste Exato de Fisher pode ser observada nas Tabelas 11 e 12.

Tabela 11- Comparação entre os Grupos ECP e CT quanto ao percentual de redução de 1 ponto na intensidade dos sintomas, ao longo de 48 horas. São Paulo, 2014

\begin{tabular}{|c|c|c|c|c|c|c|}
\hline \multirow{3}{*}{ Sintomas } & \multicolumn{6}{|c|}{ Redução de 1 ponto } \\
\hline & \multicolumn{2}{|c|}{ 0-24h } & \multirow[b]{2}{*}{$\begin{array}{c}\text { Valor } \\
\mathbf{p}\end{array}$} & \multicolumn{2}{|c|}{$0-48 h$} & \multirow[b]{2}{*}{$\begin{array}{c}\text { Valor } \\
\text { p }^{*}\end{array}$} \\
\hline & $\begin{array}{l}\text { ECP } \\
\text { n\% }\end{array}$ & $\begin{array}{l}\text { CT } \\
\text { n } \%\end{array}$ & & $\begin{array}{l}\text { ECP } \\
\text { n \% }\end{array}$ & $\begin{array}{l}\text { CT } \\
\text { n \% }\end{array}$ & \\
\hline ESAS & & & & & & \\
\hline Dor & $47(59.6)$ & $40(47.5)$ & 0.29 & $34(70.6)$ & $36(33.3)$ & $0.002^{*}$ \\
\hline Fadiga & $50(32.0)$ & $37(35.1)$ & 0.82 & $38(39.5)$ & $31(41.9)$ & 1.00 \\
\hline Náusea & $33(60.6)$ & $23(60.8)$ & 1.00 & $26(73.5)$ & $20(60.0)$ & 0.53 \\
\hline Ansiedade & $40(40.0)$ & $38(26.3)$ & 0.23 & $30(46.7)$ & $34(41.2)$ & 0.80 \\
\hline Sonolência & $46(39.1)$ & $37(40.5)$ & 1.00 & $35(37.1)$ & $33(36.3)$ & 1.00 \\
\hline Apetite & $44(43.1)$ & $39(25.6)$ & 0.11 & $32(46.9)$ & $33(30.3)$ & 0.21 \\
\hline $\mathrm{SBE}^{\mathrm{a}}$ & $50(22.0)$ & $38(18.4)$ & 0.79 & $37(21.6)$ & $35(22.8)$ & 1.00 \\
\hline Dispneia & $34(47.1)$ & $14(42.8)$ & 1.00 & $27(55.5)$ & $13(53.8)$ & 1.00 \\
\hline Depressão & $24(33.3)$ & $24(37.5)$ & 1.00 & $18(38.9)$ & $21(28.6)$ & 0.52 \\
\hline Sono & $42(40.4)$ & $42(35.7)$ & 0.82 & $31(51.6)$ & $39(51.3)$ & 1.00 \\
\hline TSDS $^{\mathrm{b}^{* *}}$ & $57(28.1)$ & $48(31.2)$ & 1.00 & $43(39.5)$ & $43(27.9)$ & 0.36 \\
\hline \multicolumn{7}{|l|}{ Outros } \\
\hline C.I ${ }^{\mathrm{c}}$ & $32(34.3)$ & $23(34.7)$ & 0.78 & $24(58.3)$ & $22(40.9)$ & 0.37 \\
\hline Tristeza & $30(26.7)$ & $30(33.3)$ & 0.83 & $22(45.4)$ & $27(25.9)$ & 0.23 \\
\hline
\end{tabular}

Média, Erro Padrão, Mediana

*Teste Fisher, pela redução de 1 ponto, $p<0,05$ (Estatisticamente significativo)

a Sensação de Bem-Estar; ${ }^{b}$ Sobrecarga de sintomas; ${ }^{c}$ Constipação intestinal

${ }^{* *}$ Redução de 10 pontos

Pela Tabela 11, nota-se que, na avaliação de 48 horas, mostrou que os indivíduos do Grupo ECP apresentaram redução mínima clinicamente significativa em 1 ponto para a dor $(p=0.002)$.

Não houve diferença estatisticamente significativa nas demais comparações 
Tabela 12- Comparação entre os Grupos ECP e CT quanto ao percentual de redução de 2 pontos na intensidade dos sintomas, ao longo de 48 horas. São Paulo, 2014

\begin{tabular}{|c|c|c|c|c|c|c|}
\hline \multirow{4}{*}{ Sintomas } & \multicolumn{6}{|c|}{ Redução de 2 pontos } \\
\hline & \multicolumn{2}{|c|}{$0-24 h$} & \multirow{3}{*}{$\begin{array}{c}\text { Valor } \\
\text { p }\end{array}$} & \multicolumn{2}{|c|}{$0-48 h$} & \multirow{3}{*}{$\begin{array}{c}\text { Valor } \\
\mathbf{p}^{*}\end{array}$} \\
\hline & ECP & CT & & ECP & CT & \\
\hline & $\mathrm{n} \%$ & n $\%$ & & n $\%$ & n $\%$ & \\
\hline \multicolumn{7}{|l|}{ ESAS } \\
\hline Dor & $47(46.8)$ & $40(42.5)$ & 0.83 & $34(70.6)$ & $36(30.5)$ & $0.002 *$ \\
\hline Fadiga & $50(28.0)$ & $37(32.4)$ & 0.81 & $38(34.2)$ & $31(32.2)$ & 1.00 \\
\hline Náusea & $33(57.6)$ & $23(52.2)$ & 0.79 & $26(69.2)$ & $20(60.0)$ & 0.55 \\
\hline Ansiedade & $40(35.0)$ & $38(26.3)$ & 0.47 & $30(46.7)$ & $34(38.2)$ & 0.61 \\
\hline Sonolência & $46(32.6)$ & $37(32.4)$ & 1.00 & $35(34.3)$ & $33(33.3)$ & 1.00 \\
\hline Apetite & $44(29.5)$ & $39(20.5)$ & 0.45 & $32(37.5)$ & $33(24.2)$ & 0.29 \\
\hline $\mathrm{SBE}^{\mathrm{a}}$ & $50(18.0)$ & $38(13.1)$ & 0.57 & $37(18.9)$ & $35(8.6)$ & 0.31 \\
\hline Dispneia & $34(41.2)$ & $14(35.8)$ & 1.00 & $27(48.1)$ & $13(53.4)$ & 1.00 \\
\hline Depressão & $24(25.0)$ & $24(33.3)$ & 0.75 & $18(27.8)$ & $21(28.6)$ & 1.00 \\
\hline Sono & $42(35.7)$ & $42(35.8)$ & 1.00 & $31(48.4)$ & $39(46.1)$ & 1.00 \\
\hline TSDS $^{\mathrm{b}^{* * *}}$ & $57(8.8)$ & $48(12.5)$ & 0.54 & $43(13.9)$ & 43(13.9) & 1.00 \\
\hline \multicolumn{7}{|l|}{ Outros } \\
\hline C.I ${ }^{\mathrm{c}}$ & $32(28.1)$ & $23(30.4)$ & 1.00 & $24(45.8)$ & $22(40.9)$ & 0.77 \\
\hline Tristeza & $30(16.7)$ & $30(26.7)$ & 0.53 & $22(27.3)$ & $27(22.2)$ & 0.75 \\
\hline
\end{tabular}

Média, Erro Padrão, Mediana

${ }^{*}$ Teste Fisher, pela redução de 2 pontos, p $<0,05$ (Estatisticamente significativo)

${ }^{a}$ Sensação de Bem Estar; ${ }^{b}$ Sobrecarga de sintomas; ${ }^{~}$ Constipação intestinal

${ }^{* \star}$ Redução de 20 pontos

Na Tabela 12, nota-se que na avaliação de 48 horas mostrou que os indivíduos do Grupo ECP apresentaram redução mínima clinicamente significativa em 2 pontos para a dor $(p=0.002)$.

Não houve diferença estatisticamente significativa nas demais comparações

Considerando-se as diferenças entre os Grupos ECP e CT na escolaridade, local de internação, número de metástases e Karnofsky (Tabela 5), houve a necessidade de controlar fatores de 
confusão para atribuir a melhora dos sintomas aos Grupos ECP e CT. Dessa forma, procedeu-se à análise de regressão múltipla de Poisson, ajustada pela idade, KPS e número de metástases. Julgouse que escolaridade não influenciaria no desfecho (melhora dos sintomas). Aplicou-se essa análise para verificar a redução de um ponto e dois pontos nos sintomas, e os dados podem ser observados nas Tabelas 13 e 14.

Tabela 13- Estimativa do risco relativo de melhora de 1 ponto nos sintomas do Grupo ECP em relação ao Grupo CT, pelo modelo de regressão múltipla de Poisson. São Paulo, 2014

\begin{tabular}{|c|c|c|c|c|c|c|}
\hline \multirow[b]{2}{*}{ Sintomas } & \multicolumn{2}{|c|}{ Inicial-24h } & \multirow{2}{*}{$\begin{array}{c}\text { Valor } \\
\text { p* }\end{array}$} & \multicolumn{2}{|c|}{ Inicial-48h } & \multirow{2}{*}{$\begin{array}{c}\text { Valor } \\
\text { p* }\end{array}$} \\
\hline & $\mathbf{R R}$ & IC95\% & & $\mathbf{R R}$ & IC95\% & \\
\hline \multicolumn{7}{|l|}{ ESAS } \\
\hline Dor & 1.2 & $(0.83-1.88)$ & 0.31 & 2.1 & $(1.23-3.56)$ & $0.007 *$ \\
\hline Fadiga & 0.9 & $(0.48-1.68)$ & 0.74 & 0.9 & $(0.53-1.60)$ & 0.77 \\
\hline Náusea & 1.1 & $(0.68-1.75)$ & 0.69 & 1.3 & $(0.82-2.02)$ & 0.28 \\
\hline Ansiedade & 1.6 & $(0.84-3.06)$ & 0.16 & 1.1 & $(0.61-2.05)$ & 0.72 \\
\hline Sonolência & 1.0 & $(0.60-1.86)$ & 0.85 & 1.2 & $(0.63-2.31)$ & 0.56 \\
\hline Apetite & 1.9 & $(1.00-3.81)$ & $0.04 *$ & 1.6 & $(0.85-3.09)$ & 0.14 \\
\hline Sensação bem-estar & 1.7 & $(0.74-4.15)$ & 0.20 & 1.1 & $(0.43-2.72)$ & 0.86 \\
\hline Dispneia & 0.8 & $(0.35-1.81)$ & 0.58 & 1.1 & $(0.55-2.35)$ & 0.72 \\
\hline Depressão & 1.3 & $(0.54-3.04)$ & 0.57 & 2.1 & $(0.74-5.92)$ & 0.16 \\
\hline Sono & 1.2 & $(0.65-2.11)$ & 0.58 & 0.9 & $(0.62-1.58)$ & 0.97 \\
\hline Sobrecarga sintomas & 0.9 & $(0.51-1.71)$ & 0.85 & 1.5 & $(0.79-2.77)$ & 0.21 \\
\hline \multicolumn{7}{|l|}{ Outros } \\
\hline Constipação intestinal & 1.1 & $(0.50-2.40)$ & 0.81 & 1.4 & $(0.72-2.74)$ & 0.32 \\
\hline Tristeza & 0.9 & $(0.41-2.30)$ & 0.94 & 2.2 & $(0.83-6.11)$ & 0.11 \\
\hline
\end{tabular}

Pela Tabela 13, nota-se que, em 24h, o Grupo ECP apresentou risco relativo de melhora 1.9 vezes maior que o Grupo CT para a perda do apetite $(p=0.04)$. Na análise de $48 \mathrm{~h}$, o Grupo ECP mostrou risco relativo de melhora 2.1 vezes maior que o Grupo CT para a dor $(\mathrm{p}=0.007)$. 
Não houve diferença estatisticamente significativa nas demais comparações.

Tabela 14- Estimativa do risco relativo de melhora de 2 pontos nos sintomas do Grupo ECP em relação ao Grupo CT, pelo modelo de regressão múltipla de Poisson. São Paulo, 2014.

\begin{tabular}{lccccccc}
\hline \multirow{2}{*}{\multicolumn{1}{c}{ Sintomas }} & \multicolumn{2}{c}{ Inicial-24h } & Valor & \multicolumn{2}{c}{ Inicial-48h } & Valor \\
& RR & IC95\% & p* & RR & IC95\% & p* \\
\hline ESAS & 1.0 & $(0.64-1.72)$ & 0.85 & 2.2 & $(1.27-3.81)$ & $\mathbf{0 . 0 0 5 *}$ \\
Dor & 0.8 & $(0.43-1.64)$ & 0.62 & 1.1 & $(0.57-2.17)$ & 0.75 \\
Fadiga & 1.2 & $(0.72-2.07)$ & 0.45 & 1.2 & $(0.76-1.94)$ & 0.42 \\
Nausea & 1.4 & $(0.73-2.87)$ & 0.29 & 1.3 & $(0.73-2.45)$ & 0.34 \\
Ansiedade & 1.2 & $(0.67-2.36)$ & 0.48 & 1.1 & $(0.58-2.28)$ & 0.69 \\
Sonolência & 2.0 & $(0.88-4.59)$ & 0.10 & 1.7 & $(0.79-3.65)$ & 0.17 \\
Apetite & 2.0 & $(0.79-5.16)$ & 0.14 & 4.6 & $(1.34-15.88)$ & $\mathbf{0 . 0 1}$ \\
Sensação bem-estar & 0.9 & $(0.36-2.30)$ & 0.85 & 1.1 & $(0.51-2.26)$ & 0.85 \\
Dispneia & 1.1 & $(0.40-3.15)$ & 083 & 1.3 & $(0.42-4.25)$ & 0.62 \\
Depressão & 1.0 & $(0.56-1.87)$ & 0.94 & 1.0 & $(0.63-1.75)$ & 0.85 \\
Sono & 1.1 & $(0.49-2.52)$ & 0.81 & 1.3 & $(0.45-3.77)$ & 0.62 \\
Sobrecarga sintomas & & & & & & \\
Outros & & & & & & \\
Constipação intestinal & 0.8 & $(0.27-2.85)$ & 0.83 & 0.9 & $(0.47-1.95)$ & 0.92 \\
Tristeza & 0.8 & $(0.26-2.85)$ & 0.80 & 1.7 & $(0.41-6.83)$ & 0.48 \\
\hline
\end{tabular}

Regressão Múltipla de Poisson ajustada pela idade, KPS e metástase

*Risco Relativo pela redução de 02 pontos na intensidade dos sintomas de 20 pontos na sobrecarga de sintomas

$\mathrm{Na}$ Tabela 14, observa-se que, em 48 horas, o Grupo ECP apresentou risco relativo de melhora 2.2 vezes maior que o Grupo CT para a dor $(p=0.005)$, e risco relativo de melhora de 4.6 vezes maior que o Grupo CT para a perda do bem-estar $(p=0.01)$.

Não houve diferença estatisticamente significativa nas demais comparações. 


\subsection{Tratamento analgésico}

Esta seção foi organizada para demonstrar a adequação analgésica pelo Índice de Manejo da Dor (IMD). Visto que a dor foi o sintoma que mais diferiu entre os Grupos, houve necessidade de analisá-lo com mais profundidade.

Tabela 15- Comparação da adequação analgésica nos grupos ECP e CT, segundo o IMD. São Paulo, 2014

\begin{tabular}{|c|c|c|c|c|c|c|c|c|c|}
\hline \multirow[t]{3}{*}{ IMD } & \multicolumn{2}{|c|}{ Inicial } & \multirow{3}{*}{$\begin{array}{c}\text { Valor } \\
p^{*}\end{array}$} & \multicolumn{2}{|c|}{24 horas } & \multirow{3}{*}{$\begin{array}{c}\text { Valor } \\
\text { p* }\end{array}$} & \multicolumn{2}{|c|}{48 horas } & \multirow{3}{*}{$\begin{array}{c}\text { Valor } \\
p^{*}\end{array}$} \\
\hline & $\operatorname{ECP}(n=73)$ & $C T(n=75)$ & & $\operatorname{ECP}(n=59)$ & $C T(n=50)$ & & $\operatorname{ECP}(n=43)$ & $C T(n=42)$ & \\
\hline & $n \%$ & $n \%$ & & $n \%$ & $n \%$ & & $n \%$ & $n \%$ & \\
\hline Inadequado & $22(30.1)$ & $49(65.3)$ & $<0.001 *$ & $15(25.4)$ & $22(44.0)$ & 0.14 & $07(16.3)$ & $20(47.7)$ & $0.01 *$ \\
\hline Adequado & $51(69.9)$ & $26(34.7)$ & & $44(74.6)$ & $28(56.0)$ & & $36(83.7)$ & $22(52.4)$ & \\
\hline
\end{tabular}

*Teste de Exato de Fisher, p<0,05 (Estatisticamente significativo)

Nota-se, na Tabela 15, que o Grupo ECP apresentou melhor adequação da analgesia em dois momentos: na admissão $(p<0.001)$ e em 48 horas $(p=0.01)$, comparado ao Grupo CT.

A distribuição detalhada sobre a adequação da analgesia encontra-se no Anexo 9. 


\subsection{Satisfação do doente}

A satisfação dos doentes com o alívio dos sintomas foi investigada ao longo de 48 horas nos dois grupos.

Tabela 16- Comparação da satisfação dos doentes com o alívio da dor nos grupos ECP e CT. São Paulo, 2014

\begin{tabular}{lccc}
\hline \multirow{2}{*}{ Avaliação } & \multicolumn{2}{c}{ Média(EP);Mediana } & \multirow{2}{*}{ Valor p* $^{*}$} \\
\cline { 2 - 3 } Inicial & $9.1(0.19) ; 10$ & $8.8(0.22) ; 10$ & \multirow{2}{*}{0.39} \\
$\mathbf{2 4 h}$ & $10(0.20) ; 10$ & $9.0(0.33) ; 10$ & 0.80 \\
$\mathbf{4 8 h}$ & $9.0(0.33) ; 10$ & $8.3(0.22) ; 10$ & 0.26 \\
\hline
\end{tabular}

Média, Erro Padrão, Mediana

*Teste Mann Whitney, $\mathrm{p}<0,05$ (Estatisticamente significativo)

Observa-se, na Tabela 16, que os pacientes de ambos os grupos apresentaram satisfação elevada quanto ao tratamento que receberam. Não houve diferença estatisticamente significativa na comparação entre os grupos.

\subsection{Adesão dos profissionais do Grupo CT às recomendações do Grupo ECP}

A adesão do Grupo CT às recomendações do Grupo ECP para o controle dos sintomas foi analisada, visto que, apesar da terapia ser proposta pela equipe de cuidado paliativo (Grupo ECP), estas eram implementadas pela equipe de cuidado tradicional (CT).

A adesão foi analisada separadamente para dor e outros sintomas e categorizada em total, parcial e não adesão. Os registros 
em prontuário foram a base para a alocação dos doentes nas categorias.

1- Adesão total: quando $100 \%$ das sugestões foram acatadas.

2- Adesão parcial: quando parte das sugestões não foi acatada, por exemplo, adesão ao fármaco mas não à dose proposta, adesão à classe e potência mas não ao fármaco recomendado, adesão a algum fármaco, mas não a todos, quando mais de um fármaco foi sugerido.

3- Não adesão: nenhuma das sugestões para o controle de sintomas foi seguida.

$\mathrm{Na}$ análise dos setenta e três prontuários de pacientes, a equipe de cuidados paliativos realizou 53(72.6\%) sugestões para a dor e 60 (82.2\%) para outros sintomas não dor. A Tabela 17 demonstra a adesão para as condutas sugeridas pelo Grupo ECP.

Tabela 17- Distribuição da adesão às recomendações de controle de sintomas do Grupo ECP pelo Grupo CT. São Paulo, 2014

\begin{tabular}{lcc}
\hline Adesão & DOR=53 & OUTRO=60 \\
\cline { 2 - 3 } & $\mathbf{n} \%$ & $\mathbf{n} \%$ \\
\hline Total & $40(75.5)$ & $45(75.0)$ \\
Parcial & $02(3.8)$ & $07(11.6)$ \\
Não aderiu & $11(20.7)$ & $07(11.6)$ \\
\hline
\end{tabular}

A Tabela 17 mostra que houve adesão para a maioria das orientações feitas pelo Grupo ECP para dor (75.5\%) e outros sintomas $(75 \%)$.

\subsection{Número de óbitos}


A frequência do número de óbitos em cada Grupo não foi objetivo do estudo, porém desejou-se obter melhor compreensão do conjunto de gravidade dos doentes de cada grupo.

Os dados de óbito foram obtidos, retrospectivamente, pelos registros médicos e foram considerados os óbitos que ocorreram 3 meses após a admissão dos pacientes no estudo.

Tabela 18- Distribuição do número de óbitos nos Grupos ECP e CT. São Paulo, 2014

\begin{tabular}{lccc}
\hline Óbito & $\mathrm{ECP}(\mathrm{n}=73)$ & $\mathrm{CT}(\mathrm{n}=75)$ & \multirow{2}{*}{ Valor de $\mathrm{p}^{*}$} \\
\cline { 2 - 3 } & $\mathrm{n} \%$ & $\mathrm{n} \%$ & \\
\hline Até 30 dias & $25(34.2)$ & $21(28.0)$ & 0.31 \\
$30-90$ dias & $02(2.7)$ & $05(6.6)$ & \\
& & & \\
\hline
\end{tabular}

*Teste de Exato de Fisher, $\mathrm{p}<0,05$ (Estatisticamente significativo)

Nota-se, pela Tabela 18, que os grupos mostraram distribuição semelhante no número de óbito. Maior número de óbito ocorreu em período menor que 1 mês após a admissão dos pacientes para o estudo. 


\subsection{Sumário dos resultados}

Sumarizando os resultados, pode-se destacar:

1- Frequência dos sintomas: $\mathrm{Na}$ admissão, os pacientes apresentaram alta prevalência de sintomas em ambos os grupos, sendo que o Grupo ECP apresentou maior relato de dispneia.

2- Frequência da intensidade dos sintomas: $\mathrm{Na}$ admissão, a maioria dos pacientes relatou sintomas de moderados a intensos, mas dispneia intensa foi maior no Grupo ECP e moderada no Grupo CT.

\section{3- Evolução dos sintomas ao longo de $\mathbf{4 8}$ horas nos grupos (ECP e CT):}

3.1 O Grupo ECP, nas primeiras 24 horas, mostrou redução de cinco sintomas $(23 \%$ em dor, $18 \%$ em náusea, $19 \%$ em perda de apetite, $21 \%$ em dispneia, $8 \%$ em sono e $10 \%$ na sobrecarga de sintomas). $\mathrm{Na}$ análise de 48 horas, o Grupo ECP reduziu 10 sintomas (34\% em dor, $13 \%$ em fadiga, $35 \%$ em náusea, $24 \%$ em ansiedade, $7 \%$ em prejuízo do apetite, 34\% em dispneia, 31\% em depressão, 14\% em prejuízo do sono, $34 \%$ em constipação intestinal e 14\% em tristeza).

3.3 A sobrecarga de sintomas pelo ESAS sofreu redução de 5.3 pontos (10\%) na avaliação de $24 \mathrm{~h}$ e em 48 horas a redução foi de 6.4 pontos $(10 \%)$.

3.4 O Grupo CT, nas primeiras 24 horas, mostrou redução de três sintomas (22\% para dor, 44\% para náusea e 16\% para prejuízo do sono). Na análise de 48 horas, o Grupo CT reduziu náusea em $29 \%$, ansiedade em $14 \%$, dispneia em $38 \%$ e prejuízo do sono em $17 \%$.

3.5 Não houve diferença estatisticamente significativa na análise da sobrecarga de sintomas ao longo de 48 horas.

4- Comparação da evolução dos sintomas ao longo de $\mathbf{4 8}$ horas entre os grupos (ECPxCT):

4.1 O Grupo ECP mostrou redução de dor em 48 horas. 
4.2 Diferença clínica estatisticamente significativa na redução de 1 e 2 pontos: o Grupo ECP, em 48 horas, mostrou redução de 1 e 2 pontos na dor $(70 \%)$.

\section{5- Regressão múltipla de Poisson}

5.1 Risco relativo de melhora para redução de 1 ponto: O Grupo ECP comparado ao CT, nas primeiras 24 horas, mostrou risco relativo de melhora de 1.9 vezes maior para perda do apetite e, em 48 horas, mostrou risco relativo de melhora de 2.1 vezes maior para a dor.

5.2 Risco relativo de melhora para redução de 2 pontos: $O$ Grupo ECP comparado ao CT, em 48 horas, mostrou risco relativo de melhora de 2.2 vezes maior para a dor e 4.6 vezes para o prejuízo da sensação de bem-estar.

6. Tratamento analgésico: o Grupo ECP mostrou maior adequação da analgesia do que o Grupo CT, na avaliação inicial e após 48h.

7. Satisfação com o alívio da dor: a satisfação foi elevada e sem diferença estatisticamente significativa entre os grupos. 
DISCUSSÃO 


\section{DISCUSSÃO}

Este estudo testou os efeitos de duas modalidades de equipe profissional (equipe de cuidados paliativos-ECP e equipe de cuidado tradicional-CT) no controle de sintomas em pacientes hospitalizados com câncer avançado, e observou efeito superior, embora limitado, quando o cuidado foi orientado por equipe especializada em cuidado paliativo.

O Grupo ECP apresentou melhora de cinco sintomas nas primeiras 24 horas (dor, náusea, perda do apetite, dispneia e sono); após 48h houve redução de dez sintomas (exceto por sonolência e sensação de bem estar); redução da sobrecarga dos sintomas em 24h e 48h. O Grupo CT mostrou melhora de três sintomas nas primeiras 24 horas (dor, náusea e sono); após 48h houve redução de quatro sintomas (náusea, ansiedade, depressão e prejuízo do sono).

Apesar dos bons resultados observados, a análise exige cautela. $\mathrm{Na}$ atualidade, busca-se observar, além de diferenças estatísticas, a relevância clínica das diferenças ${ }^{81}$. Buscando identificar a relevância clínica da melhora nos sintomas, considerouse redução mínima de 2 pontos no escore do sintoma avaliado, comparado à avaliação inicial. Observou-se que, no Grupo ECP, apenas dor mostrou redução clinicamente significativa, que ocorreu somente no momento 48 horas (Tabelas 12). Não houve melhora clinicamente relevante no Grupo CT.

Visando controlar possíveis fatores de confusão nos resultados, pois os pacientes encaminhados para o Grupo ECP tinham menor funcionalidade e maior número de metástases (Tabela 5), realizou-se uma regressão múltipla ajustada pela gravidade. $O$ 
Grupo ECP mostrou melhor risco relativo para redução da dor em 48 horas e melhor risco para melhora do bem-estar.

Frente aos resultados obtidos, a discussão visa, centralmente, analisar o motivo do porque o cuidado paliativo especializado foi efetivo somente em dor.

\subsection{Características demográficas, clínicas e dos sintomas}

As variáveis demográficas incluídas nos estudos prévios sobre efetividade da equipe de cuidado paliativo variam, porém idade, sexo, sítio do tumor foram as mais encontradas. Já funcionalidade foi menos frequentemente encontrada. Considerando as características demográficas mais comuns observadas nestes estudos, encontrou-se que a distribuição do sexo foi equitativa, que a idade foi em torno de 60 anos, o sítio de tumor mais frequente foi do sistema gastrodigestório ${ }^{19,21,25,28,82}$ e funcionalidade em torno de 40 a $50^{25}$. A distribuição dessas variáveis foi similar a esse estudo.

\subsection{Prevalência e magnitude de sintomas}

A prevalência de sintomas foi elevada em ambos os Grupos. $\mathrm{Na}$ admissão, os sintomas variaram de $43.8 \%$ (depressão) a $87.7 \%$ (fadiga e perda do bem-estar) para o Grupo ECP (Tabela 6). No Grupo CT, variou de $24 \%$ (dispneia) a $85.3 \%$ (dor). Dos doze sintomas avaliados, no Grupo ECP, apenas depressão ocorreu em menos que $50 \%$ dos doentes. No Grupo CT, náusea, dispneia e constipação intestinal ocorreram em menos de $50 \%$ dos doentes. Todos os sintomas eram de moderados a intensos (Tabelas 8 e 9) e a sobrecarga de sintomas apresentou mediana de $50.0 \mathrm{em}$ ambos os grupos (Tabelas 8 e 9). Esses dados mostram que os pacientes 
incluídos neste estudo apresentavam grande sobrecarga de sintomas físicos e psicológicos, com grande necessidade de manejo adequado destes sintomas.

A alta prevalência e magnitude dos sintomas observadas no presente estudo diferem de estudos prévios.

Um estudo prospectivo, realizado com 462 pacientes, com câncer, ambulatoriais e recebendo quimioterapia, identificou a prevalência e a intensidade dos sintomas, utilizando um questionário que incluiu 11 sintomas (MD Anderson Symptom Inventory-MDASI, versão japonesa). Observou-se que insônia (19\%), sofrimento psicológico (15\%), fadiga (23\%) e perda do apetite (17\%) foram os sintomas mais frequentemente relatados. Porém, este estudo foi realizado com pacientes ambulatoriais, que apresentavam boa mobilidade, estavam em tratamento curativo e antes de iniciar a primeira sessão de quimioterapia ${ }^{83}$.

Outro estudo avaliou, retrospectivamente, as características demográficas e a prevalência dos sintomas em 400 pacientes admitidos em diferentes modelos de atendimento em cuidado paliativo (internamento hospice, domiciliar, equipe de suporte paliativo para pacientes agudos hospitalizados/ambulatoriais). Noventa por cento dos pacientes eram oncológicos e os cinco sintomas mais prevalentes foram dor (64\%), fadiga (34\%), constipação intestinal (32\%), fraqueza (32\%), dispneia (31\%). Houve pequena variação, não significativa, no relato dos sintomas, de acordo com o modelo de cuidado recebido pelos pacientes ${ }^{84}$.

Estudo sobre sintomas em pacientes oncológicos hospitalizados parece mostrar maior frequência e magnitude de sintomas agudos.

Um estudo realizado com 160 pacientes hospitalizados em unidade de clínica médica, com doenças crônicas variadas, ameaçadoras da vida, mostrou que os resultados assemelharam-se 
aos observados na presente pesquisa. A prevalência de sintomas, estimada por meio da ESAS foi: dispneia (70\%), perda do bem-estar (70\%), seguidos de boca seca $(58 \%)$, fadiga $(56 \%)$, depressão $(41 \%)$, ansiedade $(37 \%)$, dor ao repouso $(30 \%)$ e em movimento $(42 \%)^{85}$.

Percentuais elevados de relato de sintomas parecem ser observados em estudos similares ao estudo vigente, mas não em sua magnitude e sobrecarga de sintomas.

Os sintomas de 162 pacientes com câncer avançado, nos primeiros sete dias de hospitalização, foram avaliados pela ESAS. $\mathrm{Na}$ admissão observaram fadiga em $88 \%$ dos avaliados (em $55 \%$ foi intensa), sonolência em $79 \%$ deles (em $44 \%$ foi intensa), ansiedade em $74 \%$ dos doentes (em $41 \%$ foi intensa), depressão em $71 \%$ dos entrevistados (40\% foi intensa), perda do apetite em $70 \%$ (em $53 \%$ foi intenso), dor em $67 \%$ dos doentes (em $40 \%$ foi intensa), prejuízo na sensação do bem-estar em $62 \%$ dos avaliados (em 35\% foi intenso), dispneia ocorreu em $47 \%$ dos pacientes (em $34 \%$ foi intensa) e náusea foi relatada por $29 \%$ dos doentes (em $26 \%$ foi intensa). $\mathrm{Na}$ avaliação inicial, a variação do escore da média entre o sintoma menos e mais intenso foi: náusea 1.57(DP2.68) e a fadiga 5.46(DP3.15). A média de sobrecarga dos sintomas, avaliada pelo TSDS, foi 33.93(DP16.24). Nota-se que a prevalência de sintomas foi aproximada à observada na presente pesquisa (Tabelas 6), mas a intensidade e a sobrecarga dos sintomas foram menores do que esse estudo (Tabelas 8 e 9). Na presente pesquisa, a variação média da intensidade de sintomas, na primeira avaliação, no Grupo ECP (Tabela 8) foi de 6.1(EP0.4) para dispneia a 7.2(EP0.3) para fadiga e, no Grupo CT (Tabelas 9), foi de 6.4(EP0.5) para dispneia e 8.1(EP0.3) para a perda do apetite. Quanto à média da sobrecarga de sintomas no Grupo ECP foi de 50(EP1.7) e, no Grupo CT, foi de 47(EP2.1) $)^{21}$. 
Avaliar a severidade de sintomas e a resposta ao tratamento em 150 pacientes hospitalizados com câncer metastático que participavam da fase II de uma intervenção da equipe de cuidados paliativos foi objetivo de um estudo. Os sintomas foram avaliados pelo ESAS e observou-se que fadiga, inapetência e dor foram os três sintomas, de onze, que apresentaram média igual ou maior a 5. Esse resultado diferiu do estudo vigente onde todos os sintomas atingiram média igual ou maior a 5, em ambos os Grupos (Tabelas 8 e 9$)^{86}$.

A prevalência e a magnitude dos sintomas do estudo corrente assemelham-se aos de estudos com foco em pacientes com doença metastática e terminais.

Em estudo que avaliou, retrospectivamente, 1612 pacientes em radioterapia paliativa ambulatorial, verificou-se que os sintomas de moderados a intensos, avaliados pelo ESAS, foram fadiga (85\%), dor $(71 \%)$, perda de bem estar (70\%), sonolência (62\%), prejuízo do sono (62\%), anorexia (52\%), ansiedade (43\%), depressão (40\%), dispneia (38\%) e náusea (27\%). O que foi similar aos achados deste estudo, pois observou-se que náusea (56.1\% e 44\%), ansiedade (73.9\% e 74.7\%), sonolência (83.5\% e 73.3\%), perda do apetite (78.1\% e 69.3\%), dispneia (58\% somente para o Grupo ECP), respectivamente, para o Grupo ECP e CT (Tabela 6) ${ }^{28}$.

Buscando comparar com pesquisas de revisão, foram encontrados dois estudos, recentes e amplos, que analisaram a prevalência de sintomas.

Estudo de revisão sistemática avaliou população diversificada para verificar os sintomas comuns de morte iminente. Vinte artigos foram incluídos, representando 2416 pacientes. Os autores incluíram estudos que avaliaram sintomas únicos ou múltiplos, com ou sem questionário padronizado. Setenta por cento dos pacientes eram oncológicos e os sintomas físicos de maior prevalência foram: 
dispneia $(56.7 \%)$ e dor $(52.4 \%)$. No presente estudo tais dados foram similares, dispneia do Grupo ECP (58.9\%), porém, com maior prevalência de dor, $78.1 \%$ e $85.3 \%$, para os Grupos ECP e CT, respectivamente (Tabela 6$)^{87}$.

Outro estudo de revisão sistemática, que teve como objetivo principal avaliar a prevalência de sintomas em pacientes com câncer incurável organizou os achados em dois conjuntos: Grupo 1, estudos que abordaram prevalência de sintomas (44 estudos, totalizando 25.074 pacientes), e o Grupo 2, estudos que analisaram a prevalência de sintomas nas duas últimas semanas de vida (6 estudos, totalizando 2.219 pacientes). Foram incluídos estudos que avaliaram a prevalência de sintomas por meio de questionário padronizado ou de registros médicos. Trinta e sete sintomas foram identificados e quase todos ocorreram em mais de $10 \%$ dos doentes. No Grupo 1, cinco sintomas ocorreram em mais de $50 \%$ dos pacientes $(74 \%$ fadiga, $71 \%$ dor, $69 \%$ falta de energia, $60 \%$ fraqueza, $53 \%$ perda do apetite); no Grupo 2, três sintomas (86\% perda de peso, $88 \%$ fadiga, $74 \%$ fraqueza) ocorreram em mais de $50 \%$ dos doentes. Na comparação entre os grupos, observou-se que perda de peso foi mais frequente no Grupo 2, comparado ao Grupo 1 , e os sintomas menos frequentes foram dor, náusea e sintomas urinários. Os autores chamaram a atenção para a maior frequência de sintomas quando os estudos avaliaram os sintomas por meio de questionário padronizado. $\mathrm{Na}$ pesquisa vigente, observou-se que todos os sintomas ocorreram em mais de $50 \%$ dos pacientes, exceto depressão (43.8\%) do Grupo ECP e dispneia (24\%) pertencente ao Grupo CT (Tabela 6) ${ }^{50}$.

Considerando a prevalência de sintomas na população brasileira, encontrou-se um estudo prévio, com pacientes ambulatoriais de um hospital especializado em oncologia. Sintomas de moderados a intensos também foram encontrados nessa população. Duzentos e trinta e dois pacientes com câncer avançado 
foram avaliados, retrospectivamente, com o objetivo de verificar a evolução dos sintomas, após a admissão para a equipe de cuidado paliativo. Os sintomas foram avaliados por meio da ESAS com o sono. $\mathrm{Na}$ avaliação inicial, observaram que os pacientes apresentaram todos os sintomas do ESAS, $50 \%$ ou mais dos pacientes mostraram sintomas moderados e, aproximadamente $30 \%$ deles eram intensos ${ }^{26}$.

A prevalência de sintomas observada na presente pesquisa aproximou-se da de estudos que incluíram pacientes em estágio terminal. Corroborou também os achados de outros estudos, que indicaram que sintomas múltiplos, concomitantes e de magnitude significativa são frequentes em pacientes com câncer avançado. Tais fatos mostram a necessidade de equipes de profissionais preparados para controlar adequadamente essa miríade de sintomas.

Conhecer a prevalência de sintomas de uma população é de grande importância, pois permite aos profissionais anteciparem-se aos eventos, priorizar as necessidades de cuidado do paciente e avaliar a efetividade do seu trabalho.

\subsection{Evolução dos sintomas: equipe de cuidados paliativos versus equipe de cuidado tradicional}

No presente estudo, interessava analisar o tempo médio para se obter alívio dos sintomas e a duração desse alívio, visto que o descontrole de sintomas em cuidado paliativo é considerado urgência/emergência.

Pacientes com câncer avançado relatam muitos sintomas físicos e emocionais ${ }^{88}$, o desejo de ter conforto e alívio de sintomas $^{89,90}$, visando apreciar as pequenas coisas da vida ${ }^{91}$. 
Equipes especializadas em cuidados paliativos estruturam-se para assegurar cuidado humano, com alívio do sofrimento e dos sintomas.

Neste estudo, para se avaliar a efetividade da equipe especializada em cuidado paliativo no controle de sintomas, utilizouse a equipe tradicional como grupo controle. Envolveu paciente com câncer avançado (localmente ou à distância) e, apesar de não ter sido objetivo desta pesquisa verificou-se a sobrevida dos doentes e notou-se que a mortalidade em 30 dias foi de $34.2 \%$, no Grupo ECP, e $28.0 \%$, no Grupo CT (Tabela 18), o que indicou a pequena sobrevida da população estudada. A curta sobrevida dos doentes clama, enfaticamente, para a necessidade de que os sintomas sejam rápida e amplamente controlados, visando oferecer a esses doentes algum bem-estar próximo à morte. $\mathrm{O}$ presente estudo observou que - Grupo ECP pareceu ter apresentado melhor desempenho no controle de sintomas do que o Grupo CT, pois em 24h e 48h melhorou cinco e dez sintomas respectivamente, bem como sua sobrecarga. Porém, ao se analisar a mínima relevância clínica significativa com redução de 2 pontos, a análise mostrou que infelizmente, estes foram insuficientemente controlados, em ambos os Grupos de doentes.

A comparação com estudos prévios foi difícil, pois poucos trabalhos com características similares foram encontrados, isto é, comparação da efetividade da equipe de cuidado paliativo de um hospital geral acadêmico versus equipe de cuidado tradicional, uso de escala para a mensuração de múltiplos sintomas, intervalos curtos entre as avaliações e critério de sucesso relacionado à ocorrência de melhora clinicamente relevante. Em geral, os estudos avaliados não tinham grupo controle e os intervalos entre as avaliações foram maiores. 
Três estudos prospectivos, com pacientes com câncer hospitalizados, aproximaram-se do procedimento metodológico adotado na presente pesquisa.

Estudo multicêntrico, prospectivo e quase experimental, foi realizado na Espanha para avaliar a efetividade dos serviços de cuidados paliativos (SCP) em pacientes com câncer avançado. Os sintomas avaliados foram: dor, dor incidental, anorexia, náusea, vômito, constipação intestinal, insônia, dispneia, ansiedade e depressão, e mensurados por escala numérica verbal de 0 a 10, na admissão, 7 dias e 14 dias após a admissão. Observou-se que a média de sobrevivência dos pacientes foi de 42 dias, que os pacientes estavam satisfeitos com o cuidado e que a melhora dos sintomas foi independente do tipo de SCP. Nos primeiros 7 dias, houve melhora de todos os sintomas e, em 14 dias, apenas da dor, constipação intestinal, ansiedade e depressão. Não houve melhora em alguns sintomas após 2 semanas. Além disso, algumas diferenças entre esse estudo e a presente pesquisa merecem ser pontuadas. Não foi estabelecido padrão para melhora clinicamente relevante dos sintomas, não houve grupo controle e foram avaliados apenas oito sintomas ${ }^{25}$.

Outro estudo avaliou o impacto da unidade de cuidado paliativo (UPC) nos sintomas de pacientes com câncer avançado. $O$ objetivo foi avaliar o impacto no controle dos sintomas nos primeiros sete dias da admissão na UPC. Os sintomas foram mensurados pela ESAS. Foram incluídos 314 pacientes e os autores mostraram que houve melhora significativa de todos os avaliados e da redução da sobrecarga de sintomas. Perceberam também que os pacientes que apresentaram sintomas de moderados a intensos, mostraram maior redução da intensidade de sua sintomatologia. $O$ que indicou beneficio da equipe de cuidado paliativo no controle de sintomas ${ }^{21}$. Contudo, os autores não adotaram grupo controle e não estabeleceram desfecho clínico de no mínimo dois pontos. 
Estudo com grupo controle não equivalente investigou o controle de sintomas em pacientes oncológicos admitidos em um hospital geral de grande porte na Inglaterra. Cinquenta pacientes que receberam a intervenção especializada em cuidados paliativos foram comparados a 50 pacientes recebendo cuidado convencional. Os sintomas dor, anorexia, náusea, insônia e constipação foram avaliados por meio da escala Palliative Care Assessment (PACA), de quatro pontos $(0$, ausência de sintoma e 3 , sintoma dominante diariamente na vida). As avaliações foram realizadas nas 24 horas seguintes à admissão, 4 dias e 7 dias após a admissão. $\mathrm{Na}$ comparação entre os grupos, houve melhora de dor e da anorexia para o grupo que recebeu a intervenção do cuidado paliativo. No entanto, algumas considerações são necessárias, pois os sintomas na admissão diferiram entre os grupos, o que dificulta atribuir a melhora à intervenção. Ainda, ambos os grupos falharam no objetivo de conquistar a redução de 1 ponto (melhora clínica significativa) nos sintomas comparando-se a inicial com as demais avaliações. $O$ estudo avaliou apenas cinco sintomas: dor, anorexia, náusea e insônia $^{17}$

No presente estudo observou-se melhora clínica significativa apenas para a dor, com redução de dois pontos, comparando-se a avaliação inicial à avaliação em 48 horas (Tabelas 12 e 14). Como os sintomas foram semelhantes nos Grupos ECP e CT no momento da admissão (Tabelas 6, 7 e 10), pode-se atribuir essa melhora à intervenção do Grupo ECP.

Análise da taxa de resposta dos sintomas, com redução de dois pontos, a partir da análise inicial, foi realizada em outros dois estudos $^{26,82}$. No estudo em que se encontrou redução de dois pontos em todos os sintomas do ESAS, o intervalo de avaliação variou de 5 a 100 dias, a amostra foi composta por pacientes ambulatoriais, com coleta retrospectiva; o que difere do presente estudo ${ }^{26}$. O outro estudo mostrou melhora de dois pontos da fadiga, dor, depressão, 
ansiedade, dispneia, prejuízo do sono e sensação de bem-estar, mas o intervalo de avaliação foi de 15 dias, com coleta retrospectiva e para pacientes ambulatoriais ${ }^{82}$. Esse também diferiu desta pesquisa pelo desenho retrospectivo e intervalo maior de avaliação.

Considerando-se que em cuidados paliativos a melhora dos sintomas precisa ser rápida, é importante que haja estudos que analisem o controle de sintomas em intervalos de $24 \mathrm{~h}$ e $48 \mathrm{~h}$, caso da presente pesquisa.

Encontrou-se somente um estudo que analisou os sintomas de pacientes com câncer, diariamente, durante sete dias e a escala de mensuração dos sintomas foi a ESAS. Porém, não estabeleceu melhora clínica significativa relevante e a análise diária dos sintomas foi demonstrada apenas pela sobrecarga de sintomas ${ }^{21}$.

Na presente pesquisa, dor foi o sintoma com melhor controle (Tabelas 10-14), o que corrobora com a recomendação da Organização Mundial de Saúde de que o alívio da dor ocorra na primeira semana de tratamento. Alívio clinicamente importante da dor foi obtido em 48 horas, e isso foi considerado um bom resultado. Dor é um dos sintomas associado a desejo de morte nos pacientes com câncer avançado ${ }^{92}$. Este resultado foi favorável para o Grupo ECP.

A regressão ajustada pela gravidade adicionou que o Grupo ECP possui maior risco relativo de melhora da sensação de bemestar, o que pode ser considerado como ganho adicional para os pacientes atendidos pela equipe especializada em cuidados paliativos (Tabela 14). Sensação de bem-estar tem sido descrita como um indicador indireto de melhor qualidade de vida (ou de morte) $)^{93,94}$.

Visando compreender as razões para o melhor alívio da dor obtido pelo Grupo ECP, calculou-se o Índice de Manejo da Dor (IMD) 
dos doentes dos dois Grupos e observou-se que o IMD dos doentes da ECP foi mais adequado que dos doentes do CT (Tabela 15).

Estudo transversal multicêntrico verificou diferenças no manejo da dor de pacientes admitidos em unidades oncológicas e não oncológicas, em 48 hospitais italianos. Os autores verificaram que as unidades oncológicas apresentaram melhor adequação analgésica (89.1\%) comparada às unidades não oncológicas $(58.9 \%)^{95}$.

$\mathrm{Na}$ presente pesquisa, o Grupo ECP obteve melhor adequação analgésica que o Grupo CT (Tabela 15) e isso sugere que os profissionais do Grupo ECP tiveram melhor habilidade para o manejo desse sintoma. No entanto, algumas considerações merecem ser feitas.

Comparando-se o índice de IMD adequado do presente estudo ao do italiano multicêntrico ${ }^{95}$, nota-se que a porcentagem de IMD adequado na presente pesquisa, 50.7\% para o Grupo ECP e 24\%, para o Grupo CT (Tabela 15), foi inferior ao observado no estudo italiano (89.1\%-ECP e 58.9\%-CT). Tais dados demonstram que o Grupo ECP pode ajustar ainda mais a prescrição analgésica à recomendado pela OMS.

A hipótese deste estudo de que os doentes do Grupo ECP teriam melhor controle de sintomas que os doentes do Grupo CT foi confirmada parcialmente. Somente dor demonstrou melhora clínica significativa com redução de 2 pontos do escore inicial.

Indagam-se os motivos por que outros sintomas não tiveram redução clinicamente significativa e algumas hipóteses foram levantadas.

A primeira hipótese refere-se à habilidade técnica dos profissionais que orientam o cuidado. É senso comum que o adequado manejo dos sintomas em cuidados paliativos requer 
formação especializada, geralmente obtida por meio de cursos formais, de moderada a longa duração, como especializações, residências ou mestrado profissional ${ }^{96,97}$. Observou-se que os profissionais do Grupo ECP fizeram cursos livres e breves em cuidados paliativos, além de participação em eventos e que o Grupo atua há apenas dois anos. É possível que profissionais com formação específica mais densa e atuação mais antiga em cuidado paliativo apresentassem resultados diferentes, mas não se encontrou estudo que pudesse confirmar essa hipótese.

Quanto ao Grupo CT, como foi constituído por equipes de diversas clínicas, que incluíam residentes médicos e médicos de diversas especialidades, não foi possível obter dados sobre a formação em cuidados paliativos.

A segunda hipótese para compreender o reduzido controle de sintomas relacionou-se ao questionamento sobre a adesão dos profissionais que cuidavam dos doentes às recomendações realizadas pelo Grupo ECP. A ECP possui como estratégia de trabalho a interconsulta e, desse modo, os pacientes permanecem sob os cuidados das equipes das diversas clínicas médicas e cirúrgicas do hospital, porém sob a orientação da equipe especializada em cuidado paliativo. Portanto, os resultados dependeriam da adesão às orientações da equipe de cuidado paliativo.

Foi verificada adesão de $75 \%$ para a dor e $75.5 \%$ para outros sintomas, o que foi considerado adesão boa (Tabelas 17). Porém, esse percentual de adesão está um pouco abaixo do encontrado em estudo prévio que relatou adesão de $90 \%$ por parte da equipe local. O estudo foi retrospectivo com análise descritiva e informa que houve $87 \%$ de melhora na dor e outros sintomas após as intervenções da ECP ${ }^{98}$. 
Apesar da boa adesão às recomendações da ECP, sabe-se que os sintomas oscilam, ao longo do dia ou dos dias, e sem a presença constante da ECP na clínica, os ajustes terapêuticos possivelmente ficavam aguardando o retorno da equipe de cuidado paliativo e isso poderia comprometer o controle do sintoma. Adicionalmente, a instituição não possui rotina de avaliação sistematizada de sintomas múltiplos que é consagradamente benéfica e necessária ${ }^{21,64-66,99}$ para identificar a necessidade de ajustes da terapia. Ausência de padronização de avaliação em equipes não especializadas em cuidados paliativos pode comprometer a identificação de sintomas fora de controle.

A terceira hipótese é que os sintomas necessitam de mais de 48 horas para serem estabilizados.

O intervalo de $0,24 \mathrm{~h}$ e $48 \mathrm{~h}$ nesse estudo foi considerado exequível para que as equipes alcançassem redução de sintomas físicos de moderados a intensos, em pacientes com câncer avançado, pois considerando o sofrimento dessa população e sua sobrevida, o tempo é um importante elemento.

Possivelmente, exista um efeito temporal no alívio dos sintomas. Isso foi observado em um estudo que constatou redução gradativa dos sintomas moderados a intensos, no período de sete dias, a partir da admissão do cuidado paliativo, com maior impacto na redução no sétimo dia de avaliação ${ }^{21}$. Porém, há necessidade de mais estudos para esclarecer essa questão.

Outros estudos prévios que observaram melhora dos sintomas fixaram intervalos maiores para a reavaliação da intervenção. Na revisão realizada no presente estudo, na seção da Introdução, foram apresentados os estudos e seu intervalo de avaliação (pág19). Nota-se que o menor período de intervalo entre as avaliações foi de três dias e o maior foi de 100 dias $^{13-28}$, o que 
dificulta as comparações sobre redução de sintomas com o estudo vigente.

A quarta hipótese estaria relacionada com os sintomas com a proximidade da morte.

Autores sugerem que dispneia, sonolência, bem-estar, anorexia e fadiga parecem ter sua intensidade aumentada, particularmente, no último mês de vida. Paralelamente a isso, a funcionalidade do paciente declina de maneira gradativa com a proximidade da morte, sendo que um terço deles apresentam sintomas de moderados a intensos no último mês de vida ${ }^{54}$.

Autores de uma coorte retrospectiva de base populacional com 45.118 pacientes ambulatoriais com câncer, sendo 12.196 (mensuração de sintomas pelo ESAS) e 8.927 (mensuração da funcionalidade pela Palliative Performance Scale-PPS) descreveram a trajetória dos sintomas e funcionalidade desses pacientes nos últimos 6 meses de vida. Observaram que, em relação aos sintomas, estabeleceram-se dois padrões, sintomas que permaneceram estáveis ao longo do tempo, ou seja, não tiveram aumento de escore maior do que um ponto (náusea, depressão, ansiedade e dor) e o segundo padrão de sintomas foi aquele que teve elevação maior que 1 ponto (dispneia, sonolência, bem-estar, falta de apetite e fadiga) nos últimos meses de vida. A sobrecarga de sintomas (TSDS) iniciou com média de 19.9 (DP13.4) e aumentou, gradativamente, ao longo do tempo, mas, nas últimas semanas, antes da morte, mostrou elevação mais rápida, atingindo 33.6 (DP14.5). O PPS iniciou com uma pontuação média de 68.4 (DP14.4), com suave diminuição ao longo do tempo, mas com acentuada e rápida diminuição uma semana antes da morte, alcançando 41.3(DP18.0). Isto mostra que sintomas mais intensos em pacientes terminais parecem ocorrer em centros com maior tradição na área de cuidado paliativo ${ }^{53}$. 
Outro estudo encontrou que pacientes com sobrevivência menor que 30 dias apresentaram intensidade significativamente maior para fadiga, sonolência, dispneia ${ }^{21,57}$.

Na tentativa de entender o padrão e a evolução de sintomas em pacientes com câncer avançado, com curta sobrevivência, admitidos em unidade de cuidado paliativo (UCP), os autores observaram que dor e depressão reduziram sua intensidade e estabilizaram após admissão na UCP, mas sintomas associados com a síndrome de anorexia-caquexia e dispneia não melhoraram $^{100}$.

Esses dados parecem mostrar que alguns sintomas (dispneia, sonolência, bem-estar, falta de apetite e fadiga) estão mais associados com o avanço da doença, independente do diagnóstico ou ajuste do tratamento, podendo parecer não favoráveis às terapias de controle de sintomas empregadas no fim da vida.

Um estudo foi realizado para verificar a relação causal com a mudança de sintomas em 82 pacientes com câncer em seu último mês de vida ${ }^{101}$. A hipótese do estudo foi que o alívio do sofrimento e a promoção de cuidados de fim da vida de qualidade requer planejamento das intervenções para modificar sintomas e sua relação no fim da vida. Os autores verificaram que dor, ansiedade, náusea, dispneia, sonolência eram sintomas que apresentaram modesta estabilidade. Porém, fadiga, depressão e bem-estar, não apresentaram estabilidade nas avaliações. Observaram também que, com a proximidade da morte, houve aumento de todos os sintomas. Esses achados mostram que, principalmente, os sintomas considerados instáveis no fim da vida devem ser monitorados, de maneira mais rigorosa, e implementar intervenções flexíveis para o seu manejo. Além disso, os autores sugerem considerar a forma como os sintomas se agrupam para melhor resultado da intervenção. 
Assim, é possível que alguns sintomas como depressão e anorexia, fadiga, entre outros, requeiram tempo superior a $48 \mathrm{~h}$ para seu controle, mas outros, como dor, náusea, constipação intestinal e prejuízo do sono, podem ser aliviados no período de 48h. Alguns analgésicos, antieméticos, laxantes, ansiolíticos e indutores de sono, entre outros, têm início de ação rápida e vida média curta, podendo alcançar níveis plasmáticos adequados em até 48 horas. Ainda, para alguns sintomas não há boas alternativas terapêticas, como por exemplo fadiga, o que justificaria a dificuldade para seu controle ${ }^{102-}$ 106. Além disso, deve-se considerar não somente a abordagem farmacológica, mas também as relacionadas ao suporte emocional, principalmente devido à possível existência de relações entre os sintomas físicos e emocionais ${ }^{57}$.

A última hipótese elaborada para explicar a falta de sucesso na redução dos sintomas é que, talvez, os resultados relacionados ao controle de sintomas em cuidados paliativos sejam, de fato, modestos.

Outro achado deste estudo foi que, em ambos os grupos, a satisfação do cliente foi elevada, apesar do limitado controle de sintomas (Tabela 16). Esse achado não concordou com estudo que avaliou a satisfação da intervenção do cuidado paliativo comparado ao tradicional, pois a maior satisfação dos pacientes foi observada quando os cuidadores eram da ECP devido à maior melhora nos sintomas ${ }^{107}$.

A elevada satisfação dos doentes pode estar relacionada ao perfil socioeconômico deles. Esses doentes possuem dificuldade de acesso às instituições de saúde e podem julgar que ser atendido, especialmente, em um hospital-escola famoso em São Paulo e no Brasil, já é suficiente para sua satisfação, independente do alívio alcançado. 
No mundo e no Brasil, casos novos de câncer aumentam exponencialmente e significativa parcela necessitará de cuidados paliativos. Esses pacientes são polissintomáticos, com variada necessidade de cuidado e podem ser atendidos de vários modos: por equipe de cuidado paliativo, em unidade especializada em cuidado paliativo, por equipe de cuidado paliativo em unidade geral, por equipe geral em unidades gerais, por oncologistas, por equipes de cuidado paliativo ou equipes não especializadas em ambiente domiciliar ou por profissionais da estratégia de saúde da família, em domicílio ou na unidade básica de saúde, entre outras possibilidades.

Visando identificar e entender as melhores opções, os resultados obtidos por essas modalidades de tratamento precisam ser comparados, o que foi o objetivo da presente pesquisa. Esperava-se um maior impacto na redução dos sintomas, o que não foi o observado. Houve uma melhora limitada nos sintomas pelo ponto de vista de redução clínica minimamente significativa e a equipe interconsultora de cuidado paliativo mostrou uma pequena superioridade na redução dos sintomas comparada à equipe tradicional. Esta pequena superioridade na melhora foi atribuída à redução da dor, o que foi um fator positivo no desempenho do Grupo $E C P$, considerando ser um dos sintomas de maior relato de controle inadequado principalmente neste grupo de pacientes. Parece que a melhora deste sintoma impactou na melhora da sensação de bem estar (Tabela 14), o que foi um bom resultado por ser um dos sintomas listados como indicador de qualidade no manejo de sintomas desta população.

Os resultados deste estudo devem ser interpretados com cautela. Se considerar apenas a melhora estatisticamente significativa, o Grupo ECP mostrou completa superioridade. Porém, este não foi o desfecho estabelecido mas sim a análise pela redução de 2 pontos em $48 \mathrm{~h}$ da admissão. $\mathrm{O}$ estudo analisou doze sintomas 
e os doentes de ambos os grupos mostraram grande sobrecarga de sintomas na admissão e apenas dor foi adequadamente controlada pelo Grupo ECP. A maioria dos estudos não estabelece um ponto de corte para o que consideram adequada redução de sintomas, porém este estudo acredita na relevância clínica para a análise de melhora de sintomas. Considerou-se no planejamento do mesmo que o sucesso na melhora dos sintomas seria redução de dois pontos nos sintomas dor e náusea e de 20 pontos na sobrecarga de sintomas comparados com a avaliação inicial. Partindo-se deste critério foi considerado que os sintomas foram insuficientemente controlados. Portanto, os resultados demandam análise de fatores que possam melhorar a efetividade das ações como, por exemplo, avaliação sistematizada dos sintomas em curtos períodos e estratégias que permitam ajuste rápido da terapêutica, se necessário.

\subsection{Limitações, contribuições e sugestões}

Uma das limitações do estudo foi a impossibilidade de realizar randomização e cegamento dos doentes para os grupos do estudo, principalmente devido a problemas éticos, uma vez que a equipe de cuidados paliativos já existia no hospital na época do estudo ${ }^{108}$.

Outra limitação foi a interrupção de seguimento dos pacientes em ambos os grupos, conforme apresentado na seção do método (Tabela 4), mas essa é a realidade dos pesquisadores que realizam estudos nesta população de doentes ${ }^{13-18,108-109}$.

As principais contribuições desse estudo foram: identificar a grande sobrecarga de sintomas desses doentes e a necessidade de cuidado; verificar que a efetividade das equipes no controle dos sintomas ainda é limitada e que a ECP obteve resultados melhores, embora ainda insuficientes. Tais achados podem servir de base para 
o planejamento de ações que melhorem a efetividade do cuidado a esses doentes.

Estudos futuros deveriam analisar se os sintomas relatados pelos pacientes são identificados pelas equipes de profissionais e como são estruturadas as prioridades de cuidado. Seria interessante também verificar quais são os motivos que levam a equipe de cuidado tradicional a solicitar interconsulta da equipe especializada em cuidados paliativos e qual a opinião sobre o cuidado executado pelos especialistas. Ainda, estudo que testasse se a existência de avaliação sistematizada por meio de escala de sintomas múltiplos contribuiria para melhor controle de sintomas. 
7.CONCLUSÕES 


\section{CONCLUSÕES}

O estudo permitiu as seguintes conclusões:

A prevalência e a magnitude dos sintomas foi elevada na admissão, e não diferiu entre os Grupos ECP e CT.

No seguimento de 24 horas o Grupo ECP mostrou redução de cinco sintomas (dor, náusea, perda do apetite, dispnéia e sono) e no Grupo $\mathrm{CT}$, houve redução de três sintomas (dor, náusea e prejuízo do sono). No seguimento de 48 horas o Grupo ECP manteve somente melhora da dor e no Grupo CT a melhora foi no prejuízo do sono. A hipótese de que o Grupo ECP teria maior redução dos sintomas e menor sobrecarga de sintomas foi aceita parcialmente, apenas para o sintoma Dor.

O desfecho principal foi a diminuição de dois pontos na intensidade da dor e da náusea após 48horas, o que foi observado apenas para dor no Grupo ECP. O Índice de Manejo da Dor também foi mais adequado no Grupo ECP. Foi confirmada a hipótese de que o Grupo ECP teria melhor controle analgésico que o Grupo CT.

A satisfação dos doentes foi elevada e não houve diferenças estatisticamente significativas entre os grupos. A hipótese de que o Grupo ECP relataria maior satisfação do que o Grupo CT foi rejeitada.

Os resultados demandam análise de fatores que possam melhorar a efetividade das ações como, por exemplo, avaliação sistematizada dos sintomas em curtos intervalos de tempo e estratégias que permitam o ajuste rápido da terapêutica, sempre que necessário.

A superioridade de atendimento por inter consulta de um grupo de profissionais de cuidados paliativos sobre um grupo de atendimento convencional foi apenas para o controle da dor. 
REFERÊNCIAS 


\section{REFERÊNCIAS}

1. Dodd MJ, Miaskowski C, Paul SM. Symptom clusters and their effect on the functional status of patients with cancer. Journal Oncology Nurse Forum 2001;28:465-70.

2. Cleeland CS. Symptom burden: multiple symptoms and their impact as patient-reported outcomes. Journal Natl Cancer Inst Monographs 2007;37:16-21.

3. Chang VT, Hwang SS, Feuerman M, Kasimis BS. Symptom and quality of life survey of medical oncology patients at a veteran affairs medical centre: a role for symptom assessment. Cancer 2000;88:1175-83.

4. Kim HJ, McGuire DB, Tulman L, Barsevick AM. Symptom clusters: concept analysis and clinical implications for cancer nursing. Cancer Nursing 2005;28:270-84.

5. Fan G, Filipczak L, Chow E. Symptom clusters in cancer patients: a review of the literature. Current Oncology 2007; 14(5): 173-180.

6. Sissel J, Jacob $\mathrm{CH}$, Stein $\mathrm{K}$, Loge JH, Materstvedt LJ. Attitudes towards, and wishes for, euthanasia in advanced cancer patients at a palliative medicine unit. Palliative Medicine 2005; 19: 454-460.

7. Echteld MA, van Zuylen L, Bannink M, Witkamp E, Van der Rijt CCD. Changes in and correlates of individual quality of life in advanced cancer patients admitted to an academic unit for palliative care. Palliative Medicine 2007; 21: 199-205.

8. Yamagishi A, , Morita T, Miyashita M, Igarashi A, Akiyama M, Akizuki N, Shirahige Y, Eguchi K. Pain Intensity, Quality of Life, Quality of Palliative Care, and Satisfaction in Outpatients With Metastatic or Recurrent Cancer: A Japanese, Nationwide, Region-Based, Multicenter Survey. Journal of Pain and Symptom Management 2012; 43(3): 503-515.

9. Gabrilove JL, Perez EA, Tomita DK, Rossi G, Cleeland CS. Assessing symptom burden using the M. D. Anderson symptom inventory in patients with chemotherapy-induced anemia: results of a multicenter, open-label study (SURPASS) of patients treated with darbepoetin-alpha at a dose of 200 microg every 2 weeks. Cancer 2007;110(7):1629-1640.

10.Simpson $\mathrm{KH}$. The use of research to facilitate the creation of a palliative care team. Palliative Medicine 1991;5:122-129.

11. Higginson IJ, Finlay I, Goodwin DM, Cook AM, Hood K, Edwards AGK, MPhil, Hannah-Rose Douglas, Norman CE. Do Hospital-Based Palliative Teams Improve Care for Patients or Families at the End of Life? Journal of Pain and Symptom Management 2002; 23(2): 96-106. 
12. Hearn J, Higgiinson I. Do specialist palliative care teams improve outcomes for cancer patients? A systematic literature review. Palliative Medicine 1998; 12:317-332.

13. Viney LL, Walker BM., Robertson T, Lilley B, Ewan C. Dying in Palliative Care Units and in Hospital: A Comparison of the Quality of Life of Terminal Cancer Patients .Journal of Consulting and Clinical Psychology 1994; 62(1): 157-164.

14. Ellershaw JE, Peat SJ, Boys LC. Assessing the effectiveness of a hospital palliative care team. Palliative Medicine 1995; 9: 145-152.Fan G, Filipczak L, Chow E. Symptom clusters in cancer patients: a review of the literature. Current Oncology 1995; 14(5): 173-180.

15. Higginson I, Hearn J. A Multicenter Evaluation of Cancer Pain Control By Palliative Care Teams. Journal of Pain and Symptom Management 1997;19(14): 29-36.

16. Mercadante S, Fulfaro F, Casuccio A. The impact of home palliative care on symptoms in advanced cancer patients. Supportive Care Cancer 2000; 8:307-310.

17.Jack B, Hillier V, Williams A, Oldham J. Hospital based palliative care teams improve the symptoms of cancer patients. Palliative Medicine 2003; 17: 498- 502.

18. Boström B, Sandh M, Lundberg D, Fridlund B. Cancer patients' experiences of care related to pain management before and after palliative care referral. European Journal of Cancer Care 2004; 13: 238-245.

19. Strasser F, Sweeney C, Willey J, Benisch-Tolley S, Palmer L, Bruera E. Impact of a Half-Day Multidisciplinary Symptom Control and Palliative Care Outpatient Clinic in a Comprehensive Cancer Center on Recommendations, Symptom Intensity, and Patient Satisfaction: A Retrospective Descriptive Study. Journal of Pain and Symptom Management 2004; 27(6):481-492.

20. Morita T, Fujimoto K, Tei Y. Palliative Care Team: The First Year Audit in Japan. Journal of Pain and Symptom Management 2005; 29(5): 459-467.

21. Modonesi C, Scarpi E, Maltoni M, Demi S, Fabri L, Martini F, Sansoni E, Amadori D. Impact of palliative care unit admission on symptom control evaluated by the Edmonton Symptom Assessment System-ESAS. Journal Pain Symptom Management 2005; 30(4):367-373.

22.Peters L and Sellick K. Quality of life of cancer patients receiving inpatient and home-based palliative care. Journal of Advanced Nursing 2006; 53(5):524-33.

23.Jack B, Hillier V, Williams A, Oldham J. Improving cancer patients' pain: the impact of the hospital specialist palliative care team. European Journal of Cancer Care 2006; 15:476480.

24. Dumitrescu L, Van den Heuvel-Olaroiu M, Van den Heuvel WJA. Changes in Symptoms and Pain Intensity of Cancer 
Patients After Enrollment in Palliative Care at Home. Journal of Pain and Symptom Management 2007;34:488-496.

25. Gomez-Batiste X, Porta-Sales J, Espinosa-Rojas J, PasculaLopez A, Tuca A, Rodriguez J. Effectiveness of Palliative Care Services in Symptom Control of Patients with Advanced Terminal Cancer: A Spanish, Multicenter, Prospective, QuasiExperimental, Pre-Post Study. Journal of Pain and Symptom Management 2010; 40(5):652-661.

26. Paiva CE, Faria CB, Nascimento MSDA, Dos Santos $R$, Scapuleto HHLRC, Costa E, Paiva BSR. Effectiveness of a palliative care outpatient programme in improving cancerrelated symptoms among ambulatory Brazilian patients 2012; 21:124-130. European Journal of Cancer Care 21, 124-130.

27. Santiago A, Portela MA, Ramos L, Larumbe A, Urdinoz J, Martinez M, Garcia-Foncillas J, Centeno C. A new palliative care consultation team at the oncology department of a university hospital: an assessment of initial efficiency and effectiveness. Supportive Care Cancer 2012; 20:2199-2203.

28. Kang JH, Kwon JH, Hui D, Yennurajalingam, Bruera E. Changes in symptom intensity among cancer patients receiving outpatient palliative care. Journal of Pain and Symptom Management 2013; 46(5):652-660.

29. Salisbury C, Bosaquet N, Wilkinson EK, Franks PJ, Kite S, Naysmith A. The impact of different models of specialist palliative care on patients' quality of life: a systematic literature review. Palliative Medicine 1999; 13: 3-17.

30.Zimmermann C, Riechelmann R, Krzyzanowska M, Rodin G, Tannock I. Effectiveness of Specialized Palliative Care: A Systematic Review. JAMA. 2008;299(14):1698-1709.

31. Higginson IJ, Finlay I, Goodwin DM, Cook AM, Hood K, Edwards AGK, Douglas HR, Normand CE. Is there evidence that palliative care teams alter end-of-life experiences of patients and their caregivers? Journal of Pain and Symptom Management 2003;25:150-168.

32. Garcia-Perez L, Martín-Olivera R, Serrano-Aguilar P, BenitezRosario MA. A systematic review of specialised palliative care for terminal patients: which model is better? Palliative Medicine 2009; 23: 17-22

33. Higginson IJ, Evans CJ. What Is the Evidence That Palliative Care Teams Improve Outcomes for Cancer Patients and Their Families? The Journal of Cancer 2010;16: 423-435.

34. World Health Organization. WHO definition of palliative care, http://www.who.int/cancer/palliative/definition/en/ (2002, accessed 1 March 2014).

35. Fallon M, Smyth J. Terminology: the historical perspective, evolution and current usage-room for confusion? European Journal Cancer 2008; 44(8):1069-1071.

36. Ferris FD, Bruera E, Cherny N, Cummings C, Currow D, Dudgeon D, Janjan N, Strasser F, von Gunten CF, Von Roenn 
$\mathrm{JH}$. Palliative cancer care a decade later: accomplishments, the need, next steps. Journal Clinical Oncolpgy 2009; 27(18):3052-3058.

37. Hanks G. Palliative care: careless use of language underminesour identity. Palliative Medicine 2008; 22(2):109_ 110.

38. Maciel MMGS. Definições e Princípios. In: Oliveira RA, coordenador. Cuidado Paliativo. São Paulo: Conselho Regional de Medicina do Estado de São Paulo, 2008. P.1532. http://www.cremesp.org.br. Acessado em março 2012.

39. Billings JA . What is palliative care? Journal Palliative Medicine 1998; 1(1):73-81.

40. Cherny $\mathrm{NI}$. Stigma associated with "palliative care": getting around it or getting over it. Cancer 2009;115(9):1808-1812.

41. Doyle D. Palliative medicine-a time for definition? Palliatiave Medicine 1993; 7(4):253-255.

42. Cherny N. Best supportive care: a euphemism for no care or a standard of good care? Seminars Oncolongy 2011; 38(3):351-357.

43.Dalal S, Palla S, Hui D, Nguyen L, Chacko R, Li Z, Fadul N, Scott C, Thornton V, Coldman B, Amin Y, Bruera E. Association between a name change from palliative to supportive care and the timing of patient referrals at a comprehensive cancer center. Oncologist 2011; 16(1):105111.

44. Fadul N, ElsayemA, Palmer JL,Del Fabbro E, Swint K, Li Z, Poulter V, Bruera E. Supportive versus palliative care: what's in a name?: a survey of medical oncologists and midlevel providers at a comprehensive cancer center. Cancer 2009; 115(9):2013-202.

45.Benini F, Fabris M, Pace DS, Verno V, Negro V, De Conno F, Orzalesi MM. Awareness, understanding and attitudes of Italians regarding palliative care. Annali dell'Istituto Superiore di Sanità 2011; 47(3):253-259.

46. Hanratty B, Hibbert D, Mair F, May C, Ward C, Corcoran G, Capewell S, Litva A . Doctors' understanding of palliative care. Palliative Medicine 2006; 20(5):493-497.

47. Payne S, Sheldon F, Jarrett N, Large S, Smith P, Davis CL, Turner P, George S. Differences in understanding of specialist palliative care amongst service providers and commissioners in South London. Palliative Medicine 2002; 16(5):395-402.

48. Higginson IJ, Shipman C, Gysels M, et al. Care provided by generalists at the end of life: a scoping exercise on research priorities. Research Summary. London: National Institute of Health Research (NIHR); 2007.

49. Davis E, Higgnson IJ. Systematic review of specialist palliative day-care for adults with cancer. Supportive Care Cancer 2005; 13: 607-627. 
50.Teunissen SCCM, Wesker W, Kruitwagen C, Haes HCJM, Voest EE, Graeff A. Symptom prevalence in patients with incurable cancer: a systematic review. Journal Pain and Symptom Management 2007; 34:94-104.

51.Laugsand EA, Kaasa S, Conno F, Hanks G, Klepstad P. Intensity and treatment of symptoms in 3,030 palliative care patients: a cross-sectional survey of the EAPC Research Network. Journal Opioid Management. 2009;5(1):11-21.

52. Hjermstad MJ, Kolflaath J, Løkken AO, Hanssen SB, Normann AP, Aass N. Are emergency admissions in palliative cancer care always necessary? Results from a descriptive study. BMJ Open 2013;3:e002515.

53. Seow H, Barbera L, Sutradhar R, Howell D, Dudgeon D, Liu CAY, Husain A, Sussman J, Earle C. Trajectory of Performance Status and Symptom Scores for Patients With Cancer During the Last Six Months of Life. Journal Clinical Oncology 29:1151-1158.

54. Mercadante, S., Casuccio, A. \& Fulfaro, F. The course of symptom frequency and intensity in advanced cancer patients followed at home. Journal of Pain and Symptom Management 2000; 20: 104-112.

55.Lien K, Zhang L, Nguyen J, Di Giovanni J, Popovic M, Jamani R, Cramarossa G, Culteon S. Predictive factors for well-being in advanced cancer patients referred for palliative radiotherapy. Clinical Oncology 2012;24:443-451.

56. Selby D, Chakraborty A, Myers J, Saskin R, Mazzotta P, Gill A. High Scores on the Edmonton Symptom Assessment Scale Identify Patients with Self-Defined High Symptom Burden. Jorunal of Palliative Medicine 2011; 14(12): 1309-1317.

57. Cheung WY, Barmala N, Zaarinehbaf S, Rodin G, Le LW, Zimmerman C: The association of physical and psychological symptom burden with time to death among palliative cancer outpatients. Journal and Pain Symptom Management 2009;37:297-304.

58. Barbera L, Seow H, Howell D, Sutradhar R, Earle C, Liu Y, Stitt A, Husain A, Sussman J, Dudgeon D: Symptom burden and performance status in a population-based cohort of ambulatory cancer patients. Cancer 2010;116:5767-5776.

59. Rosenthal DI, Mendoza TR, Chambers MS, Asper JA, Gning I, Kies MS, Weber RS, Lewin JS, Garden AS, Ang KK, S Wang $X$, Cleeland CS: Measuring head and neck cancer symptom burden: The development and validation of the M.D. Anderson symptom inventory, head and neck module. Head Neck 2007;29:923-931.

60.Bradley N, Davis L, Chow E: Symptom distress in patients attending an outpatient palliative radiotherapy clinic. Journal of Pain and Symptom Management 2005;30:123-131.

61. Brechtl JR, Murshed S, Homel P, Bookbinder M (2006) Monitoring symptoms in patients with advanced illness in long- 
term care: a pilot study. Journal of Pain and Symptom Management 32(2):168-174.

62. Dudgeon DJ, Harlos M, Clinch JJ (1999) The Edmonton Symptom Assessment Scale (ESAS) as an audit tool. Journal Palliative Care 15(3):14.

63. Paice J. Assessment of symptom clusters in people with cancer. Journal Natl Cancer Inst Monogr 2004;32: 98-102.

64. (Brechtl JR. Murshed S, Homel P, Bookbinder M. Monitoring symptoms in patients with advanced illness in long-term care: a pilot study. Journal of Pain and Symptom Management 2006;32:168-174.

65. Kirkova J, Walsh D, Russel M, Hauser K, Lasheen W. Symptom Assessment in Palliative Medicine: Hauser K, Complexities and Challenges. American Journal Hospice and Palliative Care 2010 27: 75.

66. Nekolaichuk C, Watanabe S, Beaumont C. The Edmonton Symptom Assessment System: a 15-year retrospective review of validation studies (1991-2006). Palliative Medicine 2008;2:111-22.

67.Bruera E, Kuehn N, Miller MJ, Selmser P, Macmillan K: The Edmonton Symptom Assessment System (ESAS): A simple method for the assessment of palliative care patients. Journal Palliative Care 1991;7:6-9.

68.Selby D, Cascella A, Gardiner K, Do R, Moravan V, Myers J, Chow E. A Single Set of Numerical Cutpoints to Define Moderate and Severe Symptoms for the Edmonton Symptom Assessment System. Journal of Pain and Symptom Management 2010;39:241-249.

69. Oldenmenger WH, Raaf PJ, Klerk C, Van der Rijt CCD, Cut Points on 0e10 Numeric Rating Scales for Symptoms Included in the Edmonton Symptom Assessment Scale in Cancer Patients: A Systematic Review. Journal of Pain and Symptom Management 2013;45:1083-1093.

70. Monteiro DR, Almeida MA, Kruse MHL. Tradução e adaptação transcultural do instrumento Edmonton Symptom Assessment System para uso em cuidados paliativos. Revista Gaúcha de Enfermagem. 2013;34(2):163-171.

71.Chang VT, Hwang SS, Feuerman MM.Validation of the Edmonton Symptom Assessment Scale.Cancer 2000;88:2164-71.

72. Carvajal A, Centeno C, Watson R, Bruera E. A comprehensive study of psychometric properties of the Edmonton Symptom Assessment System (ESAS) in Spanish advanced cancer patients European Journal of Cancer 2011;1863-1872.

73. Richardson LA, Jones GW. A review of the reliability and validity of the Edmonton Symptom Assessment System. Current Oncology 2009; 16(1): 53-65.

74. Nekolaichuk C, Watanabe S, Beaumont C. The Edmonton Symptom Assessment System: a 15-year retrospective review 
of validation studies (1991-2006). Palliative Medicine 2008; 22: 111-122.

75. Watanabe SM, Nekolaichuk C, Beaumont C, Johnson L, Myers J, Strasser F. A multicenter study comparing two numerical versions of the Edmonton Symptom Assessment System in palliative care patients. Journal of Pain and Symptom Management 2011; 41(2):456-68.

76. Instituto Nacional de Câncer (Brasil). Controle de sintomas do câncer avançado em adultos: normas e recomendações do INCa. Revista Brasileira de Cancerologia 2002; 48(2): 191 211.

77.Schag CC, Heinrich RL, Ganz PA. Karnofsky performance status revisited: Reliability, validity, and guidelines. Journal Clinical Oncology. 1984; 2:187-193.

78. Cleeland C, Gonin R, Hatfield A, Edmonson J, Blum R, Stewart $\mathrm{J}$ et al. Pain and its treatment in outpatients with metastatic cancer. New England Journal Medicine 1994; 330(9):592-596.

79. Pimenta, CAM. Aspectos culturais, afetivos e terapêuticos relacionados à dor no câncer. [dissertação]. São Paulo: Escola de Enfermagem, Universidade de São Paulo; 1995.

80. Calil AM, Pimenta CAM. Intensidade da dor e adequação da analgesia. Revista Latino Americana de Enfermagem 2005; 13(5):692-9.

81.Bedard G, Zeng L, Zhang L, Lauzon N, Holden L, Tsao M, Danjoux C, Barnes E, Sahgal A, Poon M, Chow E. Minimal Clinically Important Differences in the Edmonton Symptom Assessment System in Patients With Advanced Cancer. Journal of Pain and Symptom Management 2013;46:192-200.

82. Yennurajalingam S., Urbauer D.L., Casper K.L., Reyes-Gibby C.C., Chacko R.,Poulter V. \& Bruera E. Impact of a palliative care consultation team on cancer-related symptoms in advanced cancer patients referred to an outpatient supportive care clinic. Journal of Pain and Symptom Management 2011; $41,49-56$.

83. Yamagishi A, Morita T, Miyashita M, Kimura F. Symptom prevalence and longitudinal follow up in cancer outpatients receiving chemotherapy. Journal of Pain and Symptom Management 2009;37(5):823-831 .

84.Potter J, Hami F, Bryan T, Quigley C. Symptom in 400 patients referred to palliative care services: prevalence and patterns. Palliative Medicine 2003; 17:310-314.

85. Sigurdardottir KR, Haugen DF: Prevalence of distressing symptoms in hospitalised patients on medical wards: A crosssectional study. BMC Palliative Care 7:16, 2008.

86.Zimmermann C, Burman D, Follwell $M$, Wakimoto $K$, Seccareccia D, Bryson J, Le LW, Rodin G. Predictors of Symptom Severity and Response in Patients With Metastatic 
Cancer. American Journal Hospice and Palliative Care Medicine 2010; 27: 175-183.

87. Kehl KA, Kowalkowiski JÁ. A systematic review of the prevalence of signs impeding death and symptom in the last two weeks of life. American Journal of Hospice \& Palliative Medicine 2012; 30(6) 601-616.

88. Klinkenberg $M$, Willems $D L$, van der Wal G, Deeg DJ. Symptom burden in the last week of life. of Pain and Symptom Management 2004; 27: 5-13.

89. Grunberg SM. New directions in supportive care. Supportive Care Cancer 2005 ; 13: 135-37.

90. Hoekstra J, Bindels PJ, van Duijn NP, Schade E. The symptom monitor. A diary for monitoring physical symptoms for cancer patients in palliative care: feasibility, reliability and compliance. Journal of Pain and Symptom Management 2004; 27: 24-35.

91.Perkins P, Booth S, Vowler SL, Barclay S. What are patients' priorities for palliative care research? -- a questionnaire study. Palliative Medicine 2008 22: 7.

92. Mystakidou K, Parpa E, Katsouda E, Galanos A, Vlahos L. The role of physical and psychological symptoms in desire for death: a study of terminally ill cancer patients. PsychoOncology 2006;15:355-360.

93.Bush S.H., Parsons H.A., Palmer J.L., Li Z., Chacko R. \& Bruera E. Single- vs.multiple-item instruments in the assessment of quality of life in patients with advanced cancer. Journal of Pain and Symptom Management 2010; 39, 564571.

94. Stiel S, Kues K, Krumm N, Radbruch L, Elsner F. Assessment of quality of life in patients receiving palliative care: comparison of measurement tools and single item on subjective well-being. Journal of Palliative Medicine 2011; 14, 599-606.

95.Sichetti D, Bandieri E, Romero M, Di Biagio K, Luppi M, Belfiglio M, Tognoni G, Ripamonti Cl. Impact of setting of care on pain management in patients with cancer: a multicentre cross-sectional study. Annals of Oncology 2010;21: 20882093.

96. Salminen E, Clemens KE, Syrjänen K, Salmenoja H. Needs of developing the skills of palliative care at the oncology ward. Supportive Care Cancer 2008; 16:3-8.

97.Tsai LY, Li IF, Liu CP, Su WH, Change TY. Application of quality audit tools to evaluate care quality received by terminal cancer patients admitted to a palliative care unit. Supportive Care Cancer 2008; 16:1067-1074.

98. Blank AE, Zallman L, O'Mahoni S, Selwyn PA. The Benefits of a Hospital-Based Inpatient Palliative Care Consultation Service: Preliminary Outcome Data. Journal of Palliative Medicine 2005; 8(5): 1033-1039. 
99. Silva MASS, Pimenta CAM, Cruz DALM.Treinamento e avaliação sistematizada da dor: impacto no controle da dor do pós-operatório de cirurgia cardíaca. Revista da Escola de Enfermagem USP 2013; 47(1):84-92.

100. Tsai Jaw-Shium, Wu Chin-Hsum, Chiu Tai-Yuan, Hu WenYu, Chen Ching-Yu. Symptoms patterns of advanced cancer in a palliative care unit. Palliative Medicine 2006; 20:617-622.

101. Hayduk L, Olson K, Quan H, Cree M, Cui Y. Temporal changes in the causal foundational of palliative care symptoms. Qual Life Res (2010) 19:299-306.

102. Normas e recomendações do INCA/MS. Controle de sintomas do câncer avançado em adultos. Revista Brasileira de Cancerologia, 2000, 46(3): 243-256.

103. Cleeland C. Cancer-related symptoms. Seminars in Radiation Oncologv 2000; 110(3):175-190.

104. Torroella M, Meier DE. Palliative care and end-of-life issues. Anesthesiology Clinics of North America 2000; 18(1):183210.

105. Lee NP, Washington G. Management of common symptoms at end of life in acute care settings. The Journal for Nurse Practitioners - JNP 2008, 610-616.

106. Bruera E, Hui D. Palliative care research: Lessons learned by our team over the last 25 years. Palliative Medicine 2013; 26:1-14.

107. Gade G, Venhor I, Conner D, McGrady K, Beane J, Liberson M, Blum M, Della Penna R. Impact of an Inpatient Palliative Care Team: A Randomized Controlled Trial. Journal of Palliative Medicine 2008; 11(2):180-194.

108. Seymour J, Payne S, Reid D, Sargeant A, Skilbeck J, Smith $P$. Ethical and methodological issues in palliative care studies: The experiences of a research group. Journal of Research in Nursing 2005 10: 69-190.

109. McWhinney IR, Bass MJ, Donner A. Evaluation of a palliative care service: problems and pitfalls. British Medical Journal 1994;309(19):1340-1342. 
ANEXOS 


\section{ANEXO 1}

\section{Parecer de Aprovação}

\section{ESCOLA DE ENFERMAGEM DA UNIVERSIDADE DE SÃO PAULO - EEUSP}

\section{PARECER CONSUBSTANCIADO DO CEP}

\section{DADOS DO PROJETO DE PESQUISA}

Título da Pesquisa: ANÁLISE DA EFETIVIDADE DO ATENDIMENTO DA EQUIPE DE CUIDADOS PALIATIVOS EM PACIENTES ONCOLÓGICOS HOSPITALIZADOS

Pesquisador: Cibele Andruccioli de Mattos Pimenta

Área Temática:

Versão: 1

CAAE: 08839412.8 .0000 .5392

Instituição Proponente: Escola de Enfermagem da Universidade de São Paulo - EEUSP

DADOS DO PARECER

Número do Parecer: 123.190

Data da Relatoria: $16 / 10 / 2012$

\section{HOSPITAL DAS CLÍNICAS DA FACULDADE DE MEDICINA DA USP - HCFMUSP}

\section{PARECER CONSUBSTANCIADO DO CEP}

\section{Elaborado pela Instituição Coparticipante}

\section{DADOS DO PROJETO DE PESQUISA}

Título da Pesquisa: ANÁLISE DA EFETIVIDADE DO ATENDIMENTO DA EQUIPE DE CUIDADO PALIATIVOS EM PACIENTES ONCOLÓGICOS HOSPITALIZADOS

Pesquisador: Cibele Andruccioli de Mattos Pimenta

Área Temática:

Versão: 1

CAAE: 08839412.8 .3001 .0068

Instituição Proponente: Escola de Enfermagem da Universidade de São Paulo - EEUSP

Patrocinador Principal: Financiamento Próprio 


\section{ANEXO 1}

\section{Parecer de Aprovação}

continuação do Anexo 1

\section{HOSPITAL DAS CLÍNICAS DA FACULDADE DE MEDICINA DA USP - HCFMUSP}

Contnuaçlo do Parecer: $597.590-0$

Conclusões ou Pendências e Lista de Inadequações:

Nenhuma

Situaçäo do Parecer:

Aprovado

Necessita Apreciação da CONEP:

Não

Considerações Finais a critério do CEP:

SAO PAULO, 11 de Abril de 2014

Assinador por:

Luiz Eugênio Garcez Leme

(Relator)

Este parecer reemitido substitui o parecer número 597590 gerado na data 17/10/2012 13:52:11, onde o número CAAE foi alterado de 08839412.8.0000.5392 para 08839412.8.3001.0068. 


\section{ANEXO 2}

\section{Escola de Enfermagem da Universidade de São Paulo TERMO DE CONSENTIMENTO LIVRE E ESCLARECIDO}

DADOS DE IDENTIFICAÇÃO DO SUJEITO DA PESQUISA OU RESPONSÁVEL LEGAL

1.NOME:

DOCUMENTO DE IDENTIDADE N ${ }^{\circ}$ : SEXO :.$M \square F \square$ DATA NASCIMENTO: ........................ ENDEREÇO. BAIRRO: CEP:. TELEFONE:DDD №. APTO:

2.RESPONSÁVEL LEGAL

NATUREZA (grau de parentesco, tutor, curador etc.) DOCUMENTO DE IDENTIDADE :. DATA NASCIMENTO.: ..................... ENDEREÇO: BAIRRO: CEP:. TELEFONE:DDD (.................. SEXO: $M \square F \square$ No CIDADE: $-$

\section{DADOS SOBRE A PESQUISA}

1. TÍTULO DO PROTOCOLO DE PESQUISA:

Análise da efetividade do atendimento da equipe de cuidados paliativos em pacientes oncológicos hospitalizados

2. PESQUISADOR : Cibele Andruccioli de Mattos Pimenta

CARGO/FUNÇÃO: Doutoranda INSCRIÇÃO CONSELHO REGIONAL № 75303

UNIDADE DO HCFMUSP: Escola de Enfermagem da USP (EEUSP)/parceria com a equipe de cuidados paliativos do departamento de Geriatria do HCFMUSP.

3. AVALIAÇÃO DO RISCO DA PESQUISA:

$\begin{array}{ll}\text { RISCO MÍNIMO } & \text { RISCO MÉDIO } \\ \text { RISCO BAIXO } & \text { RISCO MAIOR } \\ \text { DURAÇÃO DA PESQUISA : } 2 \text { anos } & \end{array}$

$-$

\section{Escola de Enfermagem da Universidade de São Paulo}

O senhor (a) está sendo convidado a participar de um estudo sobre avaliação e controle dos sintomas, principalmente de sua dor, bem como avaliar sua satisfação com o alívio destes sintomas. Estes sintomas podem ser decorrentes do estado atual de sua doença e do tratamento. É importante dizer que o estudo não utiliza testes de medicamentos ou de procedimentos. Para o desenvolvimento do estudo receberá mais duas visitas do pesquisador, com intervalo de 24 horas, e deverá responder um questionário de aplicação rápida sobre a presença de sintomas e sua intensidade em uma escala de zero a dez. A sua contribuição voluntária poderá trazer como benefício o conhecimento dos sintomas e o alívio obtido em pacientes oncológicos (com câncer) desta instituição. Desta forma, esperamos contribuir mais adequadamente no controle de sintomas dos pacientes com câncer que serão atendidos fı ıtıramente nesta institıic:ãn. 


\section{ANEXO 2 \\ continuação do Anexo 2 \\ Escola de Enfermagem da Universidade de São Paulo}

Abaixo segue informações adicionais sobre sua participação neste estudo:

- Em qualquer etapa do estudo, você terá acesso aos profissionais responsáveis pela pesquisa para esclarecimento de eventuais dúvidas. O principal investigador é a professora doutora (Cibele Andruccioli de Mattos Pimenta), que pode ser encontrado no endereço (Rua Dr. Eneas de Carvalho Aguiar, 419. CEP. 05403000) Telefone(s) 01130617544 . Se você tiver alguma consideração ou dúvida sobre a ética da pesquisa, entre em contato com o Comitê de Ética em Pesquisa (CEP) da Escola de Enfermagem da USP. Fone: 1130617548. E-mail: edipesq@ usp.br.

- É garantida a liberdade da retirada de seu consentimento a qualquer momento e deixar de participar do estudo, sem qualquer prejuízo à continuidade de seu tratamento na Instituição;

- As informações obtidas serão analisadas em conjunto com outros pacientes, não sendo divulgada a identificação de nenhum paciente, garantindo a sua confidencialidade;

- Não há despesas pessoais para o participante em qualquer fase do estudo, incluindo exames e consultas. Também não há compensação financeira relacionada à sua participação.

- O pesquisador deverá utilizar os dados e o material coletado somente para esta pesquisa.

- De acordo com o item IV da Resolução 196/96, este documento deverá ser assinado em duas vias, sendo uma via para o pesquisador e outra para o sujeito de pesquisa (paciente).

Acredito ter sido suficientemente informado a respeito das informações que li ou que foram lidas para mim, descrevendo o estudo" Análise da efetividade do atendimento da equipe de cuidados paliativos em pacientes oncológicos hospitalizados". Eu discuti com o Dra. (Cibele Andruccioli de Mattos Pimenta). sobre a minha decisão em participar nesse estudo. Ficaram claros para mim quais são os propósitos do estudo, os procedimentos a serem realizados, seus desconfortos e riscos, as garantias de confidencialidade e de esclarecimentos permanentes. Ficou claro também que minha participação é isenta de despesas e que tenho garantia do acesso a tratamento hospitalar quando necessário. Concordo voluntariamente em participar deste estudo e poderei retirar o meu consentimento a qualquer momento, antes ou durante o mesmo, sem penalidades ou prejuízo ou perda de qualquer benefício que eu possa ter adquirido, ou no meu atendimento neste Serviço.

Assinatura do paciente/representante legal

Data

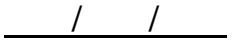

Assinatura da testemunha

Data

para casos de pacientes menores de 18 anos, analfabetos, semi-analfabetos ou portadores de deficiência auditiva ou visual.

(Somente para o responsável do projeto)

Declaro que obtive de forma apropriada e voluntária o Consentimento Livre e Esclarecido deste paciente ou representante legal para a participação neste estudo.

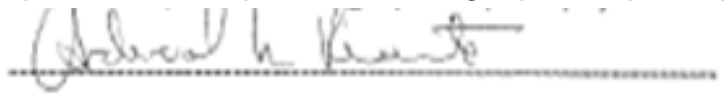

Assinatura do responsável pelo estudo

Data 


\begin{tabular}{|l|}
\hline \multicolumn{2}{|c|}{ Ficha no.: } \\
( ) IECP
\end{tabular}

\section{CARACTERÍSITCAS DEMOGRÁFICAS E CLÍNICAS}

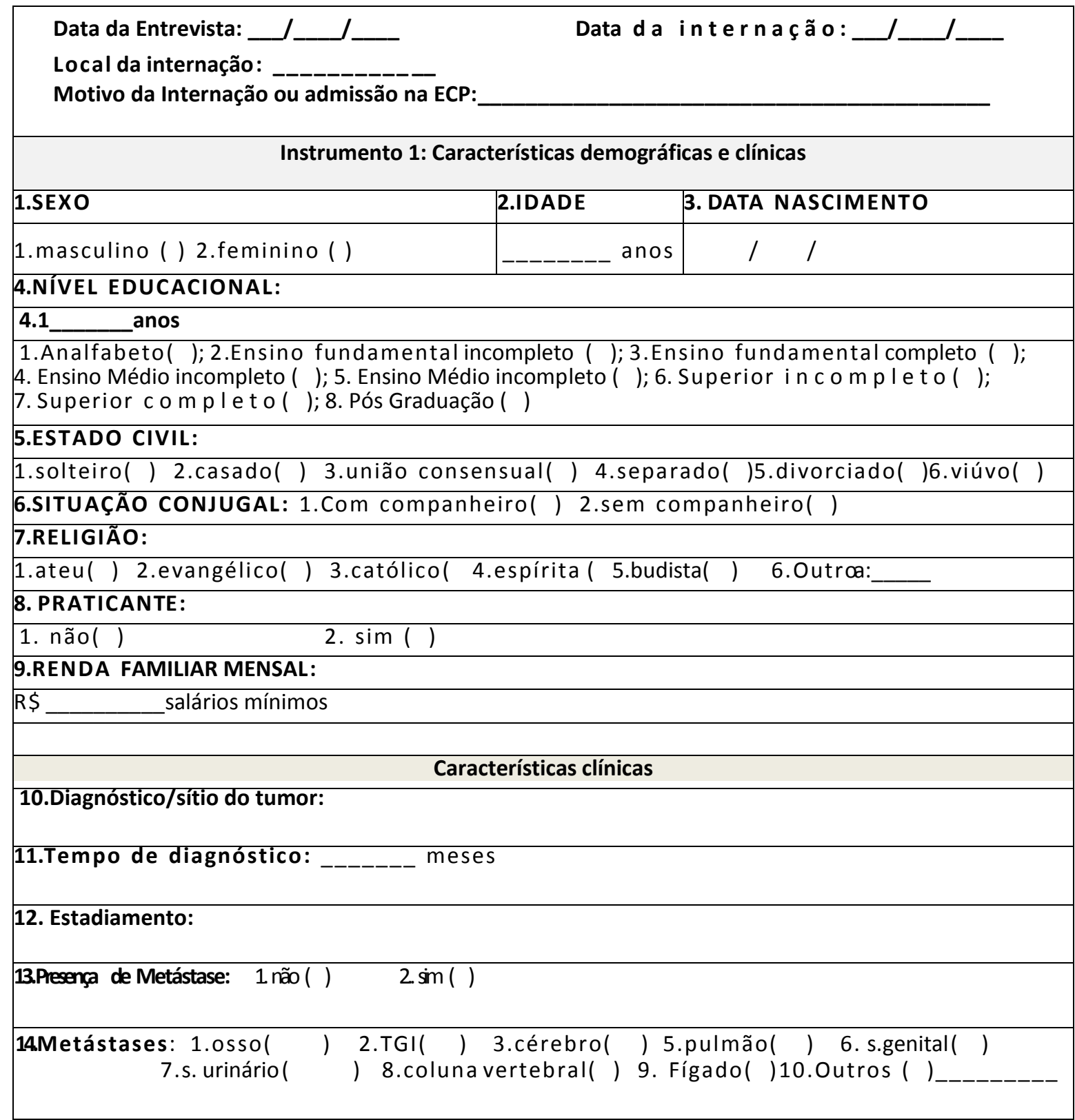
15. Óbito? 1. não ( )
2. $\operatorname{sim}($ ): Data

Observações da coleta: 


\section{ESCALA DE AVALIAÇÃO DE SINTOMAS (ESAS)}

Sr(a). Esta é uma escala de avaliação de sintomas. Você responderá a 10 itens com respostas que variam de 0 (sem o sintoma) a 10 (máxima intensidade). Por favor, diga-me o número/nota de 0 a 10 que melhor descreve os seus sintomas nas últimas 24 horas:

\begin{tabular}{|c|c|c|c|c|c|c|c|c|c|c|c|c|c|c|c|}
\hline \multirow{2}{*}{ Sem dor } & \multicolumn{11}{|c|}{ ESAS } & \multirow{2}{*}{ Pior dor possível } & \multirow[t]{2}{*}{$\mathbf{0}$} & \multirow[t]{2}{*}{$24 h$} & \multirow[t]{2}{*}{$48 h$} \\
\hline & 0 & 1 & 2 & 3 & 4 & 5 & 6 & 7 & 8 & 9 & $\overline{10}$ & & & & \\
\hline $\begin{array}{l}\text { Sem cansaço } \\
\text { (fraqueza, } \\
\text { falta de energia) }\end{array}$ & 0 & 1 & 2 & 3 & 4 & 5 & 6 & 7 & 8 & 9 & $\overline{10}$ & $\begin{array}{l}\text { Pior cansaço } \\
\text { possível }\end{array}$ & & & \\
\hline$\underset{\text { (enjoo) }}{\text { Sem náusea }}$ & 0 & 1 & 2 & 3 & 4 & 5 & 6 & 7 & 8 & 9 & $\overline{10}$ & Pior náusea possível & & & \\
\hline Sem depressão & $\mathbf{0}$ & 1 & 2 & 3 & 4 & 5 & 6 & 7 & 8 & 9 & 10 & $\begin{array}{c}\text { Pior depressão } \\
\text { possível }\end{array}$ & & & \\
\hline $\begin{array}{l}\text { Sem ansiedade } \\
\text { (sentir-se nervoso) }\end{array}$ & 0 & 1 & 2 & 3 & 4 & 5 & 6 & 7 & 8 & 9 & $\overline{10}$ & $\begin{array}{c}\text { Pior ansiedade } \\
\text { possível }\end{array}$ & & & \\
\hline $\begin{array}{l}\text { Sem sonolência } \\
\text { (sentir-se com sono) }\end{array}$ & 0 & 1 & 2 & 3 & 4 & 5 & 6 & 7 & 8 & 9 & 10 & $\begin{array}{c}\text { Pior sonolência } \\
\text { possível }\end{array}$ & & & \\
\hline Melhor apetite & $\mathbf{0}$ & 1 & 2 & 3 & 4 & 5 & 6 & 7 & 8 & 9 & $\overline{10}$ & Pior apetite possível & & & \\
\hline $\begin{array}{c}\text { Melhor sensação de } \\
\text { bem estar (como } \\
\text { sente em geral:corpo, } \\
\text { mente e alma) }\end{array}$ & o & 1 & 2 & 3 & 4 & 5 & 6 & 7 & 8 & 9 & 10 & $\begin{array}{l}\text { Pior sensação de } \\
\text { mal estar possível }\end{array}$ & & & \\
\hline Sem falta de ar & 0 & 1 & 2 & 3 & 4 & 5 & 6 & 7 & 8 & 9 & 10 & $\begin{array}{c}\text { Pior falta de ar } \\
\text { possível }\end{array}$ & & & \\
\hline Melhor sono & 0 & 1 & 2 & 3 & 4 & 5 & 6 & 7 & 8 & 9 & $\overline{10}$ & Pior sono possível & & & \\
\hline $\begin{array}{l}\text { Sem constipação } \\
\text { intestinal (prisão de } \\
\text { ventre, intestino preso) }\end{array}$ & $\mathbf{0}$ & 1 & 2 & 3 & 4 & 5 & 6 & 7 & 8 & 9 & 10 & Pior possível & & & \\
\hline Sem tristeza & 0 & 1 & 2 & 3 & 4 & 5 & 6 & 7 & 8 & 9 & 10 & Pior possível & & & \\
\hline
\end{tabular}

\section{Instrumento 2: Satisfação do paciente com o alívio dos sintomas}

Sr(a), por gentileza, quanto em uma nota de 0 a 10 (0, insatisfeito e 10, muito satisfeito) o senhor está satisfeito com o tratamento para alívio de seus sintomas.

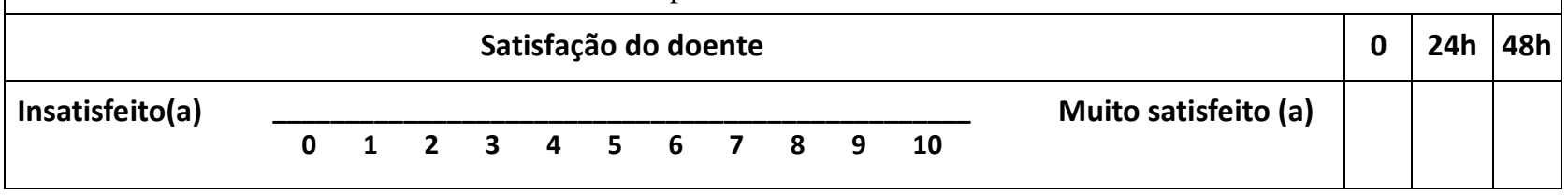




\begin{tabular}{|l|l|}
\hline \multicolumn{2}{|c|}{ Ficha no.: __ } \\
( )ECP $\quad$ ( )CT \\
\hline
\end{tabular}

\section{ANEXO 5 \\ ESCALA DE DESEMPENHO FUNCIONAL KARNOFSKY-KPS}

\begin{tabular}{|c|c|}
\hline $\begin{array}{c}\text { Escala de } \\
\text { Zubrod(ECOG }\end{array}$ & Escala de Karnofsky(\%) \\
\hline \multirow[t]{2}{*}{$\begin{array}{l}\text { PS0 } \\
\text { normal }^{-} \text {Atividade }\end{array}$} & $\begin{array}{l}\text { 100- nenhuma queixa: ausência de } \\
\text { evidencia da doença }\end{array}$ \\
\hline & $\begin{array}{l}\text { 90- capaz de levas vida normal; sinais } \\
\text { menores ou sintoma da doença }\end{array}$ \\
\hline \multirow{2}{*}{$\begin{array}{l}\text { PS 1- Sintomas da } \\
\text { doença, mas } \\
\text { deambula e leva seu } \\
\text { dia a dia normal }\end{array}$} & $\begin{array}{l}\text { 80- alguns sinais ou sintoma da } \\
\text { doença com o esforço }\end{array}$ \\
\hline & $\begin{array}{l}\text { 70-capaz de cuidar de si mesmo; } \\
\text { incapaz de levar suas atividades } \\
\text { normais ou exercer trabalho ativo }\end{array}$ \\
\hline \multirow[t]{2}{*}{$\begin{array}{l}\text { PS } 2 \text { - Fora do leito } \\
\text { mais de } 50 \% \text { do } \\
\text { tempo }\end{array}$} & $\begin{array}{l}\text { 60- necessita de assitencia ocasional, } \\
\text { mas ainda é capaz de prover a } \\
\text { maioria de suas atividades }\end{array}$ \\
\hline & $\begin{array}{l}\text { 50- requer assistência considerável e } \\
\text { cuidados médicos frequentes }\end{array}$ \\
\hline \multirow{2}{*}{$\begin{array}{l}\text { PS 3- No leito mais } \\
\text { de } 50 \% \text { do tempo, } \\
\text { carente de cuidados } \\
\text { mais intensivos }\end{array}$} & $\begin{array}{l}\text { 40- incapaz, requer cuidados } \\
\text { especiais e assistência }\end{array}$ \\
\hline & $\begin{array}{l}\text { 30- muito incapaz; indicada } \\
\text { hospitalização, apesar da morte não } \\
\text { ser iminente }\end{array}$ \\
\hline \multirow[t]{2}{*}{ PS 4- Preso no leito } & $\begin{array}{l}\text { 20- muito debilitado; hospitalização } \\
\text { necessária; necessitando de } \\
\text { tratamento e apoio ativo }\end{array}$ \\
\hline & $\begin{array}{l}\text { 10- moribundo, processos letais } \\
\text { progredindo rapidamente }\end{array}$ \\
\hline
\end{tabular}

Instituto Nacional de Câncer (Brasil). Controle de sintomas do câncer avançado em adultos: normas e recomendações do INCa. Revista Brasileira de Cancerologia 2002; 48(2): 191-211

\begin{tabular}{|l|l|l|l|}
\hline Indice Karnofsky & 0 & $24 \mathrm{~h}$ & $48 \mathrm{~h}$ \\
\hline KPS & & & \\
\hline
\end{tabular}

Observações da coleta: 


\begin{tabular}{|ll|}
\hline \multicolumn{2}{|c|}{ Ficha no.: } \\
( )ECP & $($ )CT \\
\hline
\end{tabular}

ANEXO 6

TERAPEUTICA FARMACOLÓGICA

\begin{tabular}{|l|l|}
\hline \multicolumn{2}{|c|}{ Instrumento 3: Terapêutica empregada para o controle dos sintomas } \\
\hline 0 (ECP) & \\
\hline $0(C T)$ & \\
\hline $24 h(E C P)$ & \\
& \\
\hline $24 h(C T)$ & \\
& \\
\hline $48 h$ (ECP) & \\
\hline $48 h(C T)$ & \\
& \\
& \\
\hline
\end{tabular}

Observações da coleta: 
ANEXO 7

Média das diferenças da intensidade dos sintomas ao longo de 48 horas nos Grupos ECP e CT. São Paulo, 2014

\begin{tabular}{|c|c|c|c|c|}
\hline \multirow{3}{*}{ Sintomas } & \multicolumn{4}{|c|}{ Média(EP);Mediana } \\
\hline & \multicolumn{2}{|c|}{ Grupo ECP } & \multicolumn{2}{|c|}{ Grupo CT } \\
\hline & 0-24h & $0-48 h$ & 0-24h & $0-48 h$ \\
\hline \multicolumn{5}{|l|}{ ESAS } \\
\hline Dor & $-2.0(0.6) ;-1.0$ & $-2.8(0.7) ;-3.0$ & $-1.9(0.6) ; 0.0$ & $-1.2(0.5) ; 0.0$ \\
\hline Fadiga & $-0.7(0.4) ; 0.0$ & $-1.3(0.6) ; 0.0$ & $-1.0(0.6) ; 0.0$ & $-1.0(0.7) ; 0.0$ \\
\hline Náusea & $-1.9(0.7) ;-2.0$ & $-3.3(0.8) ;-4.5$ & $-3.2(0.8) ;-2.0$ & $-2.3(0.9) ; 0.0$ \\
\hline Ansiedade & $-0.9(0.5) ; 0.0$ & $-1.6(0.6) ; 0.0$ & $-1.1(0.5) ; 0.0$ & $-1.2(0.5) ; 0.0$ \\
\hline Sonolência & $-0.6(0.4) ; 0.0$ & $-0.4(0.6) ; 0.0$ & $-1.0(0.5) ; 0.0$ & $-0.3(0.5) ; 0.0$ \\
\hline Apetite & $-1.5(0.4) ; 0.0$ & $-1.2(0.6) ; 0.0$ & $-0.5(0.6) ; 0.0$ & $-0.5(0.6) ; 0.0$ \\
\hline Sensação bem estar & $-0.2(0.4) ; 0.0$ & $-0.3(0.4) ; 0.0$ & $-0.0(0.5) ; 0.0$ & $0.3(0.3) ; 0.0$ \\
\hline Dispnéia & $-1.4(0.6) ; 0.0$ & $-1.8(0.5) ;-1.0$ & $-1.8(0.9) ; 0.0$ & $-2.6(1.1) ;-3.0$ \\
\hline Depressão & $-1.0(0.6) ; 0.0$ & $-1.5(0.6) ; 0.0$ & $-0.7(0.6) ; 0.0$ & $-0.5(0.5) ; 0.0$ \\
\hline Sono & $-1.5(0.5) ; 0.0$ & $-1.4(0.7) ;-1.0$ & $-1.6(0.6) ; 0.0$ & $-2.1(0.6) ;-1.0$ \\
\hline Sobrecarga sintomas & $-5.3(1.8) ;-5.0$ & $-6.4(2.4) ;-7.0$ & $-3.2(2.2) ;-1.0$ & $-0.5(2.7) ; 1.0$ \\
\hline \multicolumn{5}{|l|}{ Outros } \\
\hline Constipação intestinal & $-1.0(0.6) ; 0.0$ & $-2.6(0.7) ;-1.0$ & $-0.3(0.6) ; 0.0$ & $-1.2(0.8) ; 0.0$ \\
\hline Tristeza & $-0.3(0.4) ; 0.0$ & $-1.1(0.5) ; 0.0$ & $-1.1(0.6) ; 0.0$ & $0.7(0.6) ; 0.0$ \\
\hline
\end{tabular}

Média, Erro Padrão, Mediana 
ANEXO 8

Média das diferenças dos percentuais da intensidade dos sintomas ao longo de 48 horas nos Grupos ECP e CT. São Paulo, 2014

\begin{tabular}{|c|c|c|c|c|}
\hline \multirow{3}{*}{ Sintomas } & \multicolumn{4}{|c|}{ Média(EP);Mediana } \\
\hline & \multicolumn{2}{|c|}{ Grupo ECP } & \multicolumn{2}{|c|}{ Grupo CT } \\
\hline & $0-24 h$ & $0-48 h$ & 0-24h & $0-48 h$ \\
\hline \multicolumn{5}{|l|}{ ESAS } \\
\hline Dor & $-23.2(8.7) ;-16.7$ & $-34.2(10.5) ;-50.0$ & $-22.2(7.7) ; 0.0$ & $-0.4(14.7) ; 0.0$ \\
\hline Fadiga & $-4.1(7.4) ; 0.0$ & $-13.5(8.2) ; 0.0$ & $-7.4(9.9) ; 0.0$ & $-5.0(10.2) ; 0.0$ \\
\hline Náusea & $-18.3(14.7) ;-28.6$ & $-35.4(16.5) ;-56.2$ & $-44.9(10.7) ;-20.0$ & $-29.7(18.3) ;-35.0$ \\
\hline Ansiedade & $-4.8(12.4) ; 0.0$ & $-24.3(10.1) ; 0.0$ & $-10.7(6.9) ; 0.0$ & $-14.2(9.9) ; 0.0$ \\
\hline Sonolência & $3.3(12.1) ; 0.0$ & $17.2(20.3) ; 0.0$ & $-14.7(8.7) ; 0.0$ & $-3.4(8.2) ; 0.0$ \\
\hline Apetite & $-18.6(6.8) ; 0.0$ & $-7.7(9.5) ; 0.0$ & $17.2(20.3) ; 0.0$ & $27.9(30.7) ; 0.0$ \\
\hline Sensação bem estar & $3.6(7.6) ; 0.0$ & $-3.1(7.3) ; 0.0$ & $7.4(7.3) ; 0.0$ & $14.2(9.1) ; 0.0$ \\
\hline Dispnéia & $-21.4(11.6) ; 0.0$ & $-34.6(9.8) ;-16.7$ & $-28.8(13.8) ; 0.0$ & $-38.8(16.4) ;-60.0$ \\
\hline Depressão & $-9.5(12.3) ; 0.0$ & $-31.2(10.6) ; 0.0$ & $-20.2(11.5) ; 0.0$ & $-15.0(11.4) ; 0.0$ \\
\hline Sono & $-7.6(12.1) ; 0.0$ & $-14.2(11.1) ;-20.0$ & $-15.9(8.3) ; 0.0$ & $-17.4(11.1) ;-20.0$ \\
\hline Sobrecarga sintomas & $-10.3(3.5) ;-12.1$ & $-10.8(4.9) ;-14.3$ & $-3.6(4.5) ;-2.3$ & $-0.4(5.5) ; 3.1$ \\
\hline \multicolumn{5}{|l|}{ Outros } \\
\hline Constipação intestinal & $-11.9(8.7) ; 0.0$ & $-34.8(9.2) ;-18.3$ & $-0.9(14.2) ; 0.0$ & $-11.3(16.6) ; 0.0$ \\
\hline Tristeza & $1.5(9.9) ; 0.0$ & $-14.7(8.5) ; 0.0$ & $-11.1(8.4) ;-2.3$ & $-5.3(8.5) ; 0.0$ \\
\hline
\end{tabular}




\section{ANEXO 9}

Adequação analgésica nos grupos ECP e CT, segundo o IMD. São Paulo, 2014

\begin{tabular}{|c|c|c|c|c|c|c|}
\hline \multirow[t]{3}{*}{ IMD } & \multicolumn{2}{|c|}{ Inicial } & \multicolumn{2}{|c|}{24 horas } & \multicolumn{2}{|c|}{48 horas } \\
\hline & $\begin{array}{c}\text { ECP } \\
(n=73)\end{array}$ & $\underset{(n=75)}{C T}$ & $\begin{array}{c}\mathbf{E C P} \\
(n=59)\end{array}$ & $\underset{(n=50)}{C T}$ & $\underset{(n=43)}{\mathbf{E C P}}$ & $\underset{(n=42)}{\text { CT }}$ \\
\hline & n\% & n\% & n\% & n\% & n\% & n\% \\
\hline \multicolumn{7}{|c|}{ Inadequado } \\
\hline-3 & $05(6.8)$ & $12(16.0)$ & $05(8.5)$ & $06(12.0)$ & 00 & 05(11.9) \\
\hline-2 & $06(8.3)$ & $19(25.3)$ & $05(8.5)$ & $09(18.0)$ & $03(7.0)$ & $10(23.8)$ \\
\hline-1 & $11(15.1)$ & $18(24.0)$ & $05(8.5)$ & $07(14.0)$ & $04(9.3)$ & 05(11.9) \\
\hline Subtotal & $22(30.1)$ & $49(65.3)$ & $15(25.4)$ & $22(44.0)$ & $07(16.3)$ & $20(47.7)$ \\
\hline \multicolumn{7}{|l|}{ Adequado } \\
\hline $\mathbf{0}$ & $37(50.7)$ & $18(24.0)$ & $25(42.4)$ & $17(34.0)$ & $15(34.9)$ & $11(26.2)$ \\
\hline 1 & $07(9.6)$ & $05(6.7)$ & 07(11.8) & $08(16.0)$ & 08(18.6) & $07(16.7)$ \\
\hline 2 & $02(2.7)$ & 03(4.0) & $06(10.2)$ & $03(6.0)$ & 09(20.9) & $04(9.5)$ \\
\hline 3 & $05(6.8)$ & 00 & $06(10.2)$ & 00 & $04(9.3)$ & 00 \\
\hline Subtotal & $51(69.9)$ & $26(34.7)$ & $44(74.6)$ & $28(56.0)$ & $36(83.7)$ & $22(52.4)$ \\
\hline
\end{tabular}

